\title{
LIBOR Floors in Leveraged Loans
}

\author{
by \\ Robert Arscott
}

Submitted in Partial Fulfillment of the

Requirements for the Degree

Doctor of Philosophy

Supervised by Professor G. William Schwert and Professor Clifford W. Smith

Business Administration

Simon Business School

University of Rochester

Rochester, New York 
For my family. 


\section{Table of Contents}

Biographical Sketch $\quad$ v

Acknowledgments $\quad$ vi

Abstract vii

Contributors and Funding Sources viii

List of Tables $\quad x$

List of Figures

1 Introduction $\quad 1$

2 Background and Literature Review $\quad 8$

2.1 Relation between call protection, LIBOR floors and OIDs . . . . . . . . . 17

3 Calculation of Floor and OID Spreads $\quad 20$

3.1 Floor spread calculation . . . . . . . . . . . . . . . . . . 20

3.2 OID spread calculation . . . . . . . . . . . . . . . 24

4 Data $\quad 26$

4.1 Pooled LCD sample . . . . . . . . . . . . . . . . . . . . . 29

4.2 Lender data . . . . . . . . . . . . . . . . . . . . . . 32 
5 Empirical Methods and Observations

5.1 Estimates of floor spreads and OID spreads . . . . . . . . . . . . 35

5.2 Time series analysis . . . . . . . . . . . . . . . . . . . 39

5.3 On the probability of including a floor option in a leveraged loan . . . . . . 50

5.4 On the effect of floors on loan extensions . . . . . . . . . . . . . 56

5.5 Analysis of syndicate composition in relation to floors . . . . . . . . . . 58

5.6 Analysis of bank attributes in relation to floors . . . . . . . . . . . . 61

5.7 Estimating the probability of embedding floors absent borrower-specific and

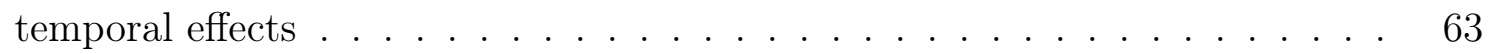

5.8 On the impact of LIBOR floors on term loan prices in the secondary market 65

5.9 On the effect of LIBOR floors on optional prepayment terms . . . . . . . . 67

6 Conclusion $\quad 73$

$\begin{array}{ll}\text { References } & 75\end{array}$

$\begin{array}{ll}\text { Appendices } & 82\end{array}$

A-1 Additional data description . . . . . . . . . . . . . . . . 83

A-2 Lender classification . . . . . . . . . . . . . . . . . 87

A-3 Investment grade loan observations . . . . . . . . . . . . . . 88

A-4 Sensitivity analysis of option valuation . . . . . . . . . . . . . 90

A-5 Loan extension analysis segmented by crisis years . . . . . . . . . . . 95 


\section{Biographical Sketch}

Robert was born in Toronto, Ontario. He attended Concordia University Texas and graduated with a Bachelor of Business Administration degree. After several years working for UBS AG in Stamford, CT, Robert moved to the United Kingdom where he attended the University of Oxford's Saïd Business School, graduating with a Master of Business Administration degree in 2011. He began doctoral studies in Business Administration with a concentration in Finance and a minor in Macroeconomics at the University of Rochester's Simon Business School in 2013. He received a Master of Science in Business Administration degree from the University of Rochester in 2016. 


\title{
Acknowledgments
}

\author{
Above all, I am thankful for the love and support of my family, without whom this work would \\ not have been possible. I am especially indebted to Meghan, Mer, Sheila, Ron, Luci, Nancy, \\ Dick, and Velma. I am also grateful to Jim Brickley, Delores Conway, Jacquelyn Gillette, \\ Michael Gofman, Ron Kaniel, Hunter Land, Rob Ready, Bill Schwert, Cliff Smith, Erin \\ Smith, Jerry Warner, Gerry Wedig, Pavel Zryumov, and seminar participants at Syracuse \\ University, University of Sydney, the Federal Reserve Bank of Richmond, and the SEC for \\ their many helpful comments and suggestions.
}




\section{Abstract}

I examine the use of LIBOR floors in U.S. leveraged (syndicated) loans. These options, rare prior to 2008, provide a minimum interest rate on these otherwise floating rate loans. This contract design is consistent with theory suggesting lenders prefer more fixed rate assets while interest rates are low in order to cover their fixed costs. Two main findings support this rationale. First, borrowers seeking to extend loans between 2009 and 2016 were able to attract 34\% more principal from lenders if a floor was added, suggesting demand for floors originated from the supply of credit. Second, banks that participated in floor-adjusted credit lines had significantly higher fixed costs than did banks in purely floating rate facilities. Floors are concentrated in institutional facilities, in particular those that are most likely to trade in the secondary market. This is consistent with cost savings associated with embedded floors over those obtained through third-parties when expected trading volume is high. Consistent with their theoretically higher interest rate sensitivity, loans that embed floors are more likely to include call protection, in the form of cancellation and upfront fees. Floors represent a significant component of loan pricing, contributing three to five times as much as upfront fees to total lender compensation. 


\section{Contributors and Funding Sources}

This work was supported by a dissertation committee consisting of Professor G. William Schwert (co-advisor), Professor Clifford W. Smith (co-advisor), Professor Jerold B. Warner, and Professor Charles E. Wasley of the Simon Business School, and Professor Curtis Signorino from the Department of Political Science. Graduate study was supported by a fellowship from the University of Rochester. 


\section{List of Tables}

4.1 Summary statistics . . . . . . . . . . . . . . . . . 30

4.2 Lender classification . . . . . . . . . . . . . . . . . . . . . 33

5.1 Loan spreads by year of origination . . . . . . . . . . . . . . 36

5.2 Granger causality estimates . . . . . . . . . . . . . . . . 44

5.3 Orthogonalized bid-ask spread . . . . . . . . . . . . . . 45

5.4 Estimates of the probability that a floor is embedded in a leveraged loan . . 52

5.5 Estimates of the percentage of loans extended when LIBOR floors are added to existing loan pricing, 2009-2016 . . . . . . . . . . . 58

5.6 Differences in means of lending syndicate variables among revolving credit facilities with and without embedded floors . . . . . . . . . . . . . 60

5.7 Differences in means of bank holding company variables among revolving credit facilities with and without embedded floors . . . . . . . . . . . . 63

5.8 Estimates of the probability that a floor option is embedded in a loan facility

5.9 Empirical duration estimates for loan indexes formed on LIBOR floor strike

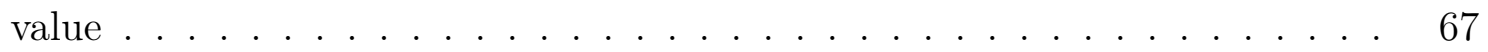

5.10 OLS regressions of initial call premium and LIBOR floor moneyness on floor

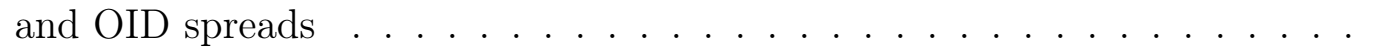

5.11 Estimates of the probability of incorporating a call premium in a loan facility given LIBOR floor- and OID-related variables . . . . . . . . . . . 
A-1 Variable definitions . . . . . . . . . . . . . . . . . 83

A-2 Loan purpose, borrower industry, and credit rating . . . . . . . . . . . . 84

A-3 Summary statistics for data subset on floor matching . . . . . . . . . . 85

A-4 Summary statistics for data subset on call premium matching . . . . . . 86

A-5 Reconciliation of floors recorded in Bloomberg, Thompson Reuters Dealscan, and S\&P Leveraged Commentary and Data . . . . . . . . . . . . . . 89

A-6 Differences between strike rates and option expiration of embedded floors and the options for which market prices are used to determine volatility . . . . . 91

A-7 Floor spread sensitivity analysis . . . . . . . . . . . . . . . . . . . 94

A-8 Estimates of the percentage of loans extended when LIBOR floors are added to existing loan pricing, 2009-2010 . . . . . . . . . . . . . . . . . . . 96

A-9 Estimates of the percentage of extended loans when LIBOR floors are added to existing loan pricing, $2011-2016 \ldots \ldots$. . . . . . . . . . 97 


\section{List of Figures}

1.1 Bank holding company annual noninterest expense, three-month USD LIBOR (lagged 3 months), and the percentage of new institutional tranche term loan issuance that contain floors between 1997 and 2016 . . . . . . . . . . . 3

2.1 Primary market for highly leveraged loans: issuance volume . . . . . . . . 10

2.2 Google trends search volume for terms "LIBOR Fraud" and "LIBOR Manip-

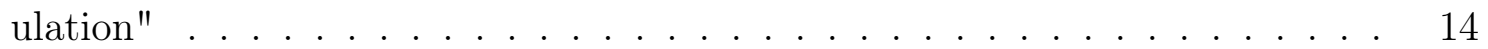

5.1 The importance of floor options relative to total compensation after 2007 . . 37

5.2 Total spreads over time . . . . . . . . . . . . . . . . . 39

5.3 Quarterly observations of loan market institutional investor participation and

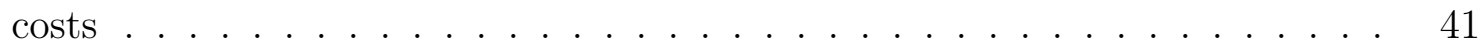

5.4 Quarterly observations of interest spreads and bank costs . . . . . . . . . . 42

5.5 Fitted values of the likelihood of embedding a floor in a leveraged loan according to the degree to which the borrower's EBITDA is correlated with LIBOR . . . . . . . . . . . . . . . . . . . .

A-1 Empirical density estimate on floor spreads with and without observations that have zero strike rates . . . . . . . . . . . . . . . 93

A-2 Empirical density estimates of floor spreads under three sets of assumptions 


\section{Chapter 1}

\section{Introduction}

Given the choice between quasi-fixed or purely floating rate interest payments in the years immediately following the credit crisis of the late 2000s, borrowers and lenders in leveraged loans have overwhelmingly opted for the former. ${ }^{1}$ This stands in contrast to the pre-crisis period, during which these loans were almost exclusively floating rate contracts. This change is a result of interest rate (LIBOR) floors, which convert loans to fixed rate while the market rate remains below the floor. ${ }^{2}$ For illustration, these loans typically pay a fixed spread over the prevailing LIBOR, rolled over every three months (or some other frequency at the borrower's discretion). Where floors are included, loans pay the spread plus the greater of LIBOR or the floor. Accordingly, nearly all leveraged loans have presented fixed interest payments over the past several years due to near zero LIBOR. Despite this, there has been little attention paid to these floors in the academic literature. This paper is the first to explore the use of LIBOR floors in the leveraged loan market. I find that floors account for a considerable fraction of compensation to lenders, averaging between $7 \%$ and $20 \%$ of total interest and fees above the base rate at the median. For comparison, these floors have contributed approximately three to five times as much toward loan yields than did upfront

\footnotetext{
${ }^{1}$ While the definition varies, leveraged loans are generally defined as syndicated loans that carry credit ratings below investment grade or have spreads above LIBOR in excess of $250 \mathrm{bps}$. The latter definition is problematic as many investment grade loans issued after the recent financial crisis carry spreads of 250 bps or higher.

${ }^{2}$ The reference rate most commonly used to index the floating rate is LIBOR
} 
fees since 2008. Given their significance, one wonders why they were introduced in lieu of simply maintaining the floating rate nature of the loan with a higher spread. ${ }^{3}$

I address this question by evaluating the decision to embed a LIBOR floor in a loan within the framework of theories regarding why borrowers and lenders prefer fixed versus floating rate debt. Of these, I find the most support for Dreschsler, Savov, and Schnabl's (2017) hypothesis that banks prefer fixed assets when interest rates are low as a means of covering their fixed costs. Banks that participated in floor-adjusted credit line facilities (revolvers) between 2008 and 2016 were, on average, 14\% smaller (by assets) and faced larger noninterest expenses by 10-20 basis points (bps) per year in comparison to banks that participated in purely floating rate loans. Further, noninterest expenses were 29-37 bps higher than LIBOR on average for banks in floor-adjusted facilities than for those in nonfloor facilities. Figure 1.1 illustrates this point, plotting the percentage of new institutional term loans that were issued with floors along with three-month LIBOR and the average of US bank holding companies' noninterest expense expressed as an annual interest rate. Banks' fixed costs in relation to LIBOR appear related to the uptick in embedded floors. These facilities are funded by banks in addition to institutional investors and contain the most valuable floors by virtue of their fully funded nature. By issuing a floating rate loan with an in-the-money floor option, lenders benefit from a fixed rate asset while LIBOR is low with the convenience of converting the loan back to floating without costly renegotiation when market rates rise. This arrangement is appealing for banks given their preference for short term funding [Stein (2012)].

In similar fashion, institutional investors benefit from minimum interest rates in these loans as well. Barucci (2003) notes many fund managers employ trading strategies that provide guaranteed levels of wealth because of the agency issues associated with financial

\footnotetext{
${ }^{3}$ The spread over LIBOR is commonly referred to as the 'all-in-drawn' spread, as it's identified in Thompson Reuters' Dealscan data
} 
Figure 1.1: Aggregate bank holding company annual noninterest expense, three-month USD LIBOR (lagged 3 months), and the percentage of new institutional tranche term loan issuance that contain floors between 1997 and 2016. Noninterest expense is expressed as an annual interest rate for comparison's sake. BHC data are compiled from the Chicago Fed's Y9C Call Report data and are limited to US bank holding companies.

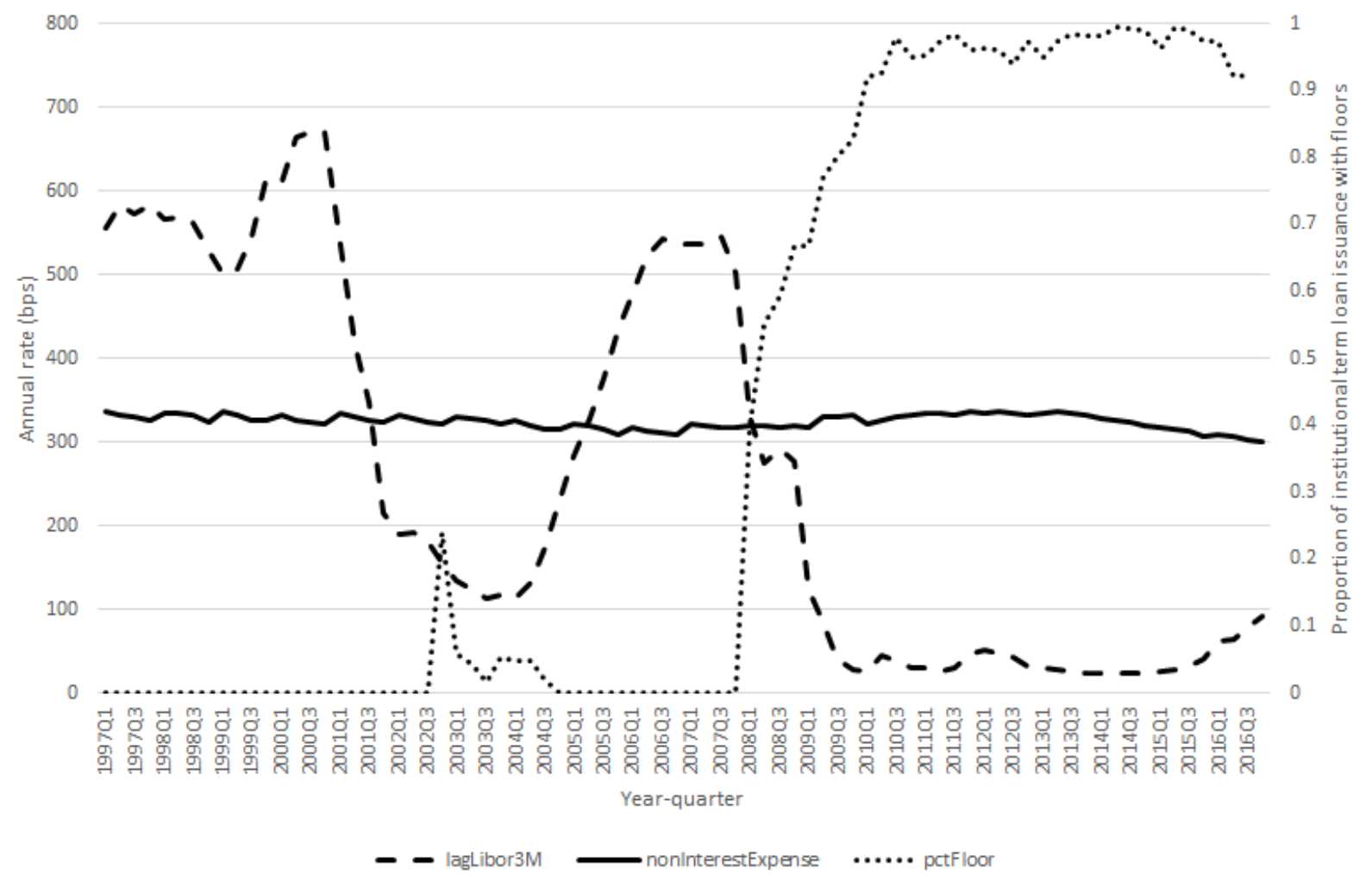

intermediation and the fund-flow sensitivity to past performance. Consistent with this, I find that the probability that a facility includes a floor option is positively correlated with factors associated with large, institutional term loans and not the originate-to-hold pro rata tranches typically retained by banks. In an analysis of the composition of credit line lending syndicates, I find that floor-adjusted facilities have much higher participation rates of asset managers and finance companies. In a matched sample of credit lines, asset mangers are present in $12 \%-13 \%$ of floor facilities but only $5 \%-7 \%$ in those without floors. Similarly, finance companies participate in nearly half of floor facilities but only a third of non-floor facilities. Further, the significance of floors in leveraged loans is inversely related to the participation of Collateralized Loan Obligations (CLOs), which have traditionally supplied 
the lion's share of credit in the primary market. Indeed, the emergence of floors corresponds with a time in which the issuance of new CLOs dropped to zero. This supports Culp's (2012) claim that the growth in embedded floor options can be attributed to underwriters' efforts to entice more institutional demand.

The decision to include a floor in a loan is the result of bargaining between lenders and the borrower. Although, a purely lender-centric argument for their inclusion may be justified in light of the fact that leveraged loan borrowers tend to be bank-dependent. Indeed, I find that borrowers that sought amendments to lengthen the maturity on their existing loans between 2009 and 2016 achieved 34\% larger principal amounts on their extensions when floors were added. Presumably, this was driven by supply concerns. Loans that included floors were able to attract larger commitments from lenders during a period when credit was tight [Ivashina and Scharfstein (2010)]. Regardless, borrowers may have had reason to prefer fixed rate payments during this time as well. I test whether the use of floors is inversely related to the degree to which a borrower's earnings form a natural interest rate hedge. This behavior is predicted by Agmon, Ofer, and Tamir (1981) and Santomero (1983) who posit that borrowers and lenders are aligned in their preference for floating rate debt when the borrower's earnings are positively correlated with the reference interest rate. In my sample, the average partial effect of a unit change in the correlation between EBITDA and LIBOR over the three years subsequent to loan issuance is a $4.5 \%$ decrease in the likelihood of including a floor. While this implies firms that possess natural hedges against interest rate risk are less likely to adopt the quasi-fixed rate interest schedule offered in floor-adjusted loans, the unit change spans a considerable fraction of the data. Indeed, the effect is significant only moving from one extreme of the data to the other. Further, I find no relation between the significance of embedded floors and the correlation of aggregate US corporate earnings and LIBOR. Thus, the evidence in support of this explanation is weak.

I also consider the subject of LIBOR manipulation as a possible motive for embedding 
floors. The rapid incorporation of floors into syndicated loans during the crisis coincided with publicly visible signals that LIBOR diverged from actual funding costs. Google search activity during 2007 and 2008 for the terms "LIBOR manipulation" and "LIBOR fraud" coincide with the introduction of LIBOR floors, as do articles in the popular press regarding the reliability of LIBOR. Lenders that viewed LIBOR as artificially low may have negotiated LIBOR floors as a means of offsetting the tendency of banks to under-report funding costs during this time. Further evidence of this is found in the time series of alternative funding rates faced by banks and other financial institutions. As they offer nearly identical lending terms, rates on 90-day AA financial commercial paper and 3-month LIBOR differ very little. However, commercial paper rates are not vulnerable to the same types of manipulation as LIBORs. While commercial paper is free of interbank credit risk and should therefore be slightly lower than LIBOR the opposite was true during the crisis; the spread between LIBOR and comparable commercial paper was often zero or negative, suggesting reported LIBOR was lower than actual funding costs. Moral hazard concerns associated with rate manipulation could be addressed through participation of LIBOR submitting banks alongside non-submitters as co-investment would ensure loan-related costs associated with downward bias in the reference rate would be borne proportionately by rate fixing banks. This hypothesis is somewhat supported by the data. Lending syndicates for floor-adjusted credit lines have a lower proportion (of 3\%-6\%) of LIBOR submitting banks than those that do not contain floors.

Certainly, interest rate hedging can be accomplished through various means; lenders do not need borrowers to supply the floor option and borrowers do not need to sell the option to lenders. Each party can obtain any manner of hedge via transactions in interest rate caps, floors, and swaps or forwards in the OTC market. Further, as Smith, Smithson, and Wakeman (1988) point out, the presence of a large market for swaps likely removes any competitive advantage firms might possess in borrowing at fixed or floating rates. Yet, 
floors have become standard in leveraged loan contracts, which remain largely floating rate otherwise. As one possible explanation, embedded floors offer reduced transaction and administrative costs associated with hedging a loan portfolio against low interest rates than an equivalent floor contracted through a third party. While the CME estimates that bid-ask spreads (representing about half the total costs in maintaining a swap) on interest swaps are typically 4 bps per annum, they can be significantly higher in some cases (10 to 40 bps) [e.g. see, Awad and McPartland (2015) and Bauman, Coleman, and Powell (2009)]. Alternatively, lenders could replicate the swap at lower cost by selling Eurodollar futures. While these offer considerably lower bid-ask spreads in comparison to swaps (typically 1.5 bps per annum), they come with the added complication of frequent margin calls (positions are marked to market daily). Regardless of whether swaps or futures are considered, the costs associated with implementing these hedges are strictly higher than those of embedded floors, which help to explain their rapid adoption into loan contracts during the crisis.

Additionally, the frequent adjustments required to maintain a desired hedging ratio on a loan portfolio whose value is constantly changing due to unscheduled principal prepayments, toggle PIKs, ${ }^{4}$ and secondary market trading are carried out automatically if the hedge is embedded in the loan contracts themselves. This benefit ought to be magnified for institutional lenders such as asset managers who anticipate regular trading as a result of inflows and redemptions of investor funds. I find evidence to support this conjecture, as the subset of loans most likely to trade in the secondary market has a higher likelihood of containing a floor option. I estimate that loans with active secondary market trading around the time of issuance are about $9 \%$ more likely to include a floor option than those that do not trade.

Regardless of the motives for their inclusion, floors have had a significant effect on loan

\footnotetext{
${ }^{4}$ Toggle PIK (payment-in-kind) options allow borrowers to pay interest in the form of cash or capitalization. In the event a borrower elects to capitalize its interest obligation, the principal balance of the loan increases by the amount of accrued interest. As the capitalization decision is at the borrower's discretion at each rollover date, lenders cannot perfectly predict the effect on the future loan balance.
} 
prices and terms. I find that loans with higher strike rates on their embedded floor options are significantly more sensitive to movements in interest rates. Unlike bonds, loans are implicitly callable forms of debt. As borrowers possess the option to prepay their loans in the event that rates fall and not prepay should they rise, lenders in floor-adjusted loans face short options risk (negative convexity), leading to compressed margins in the event that rates change. As compensation for the increase in short options risk, I find the likelihood that a loan incorporates a call premium (cancellation fee) increases by about $52.7 \%$ when a LIBOR floor is present. Similarly, term loans with embedded floor options also carry larger original issue discounts (OIDs), which, like call premiums, effectively increase the costs associated with early prepayment. ${ }^{5}$

In addition to these effects, floors also limit the effectiveness of monetary policy through the floating-rate channel discussed in Ippolito, Ozdagli, and Perez (2015). They argue that increases in the Fed Funds rate lead to less firm investment due to higher interest expense, an effect most pronounced in floating-rate paying firms. They document that the sensitivity of floating-rate payers' investment activity to increases in the interest rate is found to be muted (or even reversed) after 2008. This fact can be attributed to the prevalence of floors embedded in floating rate contracts during this period, since they effectively converted floating rates to fixed, thereby shutting down that particular monetary policy channel.

\footnotetext{
${ }^{5}$ Commonly referred to as upfront fees, the cash payment of OIDs on term loans comes with the repayment of principal and not at the loan's origination as their name suggests. Assuming the full face value of the loan would be extended at otherwise identical loan terms, the OID would carry an upfront opportunity cost equal to the difference between the face value of the debt and the actual cash paid to the borrower at origination of the loan. These are akin to points in residential mortgages.
} 


\section{Chapter 2}

\section{Background and Literature Review}

The past 30 years have witnessed the expansion of the syndicated loan market from its roots funding leveraged buyout (LBO) and other M\&A deals of the 1980s to approximately $\$ 4.3$ trillion of loan commitments in $2017 .{ }^{1}$ During this time, the leveraged segment, through which high-risk, bank-dependent borrowers access credit, has become increasingly dependent on non-bank investors as their higher yields and long maturities (typically five to seven years) satisfy the investment criteria of institutional investors that might otherwise invest in high yield bonds. As of 2017, nearly $\$ 900$ billion of loan commitments were attributed to non-bank lenders. The various CLOs, mutual funds, insurance companies, hedge funds, pension funds and other institutional investors that collectively supply credit to this market also account for $58 \%$ of the riskiest loans according to the OCC's 2017 regulatory review, highlighting their appetite for higher risk, higher yield investments. Increased institutional participation has given rise to a liquid secondary market for trading these loans. The volume of secondary trading has grown from $\$ 40$ billion in 1995 to nearly $\$ 600$ billion in $2016 .^{2}$

OIDs, LIBOR floors, and the spread over LIBOR (all-in-drawn spread) constitute the main pricing mechanisms for syndicated loans in the primary market. They are collectively referred to as market flex because they are the flexible channels through which arrangers, via

\footnotetext{
${ }^{1}$ OCC Shared National Credit Program Review, 2017

${ }^{2}$ LSTA
} 
"price talk" with lenders, discover a market clearing yield. ${ }^{3}$ Sufi (2007) and Bruche, Malherbe, and Meisenzahl (2017) provide descriptions of the syndication process that determines pricing.

The volume of new deals in the primary leveraged loan market returned to pre-crisis levels after a two-year lull in 2008-2009 (see Figure 2.1), during which the issuance of institutional tranches - those which banks originate to distribute - all but disappeared. It is the resurgence of leveraged loan issuance that lies at the core of this paper's research question; because, with it came lingering changes in the composition of market clearing loan packages. One such change is the inclusion of interest rate floors; another is cov-lite loan contracts, in which bond-like incurrence financial covenants are included in lieu of the maintenance covenants that had been typical in these loans prior to 2007. Together, these changes have helped close the divide that separates high yield bonds from leveraged loans. ${ }^{4}$

CLOs typically constitute over $50 \%$ of demand in the primary market for leveraged loans and therefore have considerable influence on the shape of market clearing loan packages. Nearly two-thirds of the liabilities in post-crisis CLOs constitute the senior (AAA rated) tranche. Lenders in this segment receive LIBOR plus a spread and therefore see no benefit of floor options on the underlying collateral. Instead, lenders in the equity tranche, which suffers the first loss in the event of any impairments to the collateral, benefit directly from LIBOR floors. CLO Equity investors earn the spread between LIBOR and the weighted average floor strike of the collateral pool since the senior liabilities pay LIBOR plus a fixed spread. Perhaps highlighting a misunderstanding regarding the trade-off between initial loan spreads and embedded options, the parlance of the loan market refers to this spread as

\footnotetext{
${ }^{3}$ As a typical example, in April, 2016, UBS AG brought Netsmart Technologies's 7-year first lien term loan to market with price talk in the range of L+525-550 (interest spread above LIBOR of 525 to 550 bps), with a $1 \%$ floor (floor option with a strike rate of 100 basis points), offered at 98.5 (98.5\% of par value, indicating an OID of $1.5 \%$ ), for a yield to maturity of roughly $6.69-6.96 \%$.

${ }^{4}$ Chamblee and Tenholder (2005) document pre-crisis convergence while Becker and Ivashina (2016) and Billett et al (2016) both document and propose explanations for the post-crisis growth in cov-lite issuance
} 
Figure 2.1: Primary market for highly leveraged loans: issuance volume. Data are limited to the S\&P LCD sample. The proportion of new loans with embedded options is indicated with darker shading. Both institutional and pro rata tranches are included.

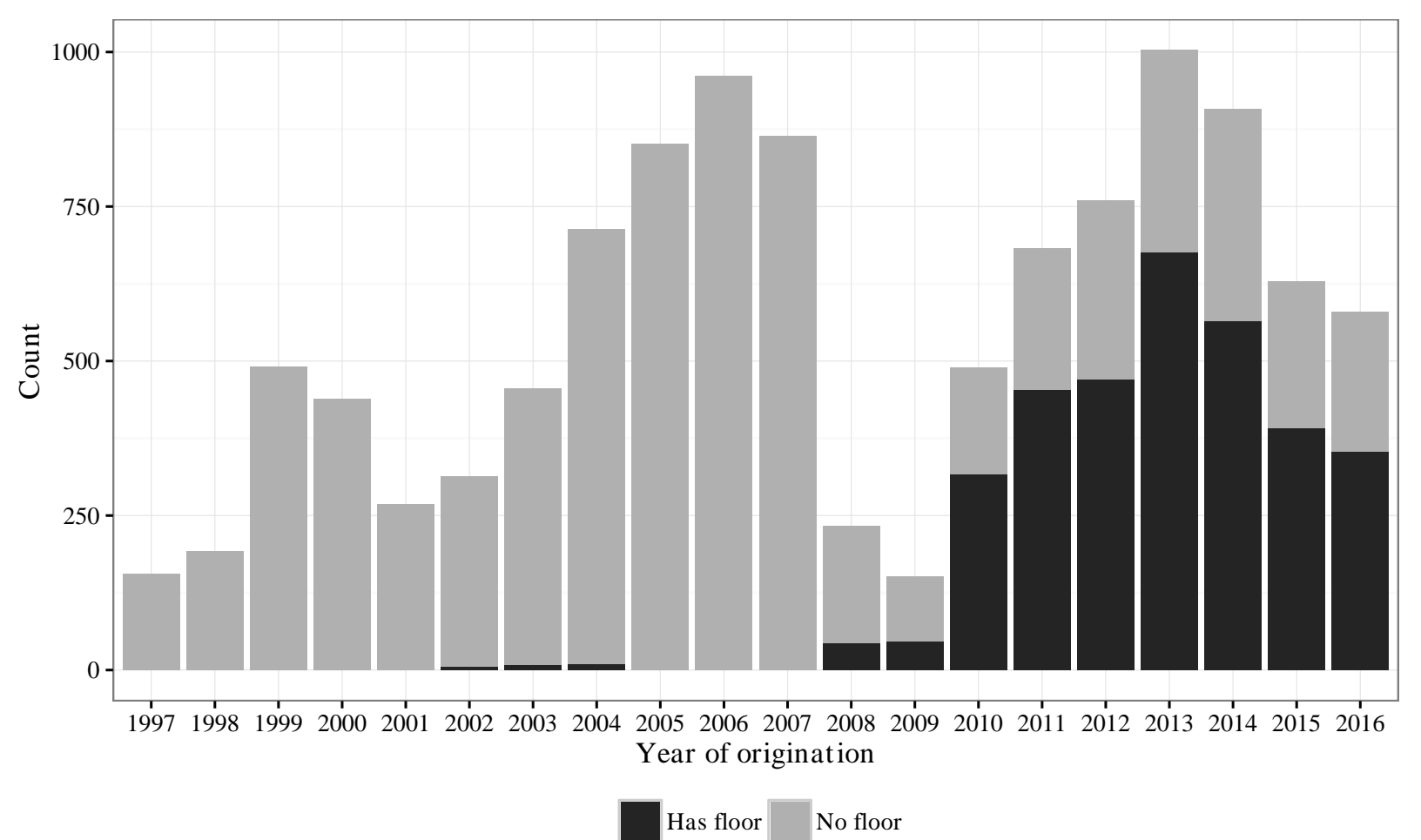

"CLO arbitrage." Demand for embedded floor options in collateral conceivably arise from the arrangers of CLOs, who determine which loans are securitized. Most portfolio managers (arrangers) of CLOs receive incentive fees similar to those of general partners in private equity funds. According to Yan (2012), these incentive fees are distributed to portfolio managers as a percentage (typically 20\%) of profits above a hurdle return to equity investors. Since these hurdle returns are calculated as IRRs on cash flows to the equity tranche, this compensation scheme motivates managers to prefer the front-loaded cash flow stream provided by LIBOR floors to that of an equivalent fixed spread. ${ }^{5}$ Therefore, demand for embedded floors may be partly a byproduct of the securitization process as CLO managers attempt to maximize

\footnotetext{
${ }^{5}$ The shape of the yield curve dictates the schedule of expected cash flows associated with the floor. Upward-sloping curves, which were the norm during the periods examined, correspond to front-loaded cash flow streams.
} 
the value of their incentive fees similar to the way in which general partners strategically time cash flows as a means of maximizing their interest carry in private equity funds [see Phalippou (2009)].

This paper is closely related to the work of Berg, Saunders, and Steffen (2016), who explore the complex pricing structure of syndicated loans. They note a lack of attention in previous loan pricing research to the various non-interest spread compensation in loans, most significantly OIDs and other fees. Their hypothesized rationale for including fees is that they offer compensation for the options embedded within these contracts. They neglect to cover LIBOR floors in their analysis, however, perhaps due to availability of data (LIBOR floors are not identified by field in the Dealscan data that they use). As a result, their suggested total borrowing cost measure, which they offer as a new pricing measure for future research, underestimates the true cost of borrowing by as much as 20\% (at the median) during the post-crisis era. Similarly, Bruche, Malherbe, and Meisenzahl (2017) ignore LIBOR floors in their study of arrangers' risk in leveraged loan syndication. They investigate underpricing in new loan issues, assessing the practice of flexing OIDs and all-in drawn spreads to entice institutional investment, a practice that became more widespread - along with LIBOR floors - after 2008.

The subject of minimum interest rates in otherwise floating rate contracts is not new. Cox, Ingersoll, and Ross (1980) discuss the valuation of such loans in their analysis of variable rate contracts. Theory regarding a borrower's preference for floating rate debt over fixed-rate debt is developed by Agmon, Ofer, and Tamir (1981), who argue that the choice hinges on the covariance between the borrower's profitability and the interest rate. Santomero (1983) develops a similar theory from the lender's perspective, also relating the decision to the covariance of borrower cash flow and the interest rate. Both theories imply that borrowers and lenders are aligned in their preference for floating rate debt when the covariance is high and for fixed rate debt when the covariance is low. Central to both theories, the threat of 
costly bankruptcy leads borrowers and lenders to prefer floating rate debt in cases for which a borrower's interest expense is high only in states when its income is also high. For borrowers that exhibit low (or negative) cash flow correlation with the rate, fixed rate contracts should be preferred. Empirical investigations have failed to find this relation. Faulkender (2005) and Chava and Purnanandam (2007) examine the proportion of floating rate debt employed by non-financial firms and find evidence to suggest the choice is primarily driven by speculation on future interest rates rather than in response to whether firm cash flow serves as a natural interest rate hedge.

Kirti (2015) argues that bank-dependent firms assume interest rate risk from banks through floating rate loans because they have no other recourse. This assumes banks prefer to fund at short term rates [Stein (2012)]. Banks then transfer this interest rate risk to borrowers by matching their short-term liabilities with assets that pay floating rates.

Aside from interest expense, banks also face fixed operating costs, which are invariant to changes in interest rates. This is a critical consideration of Dreschsler, Savov, and Schnabl (2017) who theorize banks have incentive to hold more fixed rate assets to cover their fixed costs in the event that interest rates fall. Banks with larger operating costs relative to interest expense should therefore hold larger fractions of fixed rate assets. The popularity of LIBOR floors after 2008 fits this theory well, as they not only provide the coverage of fixed costs while rates are low, but also preserve the floating rate nature of the assets should rates eventually rise.

Similarly, institutional investors may face pseudo fixed costs in the form of minimum rates of return or income over time. Barucci (2002) discusses the proclivity of fund managers to employ portfolio insurance strategies because of the agency costs associated with financial intermediation and the sensitivity of fund flows to past performance. The introduction of a lower bound on consumption or wealth leads to these types of portfolio insurance strategies [e.g., see Perold and Black (1992) and Dybvig (1995)]. Certainly, defined benefit pension 
plans would fit this bill, as would other institutional investors whose mandates call for regular distributions of fund assets. Leland (1980) argues that these types of investors exhibit preferences that lead them to adopt portfolio insurance strategies in some form. In this case, investors may be willing to assume the additional interest rate risk associated with embedded floors for the additional cash flow they produce during times of extremely low interest rates.

Embedded floors might also have arisen, at least in part, due to concerns over the validity of LIBOR. With hindsight, we know that LIBOR was manipulated lower during the crisis by at least some of the 16 rate setting banks out of fear that honest quotes would reveal bank instability. ${ }^{6}$ Evidence that fraudulently low rate reporting by panel banks did in fact affect LIBOR during the crisis is provided by Monticini and Thornton (2013), who identify the effect in 1-month and 3-month rates. Youle (2015) finds that LIBOR was on average eight basis points lower than it otherwise would have been absent banks' incentives to obscure their true borrowing costs. If lenders were aware - or even suspected - this at the time, embedding floor options would have been a rational and appropriate response.

Figure 2.2 depicts Google trends weekly search volumes for the phrases "LIBOR manipulation" and "LIBOR fraud" during 2007 through 2009. The week with the largest number of Google searches for those topics has a value normalized to one. All other weeks' values are listed as a fraction of that peak. Notably, there was no activity on the subject of LIBOR manipulation until January, 2008. Thereafter, positive search volumes became relatively common. Below the trends data, a timeline indicates events that produced information con-

\footnotetext{
${ }^{6}$ Most recently, The US Department of Justice charged two bank managers at Société Générale for, according to the DOJ's press release dated 24-Aug-2017, "instructing their subordinate employees to ... submit inaccurately low LIBOR contributions in an effort to make it appear that Société Générale was able to borrow money at more favorable rates than it actually was. This was allegedly done with knowledge that the true rates at which Société Générale was borrowing money were higher than the rates it was submitting as part of the LIBOR calculation. On numerous occasions, the false information ... altered the day's final U.S. Dollar LIBOR calculation, thus affecting all financial transactions tied to U.S. Dollar LIBOR on that day."
} 
cerning the validity of LIBOR. Late in the third quarter of 2007, the NY Fed's three-month Eurodollar (bid) rate began quoting above LIBOR [Ghandi et al (2008)]. Further evidence that LIBOR was artificially low came a few months later when the first Term Auction Facilities (TAFs) conducted by the Fed were oversubscribed by banks borrowing at rates 20-30 bps higher than one-month LIBOR. Most puzzling, the TAF loans were collateralized and so should have been made at lower rates than the uncollateralized LIBOR. That following March, The Wall Street Journal published an article on the divergence between LIBOR and equivalent rates such as those in the Fed's H.15 report. April saw the first mention in the popular press of possible LIBOR manipulation, followed shortly thereafter by an article detailing the inconsistencies between bank credit default swap rates and the equivalent credit risk implied by LIBOR. ${ }^{78}$ Lenders likely became aware of issues concerning LIBOR as early as the fourth quarter of 2007. In this regard, the rise of floor usage fits well.

Figure 2.2: Google trends search volume for terms "LIBOR Fraud" and "LIBOR Manipulation". Volumes are at weekly frequency and are normalized by the largest volume in the event window. For example, the week with the largest volume of searches equals 100, while the lowest is zero.

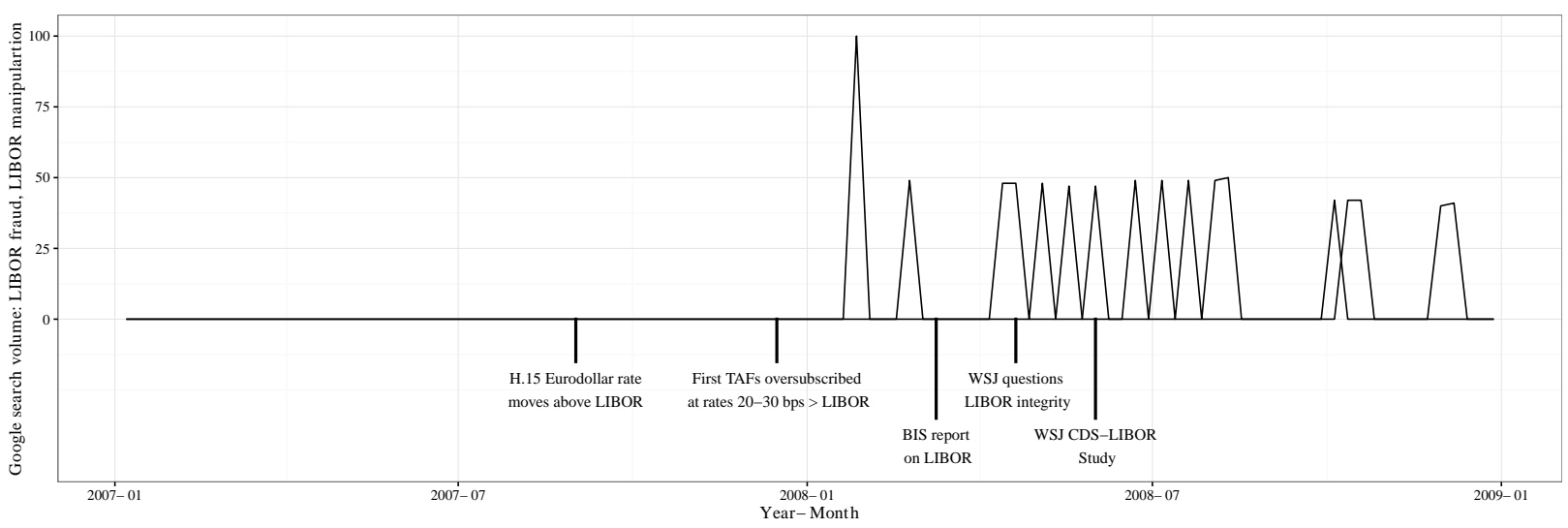

The inclusion of LIBOR floors has introduced demand for call protection, which has not been a common feature in syndicated loans prior to the crisis. Accordingly, the study of

\footnotetext{
7 "Bankers Cast Doubt on Key Rate Amid Crisis," Carrick Mollenkamp, The Wall Street Journal, April $16,2008$.

8 "Study Casts Doubt on Key Rate," Carrick Mollenkamp and Mark Whitehouse, The Wall Street Journal, May 29, 2008.
} 
callability has been mostly limited to fixed rate debt [Bodie and Tagart (1978), Barnea, Haugen, and Senbet (1980), Thatcher (1985), Flannery (1986), Kish and Livingston (1992)]. In fact, one of the central motives for issuing callable bonds, interest rate sensitivity, has traditionally been irrelevant in the loan market as these loans have until recently been purely floating rate contracts. Remaining concerns over uncertainty surrounding the credit spread component of the loan's interest rate can be handled through covenant structure. Asquith, Beatty, and Weber (2005) discuss performance pricing covenants (PPCs), a common feature of syndicated loans that serve to adjust the interest spread on the facility to fluctuations in the borrower's credit quality, thereby reducing the repricing incentive ex ante. The authors cite performance pricing as a possible reason for the lack of call premiums in bank loan contracts. That these premiums are now seen in many leveraged loan contracts suggests that their emergence is tied to evolution of other contract terms, such as LIBOR floors.

This paper also draws upon the literature concerning lenders in syndicated loans. Gatev and Strahan (2009) argue that commercial banks are more likely than institutional lenders to participate in revolving credit facilities (those in which the borrower has the option to continually draw down and repay loans during the life of the facility) because these banks are uniquely suited to hedge liquidity risks due to their FDIC deposit backing. Non-banks therefore eschew unfunded tranches in favor of fully funded term loans. Nandy and Shao (2010) investigate differences in pricing between tranches and find that those dominated by institutional lenders (term loans B, C, D, etc.) offer significantly higher interest spreads than do pro rata tranches (revolvers and term loan As). Lim, Minton, and Weisbach (2014) confirm this result and offer further evidence that higher loan pricing is concentrated in facilities that count hedge funds and private equity funds among their lenders. This is consistent with Brophy, Ouimet, and Sialm's (2009) conjecture that these types of funds serve as lenders of last resort, extracting premiums from capital constrained borrowers when the supply of bank capital is low. While the literature has explored connections between 
the composition of the lending syndicate and loan pricing, the current study is the first to explicitly investigate the linkage between lenders and the use of LIBOR floors, a very specific form of compensation that likely offers greater appeal to certain lenders according to their costs and sources of funds.

To test the hypothesis that LIBOR floors are embedded in loans that are more likely to trade in the secondary market, I rely on the literature's prior efforts to discern a loan's liklihood to trade as a function of its contract terms. Wittenberg-Moermann (2008), for example, finds evidence that variables related to information uncertainty bear significantly on the probability that a loan trades on the secondary market. Specifically, the debt of public firms, those with credit ratings, and those associated with takeovers/LBOs/MBOs are all issued with larger amounts of publicly available financial data. These loans tend to have lower bid-ask spreads in the secondary loan market due to their lower information asymmetry. Further, she finds that larger, longer-maturity, institutional term loans are the facilities that tend to have the lowest bid-ask spreads. Certainly, higher trading volume would reduce information uncertainty as well, since frequent trading would alleviate valuation issues associated with stale prices. Drucker and Puri (2009) conclude that loans are structured ex ante to facilitate trading ex post. They find that the probability of a loan sale is increasing in the number of financial covenants, the size of the borrower, loan size, maturity, the borrower's leverage, whether the issue has a speculative credit rating, and for institutional term loans as opposed to pro rata tranche term loans and revolvers. Gupta, Singh, and Zebedee (2008) find similar relations between these loan characteristics and the likelihood that a loan trades in the secondary market. They find that the majority of liquid loans are made to issuers below investment grade, with over $90 \%$ of these loans classified as leveraged. To the extent that embedded floors offer cost savings that scale with the expected level of secondary trading, these studies offer insight into the likelihood that loans include embedded floors. 


\subsection{Relation between call protection, LIBOR floors and OIDs}

Typically, floating rate notes - or loans, in this case - have extremely short durations, and therefore little interest rate sensitivity. Duration is roughly equal to the time remaining before the note's next repricing date, because the investment can be replicated by a series of investments rolled over at the prevailing short term rate, say at three-month LIBOR [Ramaswamy and Sundaresan (1986)]. Accounting for the effect of credit risk on price sensitivity to interest rates is the subject of Yawitz, et al. (1987) and Dym (1998) who show the floater's duration is a value-weighted average of the durations of two components: a par bond and an annuity that drives the floater's price away from face value. Of particular importance to this study, discounts to par shorten duration.

Nawalkha, Zhang, and Chambers (1999) consider the effect of embedded options on the duration of floaters. Although only non-callable, par floaters are considered in their analysis, interest rate options are shown to increase the duration of notes in which they are embedded. This arises from the sensitivity of the option's cash flow to changes in the underlying (interest rate), otherwise known as the option's delta. A floor's effect on overall loan duration depends on its value relative to the value of the loan as a whole, which depends on the shape of the yield curve, volatility of interest rates, and the moneyness of the option (where the strike rate lies in relation to current and expected future interest rates). All else equal, larger floor-related interest payments will lengthen a loan's duration, since these are the floor's contributions to overall yield.

Intuitively, we might think of valuing the floor option and the loan's regular interest and amortization payments separately from one another. The former would exhibit high duration while the latter would possess duration similar to that of a non-par floater. If a loan trades at par, the contracted interest spread is sufficient compensation for lenders to 
hold the loan and the OID component of the yield vanishes. However, if a loan is issued at a premium, the OID $<0$ and its effect on yield will lengthen the loan's duration. Conversely, if a loan is issued at a discount, as is often the case for highly leveraged loans, the OID $>0$ and its effect will shorten the loan's duration. In fact, if the discount to par becomes large enough, the loan will exhibit negative duration, examples of which include GMAC's floating rate notes in the mid-2000s [Smith (2006)].

A direct effect of increased duration is an increase in the borrower's cancellation option value. Casting the right to cancel in a contingent claims framework, Brennann and Schwartz (1977) relate the optimal exercise of this option to the debt's price. As the borrower's credit quality improves beyond the ability of performance pricing covenants to accommodate, or if the embedded floor option appreciates in value, the price of the loan on the secondary market will increase. There is some threshold price above which the borrower finds it optimal to prepay and reissue the loan at a lower yield. In order to prepay the loan, however, borrowers may need to pay a prespecified fee, generally 100 to 300 basis points of the outstanding principal. These call premiums effectively raise the threshold value for optimal prepayment. Similarly, OIDs increase this cost as well since loans are repaid at par value. These fees may serve as a mechanism through which a borrower can signal prepayment likelihood and recoup some of the welfare loss due to asymmetric information. Brueckner (1994) shows that borrowers with a higher probability of early prepayment prefer loan contracts that substitute mortgage points (akin to OIDs) for lower interest rates in fixed rate mortgages. Analogously, a leveraged loan borrower can signal its intention to carry the loan to maturity by accepting a larger upfront fee.

Sarkar (2001) finds that bonds with higher ex ante probabilities of being called also have higher likelihoods of incorporating a call feature. Loans should be no different in this regard. Indeed, credit agreements often provide that the payment of cancellation fees be restricted to "repricing transactions," defined as events in which the loan is replaced with a similar loan 
at overall lower yield. Given that sensitivity to interest rates increases the ex ante likelihood that a loan will be called for repricing purposes, I hypothesize that embedded floor options should coincide with inclusion of call premiums.

The opposing effects that OIDs and LIBOR floors have on a floating rate loan's duration make them natural compliments in loan pricing and may explain the positive correlation of cancellation fees and OIDs documented by Berg, Saunders, and Steffen (2016). 


\section{Chapter 3}

\section{Calculation of Floor and OID Spreads}

\subsection{Floor spread calculation}

Measuring the impact of embedded floor options is aided by presenting the option in terms of an equivalent interest spread. To accomplish this, I estimate a fixed interest payment above LIBOR that a borrower would be willing to pay in exchange for stripping out a floor option. While this holds from the borrower's point of view, there is reason to believe lenders may not be indifferent between these two payment options. Heterogeneous preferences, cost of financing, hedging motives, and portfolio manager compensation structures conceivably lead certain investors to prefer a floor-adjusted interest rate to one that is purely floating. Investors may even exhibit expectations, irrational or otherwise, that the primary market inefficiently prices new issues. Take for example this quote from a bank loan portfolio manager at Pimco (one of the largest institutional investors in leveraged loans and high yield bonds) made in May, 2015:

The idea that the loan market could trade the floors that exists today for additional spread is pure fantasy. It's all about supply and demand, and if we give issuers an inch, they will take a mile and then we will have lower spreads and no floors. ${ }^{1}$

\footnotetext{
${ }^{1}$ Bank loan portfolio manager at PIMCO. "Leveraged Loan Market Asked to Stop Pretending Rates Aren't Low," Kristen Haunss and Michelle F. Davis, Bloomberg, May 27, 2015.
} 
While there may be variation in how lenders regard these floors in the overall compensation mix for bearing risk, there is a fixed payment stream for which the borrower is indifferent; and, this is the basis for which I quantify the spread trade-off these floor options imply.

Floor contracts are the value of a portfolio of put options on the interest rate, each with a strike rate equal to the floor and maturity dates in line with the expected repricing schedule of the underlying loan. It is not uncommon for these to be valued using Black's (1976) option pricing model [see, Hull (1997)] and I do so here. Each individual put, termed a floorlet, has an ex ante value equal to

$$
Z_{n}=\tau_{n} L_{n} z_{n}
$$

where,

$$
\begin{gathered}
z_{n}=k \Phi\left(-d_{2, n}\right)-f_{n} \Phi\left(-d_{1, n}\right), \\
d_{1, n}=\frac{\ln \left(\frac{f_{n}}{k}\right)+\frac{\sigma^{2}}{2} t_{n}}{\sigma \sqrt{t_{n}}}, \quad \text { and } \\
d_{2, n}=d_{1, n}-\sigma \sqrt{t_{n}},
\end{gathered}
$$

where $\tau_{n}=T_{n}-t_{n}$ is the tenor of the $n^{\text {th }}$ repricing period. Here, $\Phi(\cdot)$ is the cumulative standard normal distribution function; $k$ is the floor's strike rate; $f_{n}$ is the $\tau_{n}$ period forward rate at the time of loan issuance; $L_{n}$ is the principal value on which interest accrues during period $n$; and, $\sigma$ is the volatility measure of the interest rate. This model assumes interest rates follow a lognormal distribution and that forward rates are unbiased estimates of the future rates. However, I must make one exception in this regard; in cases for which the floor's strike rate is zero, I assume rates follow a normal distribution and use Bachelier's 
(1900) model to value the floorlet spread. In these cases, $z_{n}$ is given by the following:

$$
z_{n}=\left(k-f_{n}\right) \Phi\left(d_{3, n}\right)+\tilde{\sigma} \sqrt{t_{n}} \phi\left(d_{3, n}\right)
$$

where

$$
d_{3, n}=\frac{k-f_{n}}{\tilde{\sigma} \sqrt{t_{n}}},
$$

where $\phi(\cdot)$ is the probability density function of the standard normal distribution. The volatility measure in this case, $\tilde{\sigma}$, assumes interest rates are distributed normal. Defining the time zero $T_{n}$ spot rate as $r_{n}$ and discounting the sum of floorlets to $t_{1}=0$, the effective date of the loan, Eq. (3.7) yields the present value of the floor option as of the loan's origination. Note that the first forward rate is the current spot rate, so the first floorlet is known with certainty.

$$
P V(\text { Floor })=\sum_{n=1}^{N} B_{n} Z_{n}
$$

where,

$$
z_{1}=\max \left[0, r_{1}-k\right]
$$

and,

$$
B_{n}=\left(1+r_{n}+y\right)^{-T_{n}}
$$

To determine the appropriate credit spread used in discounting cash flows, I solve the following for $y$ : 


$$
P=\sum_{n=1}^{N} B_{n}\left[L_{n} \tau_{n}\left(f_{n}+z_{n}+s\right)+A_{n}\right],
$$

where $A_{n}$ is the scheduled amortization payment at $T_{n}, s$ is the all-in-drawn spread, and $P$ is the issue price of the loan. For simplicity, I normalize the loan principal amount to one, i.e. $L_{1}=1$ and allow issue prices to be expressed as percentages of that amount. For example, a loan issued at a discount of 300 bps would have an issue price of $P=.97$, or $97 \%$ of par value. Eq. (3.10) simply equates the present value of the loan's cash flow stream to its price, solving for the loan's yield.

Assuming the counterparty risk on the floor option is equal the credit risk associated with the loan, there is a series of constant floor spread payments with equal present value to the series of floorlet cash flows and their associated transaction costs. Let floorSpread be that fixed spread, i.e.

$$
\begin{aligned}
\sum_{n=1}^{N} B_{n} \tau_{n} L_{n}\left(z_{n}+c_{n}\right) & =\sum_{n=1}^{N} B_{n} \tau_{n} L_{n} \text { floorSpread } \\
\Longrightarrow \text { floorSpread } & =\sum_{n=1}^{N} \lambda_{n}\left(z_{n}+c_{n}\right)
\end{aligned}
$$

The floor spread is therefore a weighted average of expected floorlet cash flows, given information available at the time of loan issuance. Here, $c_{n}$ is the expected transaction cost associated with procuring the option for period $n$, expressed as a percentage of the outstanding principal at that time. The weights, $\lambda_{i}$, are a function of the $i^{\text {th }}$ floorlet tenor, principal amount at time $t_{i}$, and the time-zero price of a discount bond maturing at time $T_{i}$.

Assuming that the floor tenors are constant, i.e. $\tau_{n}=\tau \forall n$, the weights in Eq. (3.11) are: 


$$
\lambda_{i}=\frac{B_{i} L_{i}}{\sum_{n=1}^{N} B_{n} L_{n}} .
$$

\subsection{OID spread calculation}

The discount associated with each amortization payment is the difference between the loan's issue price and par. The cash flow arising from the OID at $T_{n}$ is defined as $O I D_{n}=A_{n}(1-P)$. Assuming that the amortization payments are due at time intervals of $\tau$, e.g. every three months, the OID spread is defined as the constant that satisfies the following equality:

$$
\begin{aligned}
\sum_{n=1}^{N} B_{n} O I D_{n} & =\sum_{n=1}^{N} B_{n} \tau L_{n} \text { oidSpread } \\
\Longrightarrow \text { oidSpread } & =\sum_{n=1}^{N} \omega_{n} O I D_{n},
\end{aligned}
$$

where

$$
\omega_{i}=\frac{B_{i}}{\sum_{n=1}^{N} B_{n} \tau L_{n}} .
$$

The OID spread is therefore expressed as an additional interest spread applicable to the outstanding principal at times $\left\{t_{n}\right\}_{n=1}^{N}$. This method differs from what is usually done in practice, which is to simply divide the upfront fee by three or four, effectively amortizing the fee over the expected life of the average loan. Prior studies adopt similar methods of amortizing fees. For example, Bruche, Malherbe and Meisenzahl (2017) follow LCD's lead and divide the fee by four when computing the effective interest rate, while Berg, Saunders, and Steffen (2016) divide by the number of years until maturity. These methods slightly overstate the importance of these fees in term loans with light amortization or bullet-style 
repayment schedules, which comprise the bulk of institutional leveraged loans. Eq. (3.13), on the other hand, accounts for actual amortization and therefore provides a more accurate estimate of the OID's impact on institutional term loan pricing. 


\section{Chapter 4}

\section{Data}

The loan data are an aggregation of three sources: Bloomberg, Thompson Reuters's Dealscan, and S\&P's Leveraged Commentary and Data (LCD). The LCD data consists solely of leveraged loans whereas Bloomberg and Dealscan contain a wider spectrum of syndicated loan deals. There are advantages to combining these datasets as there are pockets of nonoverlapping fields, e.g. Bloomberg's superior coverage of minimum transfer amounts, LCD's coverage of market flex, and Dealscan's lender shares to name a few. I also incorporate accounting records from Compustat using the linking table first assembled by Chava and Roberts (2008), which has, of this writing, been updated to include records through August, 2012. For loans issued thereafter, I manually match Compustat and Dealscan records on company/borrower name. Facilities between Bloomberg, Dealscan and LCD are matched according to the month of issuance, borrower/company name, and facility type. Bank holding company (BHC) data collected from Call Reports obtained from the Chicago Fed are also used in the analysis of floor usage relative to bank attributes. As is the case with the Compustat data, the BHC observations are at quarterly frequency.

The study is restricted to US dollar-denominated syndicated loans, most of which are highly leveraged, issued in the United States. Loan observations are made at the facility level, often issued as part of the same loan package. A typical package might contain a revolving credit facility (revolver), which is usually retained for the duration of the loan's 
life by a group of banks, and a term loan, which is syndicated to a more diverse syndicate of institutional lenders. So called 'pro rata' tranches include revolvers, bridge financing, and amortizing term loans (TL As) while institutional tranches include the various term loans that are originated to distribute, most commonly referred to as term loans B, C, and D. These facilities also incorporate little amortization, repaying far slower with longer maturities than the term loan As that are issued alongside them.

There is some disagreement in the literature as to the correct categorization of these facilities. Nandy and Shao (2010) use facility names as identifiers while Lim, Minton and Weisbach (2014) classify institutional tranches as those that contain at least one institutional lender at origination. Both categorization methods likely produce similar sets, although Nandy and Shao's (2010) is both easier to implement and comes without the complication of correctly categorizing lenders. Additionally, a potential issue with Lim, Minton and Weisbach's (2014) approach is the tendency for many offshore funds to enter a deal via primary assignment as opposed to signing the credit agreement directly. These assignments bring primary lenders into a deal in the weeks after the credit agreement is signed (which is where Dealscan pulls its lender records from); so, many institutional facilities will appear to be pro rata facilities if we categorize according to signatories on the loan document itself. This practice is common among CLOs, hedge funds and other offshore funds because it allows them to claim passive investment in the loans, which shelters them from taxes under the Trading Safe Harbor rules in the US tax code. In light of these complications, I adopt Nandy and Shao's (2010) approach to facility classification and restrict my analysis of lenders to credit lines in which offshore lenders are least likely to participate.

I use several (sub)samples for my analysis. The first is a pooled sample that pertains only to leveraged loan deals listed in LCD. This provides a look at the use of floors in the leveraged market segment and affords the largest number of controls in my tests as LCD contains information not only on floor strikes, but also on market flex and credit ratings. 
The second sample incorporates loans from all three data sources, but limits observations to facilities for which each floor observation is counterbalanced by another facility that does not contain a floor, but is part of the same loan package issued on the same day. This sample construction provides perfect balance of unobserved covariates along the borrower and temporal dimensions, thus alleviating some of the omitted variables bias that might affect analysis on the pooled LCD sample. I further restrict this sample to include only term loan observations in some tests. I also make use of a one-for-one matched sample which balances observations that include call premiums with those that do not in my tests of call protection in relation to floor use. Summary statistics of these subsets are displayed in Tables A-3 and A-4 in the appendix.

While Bloomberg and LCD provide fields indicating whether facilities have embedded floors, Dealscan does not. ${ }^{1}$ Floor information is, however, detailed in the comment fields of the 'Facility' dataset in Dealscan. I run a search on keywords within these comments, pulling out information not only on LIBOR floor strike rates, but on call premiums as well.

Crucial to the calculation of floor spreads is the determination of forward rates and the volatility of the interest rate process. As USD LIBOR is the applicable base rate pertaining to nearly all US dollar-denominated syndicated loans, I use the default swap curve generated by Bloomberg for three-month LIBOR fixings. ${ }^{2}$ This curve uses LIBOR for the short-term, Eurodollar futures for the mid-tenors, and swap rates for the long end of the curve. The advantages of using Bloomberg's default curve are twofold: (1) due to Bloomberg's ubiquity, this is the curve that market participants most likely use when projecting a loan's expected cash flow; and (2), this default approach to curve construction avoids the problematic occurrence of negative implied forward rates.

I use a flat volatility measure for the interest rate, which I obtain from interest rate

\footnotetext{
${ }^{1}$ Of the 1,235 facilities that match between Bloomberg and LCD, 85\% agree on whether a floor is present. In the 185 cases in which there is disagreement, 95 involve a floor strike of zero.

${ }^{2}$ Curve 23 - US Dollar Swap (30/360 day).
} 
floor/cap prices as of loan origination. These data are from Bloomberg and are referred to as Black volatilities because they are backed out of Black's (1976) model. For cases in which the floor strike rate is zero, I convert these to normal volatilities to suit Bachelier's (1900) model assumptions. The market price for an option that matches, as closely as possible, the strike and maturity of the embedded floor option in each observation is used.

Data on secondary loan prices are used in my analysis of interest rate sensitivity. However, concerns related to light trading and stale prices lead me to limit loans for that purpose to those for which Bloomberg has assigned a high BVAL score. A measure of trading activity, the BVAL score is calculated by Bloomberg using an undisclosed formula that is meant to indicate the quality of price data. It ranges from one to ten, with better quality price information associated with higher BVAL scores. The majority of these facilities are lightly traded as over three quarters of them have BVAL scores of one or less. The data used for analysis of the price behavior of these loans is limited to the 538 loan facilities that have BVAL scores greater than one as determined when the data were downloaded (February, 2016).

\subsection{Pooled LCD sample}

To avoid statistical issues associated with duplicated variables within loan packages, I retain only one facility each from the pro rata and institutional tranches of a deal in the pooled LCD sample. For cases in which a second lien facility is issued in conjunction with another institutional tranche within the same package, I retain both. Several variables, including LIBOR floors, tend to be identical across facilities of the same group. In choosing which facilities to discard I bias retention toward term loan As over revolvers on the pro rata side and term loan Bs over other term loans on the institutional side. This produces an unbalanced panel of at most 11,523 facilities. Variable definitions are listed in the appendix 
Table A-1. Descriptive statistics are provided in Table 4.1.

Table 4.1: Summary statistics. Data are from Thompson Reuters LCD and are exclusive to the leveraged loan market. Variable descriptions are listed in Table A-1.

\begin{tabular}{|c|c|c|c|c|c|c|c|c|}
\hline Statistic & $\mathrm{N}$ & Mean & St. Dev. & Min & $\operatorname{Pctl}(25)$ & Median & $\operatorname{Pctl}(75)$ & Max \\
\hline $\begin{array}{l}\text { Loan issuance data } \\
\text { facilityAmount (\$mil) }\end{array}$ & 11,523 & 310.725 & 474.704 & 2.500 & 65.000 & 155.000 & 350.000 & $8,800.000$ \\
\hline allInDrawn (bps) & 11,523 & 363.718 & 174.844 & 37.500 & 250.000 & 325.000 & 450.000 & $1,750.000$ \\
\hline oid (bps) & 8,831 & 63.451 & 123.852 & -250.000 & 0.000 & 12.500 & 100.000 & $3,000.000$ \\
\hline floorStrike (bps) & 3,576 & 122.113 & 41.894 & 75 & 100 & 100 & 125 & 550 \\
\hline maturity (months) & 11,523 & 66.795 & 15.790 & 0 & 60 & 65 & 79 & 180 \\
\hline leadReputation & 11,499 & 0.288 & 0.120 & 0.000 & 0.190 & 0.277 & 0.371 & 1.000 \\
\hline roa & 4,467 & 0.158 & 0.161 & -2.531 & 0.092 & 0.137 & 0.195 & 2.652 \\
\hline debtEbitda & 4,622 & 6.886 & 79.796 & -193.746 & 2.277 & 3.868 & 5.646 & $3,626.610$ \\
\hline salesAtClose (\$mil) & 6,891 & 2,029 & 5,838 & -7.240 & 240 & 597 & 1,624 & 192,604 \\
\hline ebitdaCorrel & 2,114 & 0.049 & 0.281 & -0.604 & -0.147 & 0.052 & 0.252 & 0.679 \\
\hline slope & 11,522 & 81.235 & 65.489 & -105.715 & 35.870 & 80.197 & 122.865 & 354.664 \\
\hline initialCall (bps) & 4,091 & 134.439 & 64.549 & 12 & 100 & 100 & 200 & 700 \\
\hline hasFloor & 11,523 & 0.310 & 0.463 & 0 & 0 & 0 & 1 & 1 \\
\hline termLoan & 11,521 & 0.605 & 0.489 & 0 & 0 & 1 & 1 & 1 \\
\hline secondLien & 11,523 & 0.075 & 0.264 & 0 & 0 & 0 & 0 & 1 \\
\hline sponsored & 11,523 & 0.631 & 0.483 & 0 & 0 & 1 & 1 & 1 \\
\hline hasCall & 11,523 & 0.356 & 0.479 & 0 & 0 & 0 & 1 & 1 \\
\hline hasBreakPrice & 11,523 & 0.459 & 0.498 & 0 & 0 & 0 & 1 & 1 \\
\hline hasPpc & 11,523 & 0.249 & 0.433 & 0 & 0 & 0 & 0 & 1 \\
\hline proRata & 11,523 & 0.478 & 0.500 & 0 & 0 & 0 & 1 & 1 \\
\hline covLite & 11,258 & 0.145 & 0.353 & 0 & 0 & 0 & 0 & 1 \\
\hline $\begin{array}{l}\text { Loan amendment data } \\
\text { amendmentFee (bps) }\end{array}$ & 765 & 41.089 & 50.595 & 0.000 & 15.000 & 25.000 & 50.000 & 700.000 \\
\hline spreadIncrease (bps) & 765 & 98.714 & 108.890 & -50.000 & 0.000 & 75.000 & 175.000 & 625.000 \\
\hline addFloor & 765 & 0.154 & 0.361 & 0 & 0 & 0 & 0 & 1 \\
\hline covenantRelief & 765 & 0.705 & 0.457 & 0 & 0 & 1 & 1 & 1 \\
\hline proRataExtended (\$mil) & 139 & 496.765 & 853.607 & 15.000 & 55.312 & 150.000 & 610.000 & $7,200.000$ \\
\hline proRataNotExtended (\$mil) & 91 & 120.695 & 220.804 & 0.000 & 0.000 & 15.000 & 201.000 & $1,304.000$ \\
\hline institutionalExtended (\$mil) & 178 & $1,015.280$ & $1,743.801$ & 39.700 & 328.750 & 616.800 & $1,066.525$ & $15,400.000$ \\
\hline $\begin{array}{l}\text { institutionalNotExtended } \\
(\$ \mathrm{mil})\end{array}$ & 153 & 622.522 & $1,055.162$ & 0.000 & 0.000 & 178.700 & 746.000 & $5,990.000$ \\
\hline
\end{tabular}

Many of the observations taken from LCD include information on S\&P credit ratings of facilities at origination. Given these are leveraged loans, most are sub-investment grade. In order to balance the groupings of these ratings and ensure adequate numbers of loans in my tests, I aggregate all loans with ratings between $\mathrm{BBB}-$ to $\mathrm{BBB}+$ into a single group and do the same for loans rated $\mathrm{CCC}+$ and below. Similarly, primary purpose (Dealscan) and borrower industry (LCD) dummy variables are aggregated to ensure that there are enough 
observations per category to assuage concerns of bias in some of my tests, which according to Greene (2004) can be significant for small groups sizes in binary response models. In total, borrowers are allocated into 32 industry groups and 5 primary purposes: acquisition, general corporate, debt repayment, recapitalization, and other. The distributions of loan purpose, credit rating, and industry are listed in Table A-2 in the appendix.

hasBreakPrice, covLite, and hasPpc are dummy variables indicating, respectively, whether LCD reports a loan already trading in the secondary market around the time of issuance, whether a loan has bond-like financial covenants, and whether it contains a performance pricing covenant (PPC).

Some floors are recorded with zero strike rates. Inspection of a small sample of credit agreements downloaded from SEC EDGAR confirms that these options do in fact have LIBOR floors that prevent the base rate from falling below zero. I therefore categorize these zero-strike option loans as containing floors (hasFloor $=1$ ).

The dummy variable termLoan indicates roughly $60 \%$ of the sample are term loan facilities of various styles, including second lien facilities, bridge loans and delayed draws. The remaining observations are revolving credit facilities. Almost half these loans are associated with private equity deals as $63 \%$ are led by a financial sponsor $($ sponsor $=1)$.

Following Berg, Saunders, and Steffen (2016), I categorize missing call premiums as zero. Their audit of 1,000 Dealscan facilities to actual loan data downloaded through EDGAR indicates that over $98 \%$ of these call premiums are correctly identified. Similarly, I also assume missing OIDs indicate that a loan was issued at par

Borrower-specific accounting information as of a loan's closing date is scant. The most widely available is salesAtClose, which records the borrower's total annual sales around the time of loan issuance. Close to a third of facilities are linked to records in Compustat, which provide additional details on leverage and profitability. I calculate return on assets as a borrower's EBITDA in the year of loan issuance divided by lagged total assets. debtEbitda 
is the ratio of long-term debt to EBITDA in that same year. earningsCorrel measures the correlation between a borrower's EBITDA and the three-month LIBOR in the 12 quarters following loan issuance.

S\&P LCD also records data on loan amendments. I discard any records for which amendment fee data are unavailable, leaving a total of 765 amendments between 2005 and $2016 .^{3}$ The majority of these (over 90\%) occur in years 2008-2016. I therefore limit observations used in my tests to those in 2009 and later. Variables of interest are: whether an amendment altered the covenant structure of the loan (covenantRelief $=1$ ); whether the amendment changed the all-in-drawn spread (spreadChange); whether a LIBOR floor was added to the loan $($ addFloor $=1)$; and, the principal amount extended and not extended for institutional and pro rata tranches, respectively. A little over two-thirds of these amendments were covenant-related, with the remainder primarily concerned with principal extensions.

\subsection{Lender data}

Lender shares data in Dealscan are used to identify facilities in which certain types of lenders participate. This requires a classification of lenders into broad categories. I employ a method similar to Lim, Minton and Weisbach's (2014) for classifying institutions. However, I deviate from their approach in some meaningful ways. I categorize government-supported institutions like Farm Credit and development banks separately from commercial banks. I also separate loan mutual funds from CLOs and make an effort to isolate distressed credit funds, whom I expect to place a high value on embedded floor options due to their manager compensation schemes and proclivity to hedge.

Further, I subdivide asset managers and insurance companies into those that are known issuers of CLOs and those that are not. I do so in order to address the likelihood that

\footnotetext{
${ }^{3}$ I consider data with missing fees to be of lesser quality due to the importance fee information to practitioners, for whom the LCD service is targeted.
} 
Dealscan records the investment manager name as opposed to the actual lender of record and the possibility that funds which sign credit agreements make subsequent distributions of their holdings to various offshore funds under their control. As an illustration of why this is an important distinction, data from Credit Flux indicates that Ares Management LLC manages 27 different CLOs. It is likely that some lender shares belonging to Ares CLOs are mistakenly attributed to Ares Management itself. Further, even in instances for which Ares Management LLC is the correct lender of record at origination, it may only be to facilitate a so-called 'season and sell' tax strategy whereby a lender holds an initial position just long enough before syndicating to its offshore siblings to preserve those funds' favorable tax treatment.

Additional detail regarding lender categorization is relegated to an appendix. Table 4.2 summarizes the number of facilities in which these lenders participated by year, along with the average number of deals per lender.

Table 4.2: Lender classification. Number of facilities in which lenders participated per year. Lender classifications as described in Section 5. Categories labeled with the prefix 'CLO' and 'non-CLO' refer to lenders that are known arrangers/issuers of Collateralized Loan Obligations. Lender data are taken from Thompson Reuters Dealscan and are compiled from signuture pages on credit agreements. The CLO distinction is an important one as we cannot distinguish between instances in which as asset manager, for example, signs on behalf of one of its CLOs or its credit hedge funds.

\begin{tabular}{|c|c|c|c|c|c|c|c|c|c|c|c|c|}
\hline Year & $\begin{array}{c}\text { Commercial } \\
\text { Bank }\end{array}$ & $\begin{array}{c}\text { Investment } \\
\text { Bank }\end{array}$ & $\begin{array}{c}\text { Government } \\
\text { Supported }\end{array}$ & $\begin{array}{l}\text { Finance } \\
\text { Company }\end{array}$ & $\begin{array}{c}\text { CLO } \\
\text { Manager }\end{array}$ & $\begin{array}{l}\text { non-CLO } \\
\text { Manager }\end{array}$ & $\begin{array}{c}\text { CLO } \\
\text { Insurance }\end{array}$ & $\begin{array}{l}\text { non-CLO } \\
\text { Insurance }\end{array}$ & CLO & $\begin{array}{l}\text { Mutual } \\
\text { Fund }\end{array}$ & $\begin{array}{l}\text { Distressed } \\
\text { Fund }\end{array}$ & Other \\
\hline 1997 & 1,060 & 145 & 1 & 109 & 32 & 10 & 12 & 31 & 38 & 62 & 2 & 30 \\
\hline 1998 & 995 & 148 & 2 & 83 & 27 & 5 & 14 & 30 & 57 & 37 & 3 & 48 \\
\hline 1999 & 3,502 & 494 & 11 & 362 & 70 & 46 & 49 & 76 & 275 & 238 & 3 & 164 \\
\hline 2000 & 2,886 & 407 & 24 & 411 & 51 & 33 & 22 & 50 & 352 & 200 & 2 & 91 \\
\hline 2001 & 1,700 & 368 & 17 & 221 & 39 & 4 & 9 & 34 & 224 & 76 & 2 & 47 \\
\hline 2002 & 1,782 & 532 & 43 & 292 & 97 & 24 & 22 & 55 & 219 & 72 & 2 & 72 \\
\hline 2003 & 2,397 & 1,010 & 45 & 432 & 188 & 51 & 34 & 75 & 366 & 63 & 4 & 128 \\
\hline 2004 & 2,765 & 1,429 & 68 & 608 & 326 & 52 & 36 & 69 & 746 & 138 & 27 & 213 \\
\hline 2005 & 3,276 & 1,609 & 63 & 584 & 158 & 16 & 3 & 28 & 375 & 128 & 18 & 80 \\
\hline 2006 & 3,316 & 1,749 & 29 & 612 & 89 & 16 & 1 & 4 & 77 & 44 & 2 & 33 \\
\hline 2007 & 2,629 & 1,613 & 46 & 448 & 114 & 20 & 4 & 7 & 85 & 44 & 7 & 37 \\
\hline 2008 & 1,337 & 404 & 42 & 169 & 19 & 11 & - & 2 & 14 & 13 & - & 6 \\
\hline 2009 & 603 & 246 & 50 & 71 & 11 & 9 & - & - & 1 & 3 & 6 & 19 \\
\hline 2010 & 2,156 & 1,127 & 38 & 229 & 32 & 5 & - & - & 6 & 8 & - & 3 \\
\hline 2011 & 4,494 & 2,077 & 112 & 355 & 68 & 11 & 1 & 5 & 32 & 6 & 1 & 10 \\
\hline 2012 & 5,305 & 2,509 & 120 & 354 & 60 & 7 & - & - & 27 & 14 & - & 16 \\
\hline 2013 & 6,343 & 3,314 & 110 & 375 & 73 & 14 & 2 & 6 & 25 & 34 & 14 & 23 \\
\hline 2014 & 7,726 & 3,630 & 157 & 423 & 87 & 28 & 3 & 24 & 40 & 30 & 20 & 11 \\
\hline 2015 & 9,616 & 3,212 & 221 & 330 & 82 & 36 & 11 & 15 & 43 & 30 & 17 & 19 \\
\hline 2016 & 2,276 & 1,482 & 13 & 29 & 27 & 5 & 1 & 2 & 8 & 16 & - & 9 \\
\hline Total facilities & 66,164 & 27,505 & 1,212 & 6,497 & 1,650 & 403 & 224 & 513 & 3,010 & 1,256 & 130 & 1,059 \\
\hline Total lenders & 1,469 & 301 & 68 & 231 & 137 & 140 & 20 & 94 & 561 & 102 & 56 & 286 \\
\hline Facilities/lender & 45.0 & 91.4 & 17.8 & 28.1 & 12.0 & 2.9 & 11.2 & 5.5 & 5.4 & 12.3 & 2.3 & 3.7 \\
\hline
\end{tabular}


Of note, there appears to be considerable difference in the facilities per lender statistics between the CLO and non-CLO categories of asset managers and insurance companies. Managers that also issue CLOs invest in six times as many deals as those that have not issued CLOs, reflecting either that these managers are more comfortable investing in these loans and so make more investments, or that Dealscan is mislabeling CLOs controlled by these managers. The same is true of insurance companies, although CLO insurers are only twice as active as their non-CLO counterparts. Also of interest, there is a sharp decline in the number of loans in which CLOs, loan mutual funds, CLO managers, and CLO insurance companies participate around 2004-2005. At the same time, bank shares increased. This likely reflects data quality issues (related to offshore tax treatment mentioned earlier) as opposed to a real shift in the investor base for these loans. 


\section{Chapter 5}

\section{Empirical Methods and Observations}

\subsection{Estimates of floor spreads and OID spreads}

Provided they are not in default, borrowers make elections regarding how the loans under their credit facilities are rolled over. During the life of a facility, several different contracts may be issued at any time. Each of these may have a different tenor, and therefore base rate and maturity. To simplify, I assume that the entire loan commitment is expected to be rolled over in unison every three months.

I estimate floor spreads according to Eq. (3.11) and oid spreads according to Eq. (3.13). Forward and spot rates are taken from Bloomberg's Curve 23 US Dollar Swap (30/360 day) as of the loan's effective date. Flat volatilities implied by floor option prices on a loan's effective date serve as the volatility measures. Loan principal is assumed to amortize at a rate of $.25 \%$ per quarter, which is typical for institutional term loans. Expected transaction costs associated with procuring a floor option through a third party are assumed to be zero. The resulting floor spreads are therefore inflated to a small degree.

Table 5.1 presents year-by-year summaries of all-in-drawn, floor, and OID spreads in new leveraged institutional term loans. Floors first appeared briefly in 2002-2004; however, their popularity began in earnest in 2008. By 2011, floors were contained in roughly $97 \%$ of institutional leveraged terms loans coming to market, a proportion that has remained 
more or less unchanged since. However, while their inclusion in new institutional tranches has become ubiquitous, the contribution of floor options to total lender compensation has decreased over time. Embedded floor options were at their most valuable in 2009, when the median floor spread was 128 bps. That amount has decreased steadily since that time, with the median floor down to just over 30 bps in 2016. Reasons for this are twofold. First, the median strike rate on these options has decreased from 200 bps in 2010 to 100 bps in 2013 and beyond. Second, forward curves have generally been steeper in all years compared to 2009. In comparison to OIDs, however, floors have represented a significantly larger component in overall interest compensation. Excepting the crises years, median spreads associated with OIDs have been 15 bps or less.

Table 5.1: Comparison of loan spreads in new institutional term loans by year of origination. All-in drawn spreads comprise the bulk of the compensation delivered to lenders. This table shows the relative size and significance of three spreads discussed throughout this paper: All-in Drawn, defined as the initial spread above LIBOR plus facility fees that borrowers are charged as defined in a loan's credit agreement; Floor spread, calculated according to Eq. (3.11) as the equivalent spread above LIBOR which offsets the present value of a floor option at the time a loan becomes effective; and, OID spread, is the amortized value of an original issue discount over the life of a loan, calculated according to Eq. (3.13). Total spread is defined as the sum of all three spreads, assuming zero values for missing floor and OID spreads.

\begin{tabular}{|c|c|c|c|c|c|c|c|c|c|c|c|c|c|c|c|c|c|c|c|c|}
\hline & 1997 & 1998 & 1999 & 2000 & 2001 & 2002 & 2003 & 2004 & 2005 & 2006 & 2007 & 2008 & 2009 & 2010 & 2011 & 2012 & 2013 & 2014 & 2015 & 2016 \\
\hline $\begin{array}{l}\text { Medians } \\
\text { All-in drawn (bps) }\end{array}$ & 250 & 250 & 350 & 350 & 350 & 300 & 325 & 300 & 275 & 275 & 300 & 450 & 500 & 475 & 450 & 475 & 400 & 450 & 450 & 425 \\
\hline Floor spread (bps) & - & - & - & - & - & 79 & 74 & 47 & - & - & - & 99 & 128 & 101 & 73 & 83 & 60 & 45 & 37 & 32 \\
\hline OID spread (bps) & 1 & 1 & 3 & 3 & 3 & 4 & 7 & 12 & 8 & 9 & 17 & 28 & 36 & 20 & 15 & 15 & 12 & 10 & 12 & 13 \\
\hline Total spread (bps) & 250 & 250 & 350 & 352 & 350 & 305 & 325 & 300 & 275 & 275 & 300 & 558 & 663 & 590 & 542 & 576 & 484 & 501 & 491 & 481 \\
\hline $\begin{array}{l}\text { Observations } \\
\mathrm{N}\end{array}$ & 74 & 83 & 165 & 139 & 84 & 121 & 220 & 387 & 426 & 498 & 477 & 83 & 58 & 231 & 367 & 451 & 693 & 636 & 425 & 402 \\
\hline Has floor (pct pts) & 0 & 0 & 0 & 0 & 0 & 4 & 4 & 3 & 0 & 0 & 0 & 52 & 79 & 94 & 97 & 96 & 97 & 99 & 98 & 93 \\
\hline Has OID (pct pts) & 12 & 11 & 44 & 49 & 56 & 52 & 30 & 5 & 3 & 4 & 17 & 75 & 72 & 92 & 78 & 92 & 73 & 89 & 90 & 88 \\
\hline
\end{tabular}

As a measure of floor spread significance, I define the measure floorProportion as floor spread divided by the total spread, i.e. floor Proportion floor $_{i}=$ floread $_{i} \div\left(\right.$ floor $_{\text {Spread }}+$ oidSpread $_{i}+$ allInDrawn $_{i}$ ). Plotting the densities for this proportion (among institutional term loans that have all three pricing components), Figure 5.1 summarizes the relative importance of floor spreads in each of three periods: 2008-2010, 2011-2013, and 2014-2016. 
Consistent with Table 5.1, floor spreads have been a diminishing fraction of the total spread since 2008. However, there is considerably heterogeneity in this fraction across facilities. For many loans issued during the crisis, at least $20 \%$ of total interest and fees arose from floors. Even for those issued between 2011 and 2013, the majority of loans carried floors that were expected to account for over $10 \%$ of total interest. On average, floors accounted for roughly $16.5 \%$ of total interest during the crisis, $14.5 \%$ in the years immediately following the crisis and $8 \%$ most recently. Still, this dominates the relative importance of OIDs, which are at most a third the value of embedded floor options.

Figure 5.1: The importance of floor options relative to total compensation after 2007. Importance is measured according to floorProportion, the ratio of floor spread to total spread, where total spread is defined only for institutional term loans that include both a non-zero floor option and data on upfront fees. Estimates of the distribution of this proportion are listed below. Three time periods are examined: crisis, 2008 2010; immediate post-crisis, 2011-2013; and the most recent, 2014-2016. Despite continued high rates of incorporation in new issues, floor options have decreased in overall importance in the years following the credit crisis. Data are restricted to highly leveraged loans and so are taken solely from S\&P LCD.

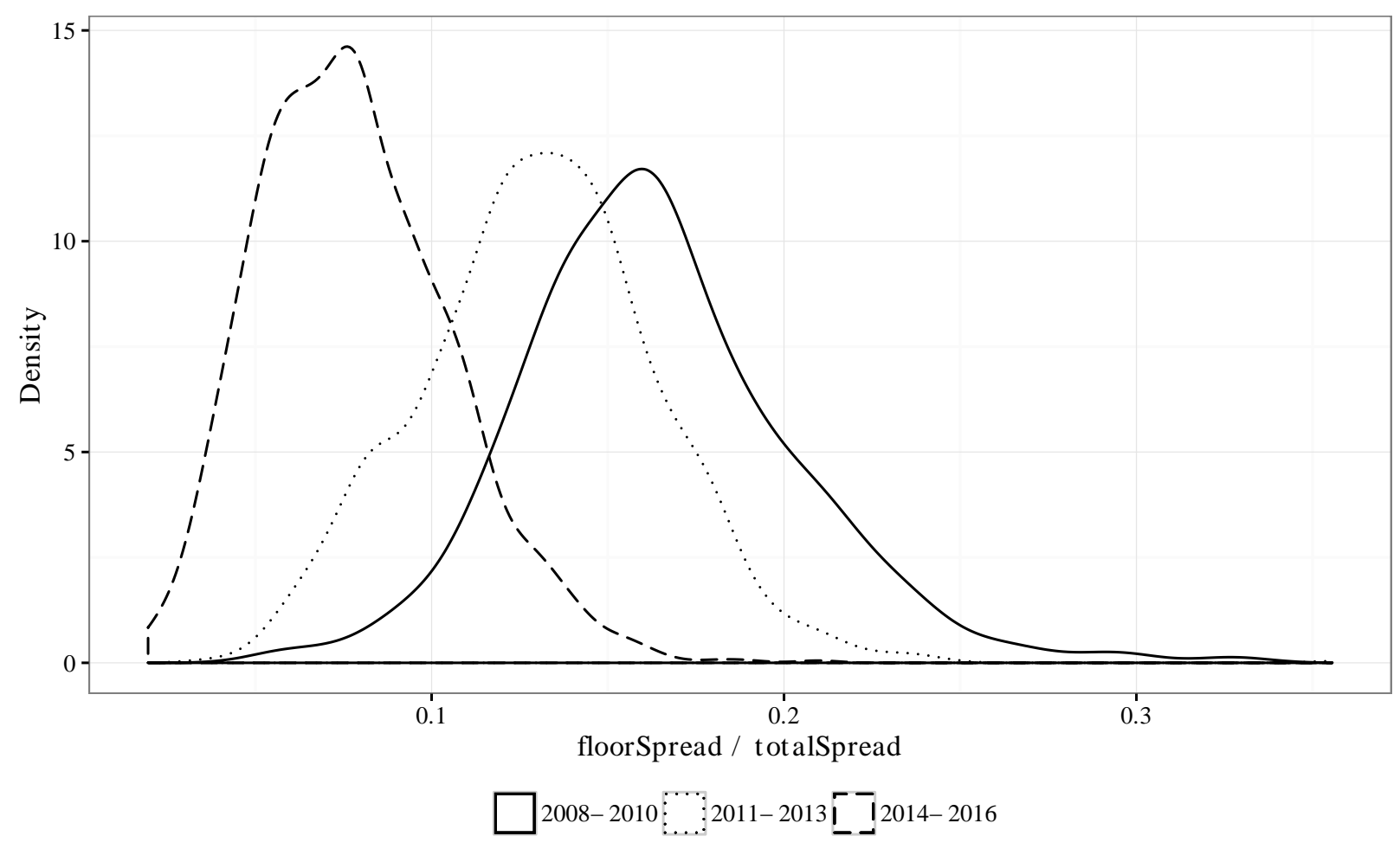

Changes in interest compensation since 2008 have not been limited to embedded floors 
and higher issue discounts. The median all-in-drawn spreads in Table 5.1 jump from a range of $250-350$ bps prior to 2008 to $400-500$ bps thereafter. Certainly, a spike in interest compensation could be expected on issues syndicated during the crisis as banks were curtailing lending to conserve capital [Ivashina and Scharfstein (2010)] and the absence of new CLOs left little demand from the institutional segment of the market. However, spreads have remained high in the years that have followed. This might indicate a fundamental shift in the composition of the median leveraged loan to a riskier contract, or that similar contracts were mispriced prior to 2008. LIBOR floors account for some of this increase, but fall short of explaining it on their own. Perhaps some can be explained by the more borrower-friendly cov-lite provisions that are commonplace today; although, these covenants were also popular in 2006 and 2007. It may be that, as Ivashina and Sun (2011) posit, cov-lite deals were simply mispriced prior to the crisis and that these pre-crisis observations, were they syndicated today, would command higher spreads. However, cov-lite also cannot fully explain the sharp increase in interest post-crisis. To illustrate the shift, Figure 5.2 depicts the interquartile ranges of total spread for leveraged first and second lien loans for years between 1997 and 2016. Not only has mean total compensation increased substantially since 2008 , the variance of that distribution has increased as well. The rise in spreads coincides with a reduction in LIBOR to historic lows, suggesting that spreads are set in conjunction with base rates to provide some lower bound to expected interest income. This is consistent with the hypothesis that fixed costs relative to LIBOR act as the primary motivation for higher interest income after 2008 . 
Figure 5.2: Total spreads over time. This plot displays the interquartile ranges (boxes) of total spreads for highly leveraged first and second lien term loans. Total spread is defined as the sum of All-in drawn, floor spread, and oid spread and assumes missing values are zero in order to capture a meaningful number of observations prior to 2008. Whiskers extend to the farthest outliers of at most 1.5 times the respective interquartile ranges. Medians are indicated as horizontal lines within boxes. Box width denotes sample size, with narrower boxes indicating smaller samples. Data are restricted to highly leveraged loans and so are taken solely from S\&P LCD.

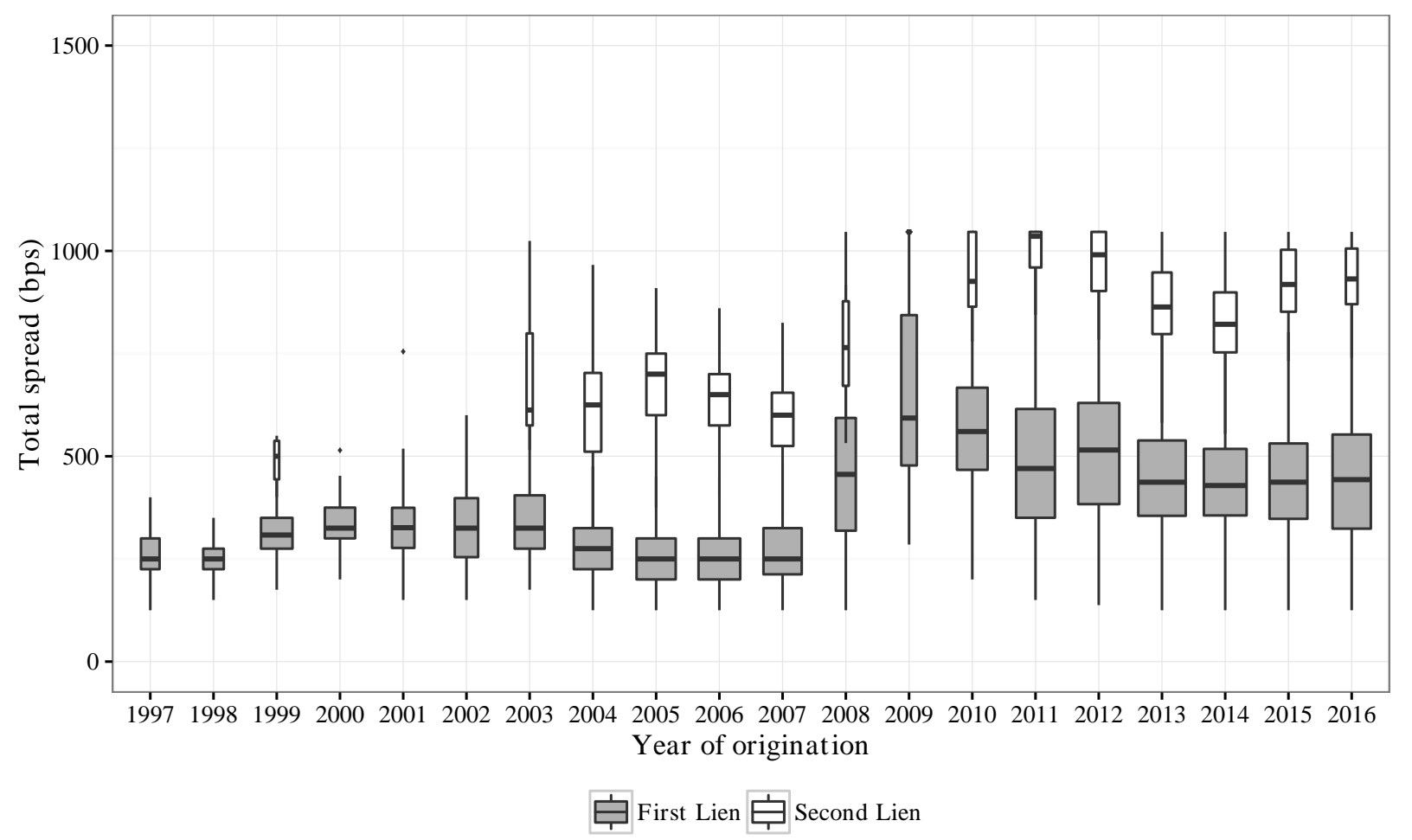

\subsection{Time series analysis}

Figures 5.3 and 5.4 depict quarterly observations of several time series. Of primary interest, floorProportion is the average proportion of expected interest spread arising from an institutional term loan's embedded floor option. This variable captures the relative importance of floors in total lender compensation over time. My hypotheses concerning motives for floor use suggest relations between floorProportion and lender costs, expected volume of loan trading and the costs of hedging, the degree to which the LIBOR is manipulated, the 
borrower's natural interest rate hedge, and the participation of non-traditional lenders.

I assess these relations in the time series by employing Yamamoto and Toda's (1995) procedure for estimating Granger causality (G-causality). This method involves estimating VAR models for floorProportion and another series of interest. Each model includes a constant and a trend parameter in addition to the lagged values of each series. The optimal number of lags, $m \leq 3$, for each model is determined according to information criteria (AIC). To this I add an additional $p$ lags to account for the maximum order of integration among the two series (e.g. if $\mathrm{I}($ floorProportion $)=1$ and $\mathrm{I}($ clo Volume $)=2$, then $p=2)$. I therefore estimate the following VAR model for $y=$ floor Proportion and several other time series variables, $x$ :

$$
\begin{aligned}
& y_{t}=\alpha_{0}+\alpha_{1} t+\sum_{i=1}^{m+p} \beta_{i} y_{t-i}+\sum_{i=1}^{m+p} \gamma_{i} x_{t-i}+\epsilon_{t} \\
& x_{t}=\delta_{0}+\delta_{1} t+\sum_{i=1}^{m+p} \eta_{i} x_{t-i}+\sum_{i=1}^{m+p} \theta_{i} y_{t-i}+\nu_{t} .
\end{aligned}
$$

Reported results are from models that pass tests for residual autocorrelation and stability. Wald tests are used to determine whether the first $m$ coefficients associated with the nonLHS variable are zero, i.e. whether $\gamma_{1}=\gamma_{2}=\cdots=\gamma_{m}=0$ and $\theta_{1}=\theta_{2}=\cdots=\theta_{m}=0$. Rejection of the null in either case indicates the presence of G-causality. This relation can run in either direction, or both and simply indicates a predictive relation between the two series, not a causal relation in the usual sense.

The second and third panels in Figure 5.3 depict the issuance of new CLOs and the aggregate total net assets of loan participation funds (by Lipper Objective Classification) in the CRSP universe, respectively. These not only indicate time-varying participation of the two primary (traditional) institutional lenders, but also by reflection, indicate the participation of non-traditional lenders. Of note, CLO issuance all but disappeared between 2008 and 
Figure 5.3: Quarterly observations of loan market institutional investor participation and costs. floorProportion is the proportion of total spread arising from the embedded floor option (i.e. floorSpread / (floorSpread + oidSpread + allInDrawnSpread)). cloVol is the volume of new CLO issuance, measured in billions of USD. fundAssets is the total net asset value of mutual funds classified as 'Loan Participation Funds' in the CRSP database, measured in billions of USD. fundExpRatio is the average fund expense ratio of mutual funds classified as 'Loan Participation Funds' in the CRSP database. bidAskSpread is the average difference between bid and ask prices on large institutional flow facilities (S\&P LCD) in the secondary market. lifeInsDuration measures the empirical duration of a market-cap-weighted average portfolio of insurance companies (SICs 6310 and 6311) listed in the CRSP-Compustat database. Duration is measured as the coefficient on monthly changes in USD 3-month LIBOR in a regression of trailing 12 months of insurance company portfolio monthly returns on corresponding monthly changes in LIBOR. earningsCorrel is the correlation between the previous 12 quarters of average USD 3-month LIBOR and aggregate US corporate profits [A053RC1Q027SBEA] according to US Bureau of Economic Analysis, accessed through FRED.

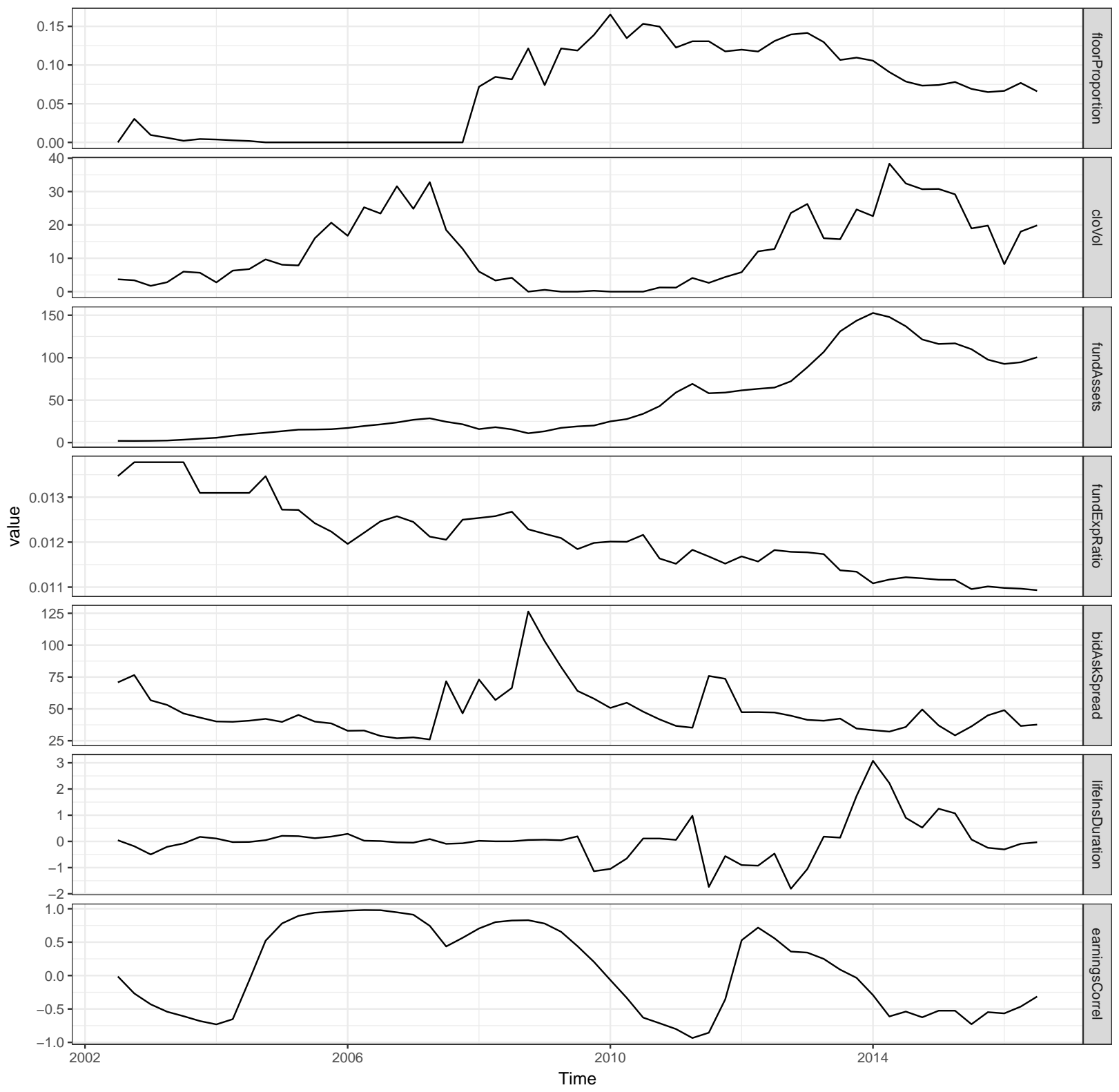


Figure 5.4: Quarterly observations of interest spreads and bank costs. floorProportion is the proportion of total spread arising from the embedded floor option (i.e. floorSpread / (floorSpread + oidSpread + allInDrawnSpread)). euroDolMargin is the average initial margin (bps) associated with eurodollar futures for members/hedge according to the CME Group. libor3m (bps) refers to the average USD 3-month LIBOR. liborMinusFixed (bps) and liborMinusVariable (bps) refer to average USD 3-month LIBOR minus median US bank holding company non-interest expense rate and USD 3-month LIBOR minus median US bank holding company interest expense rate, respectively. Bank costs (Chicago Fed Y9 report) are expressed as an annual interest rates, dividing each by total liabilities. liborMinusCP is average USD 3-month LIBOR minus the average rate on AA financial commercial paper reported by the NY Fed (H.15). yieldCurveSlope is the average difference (in bps) between the 5-year and 3-month US Treasury rates within each quarter.

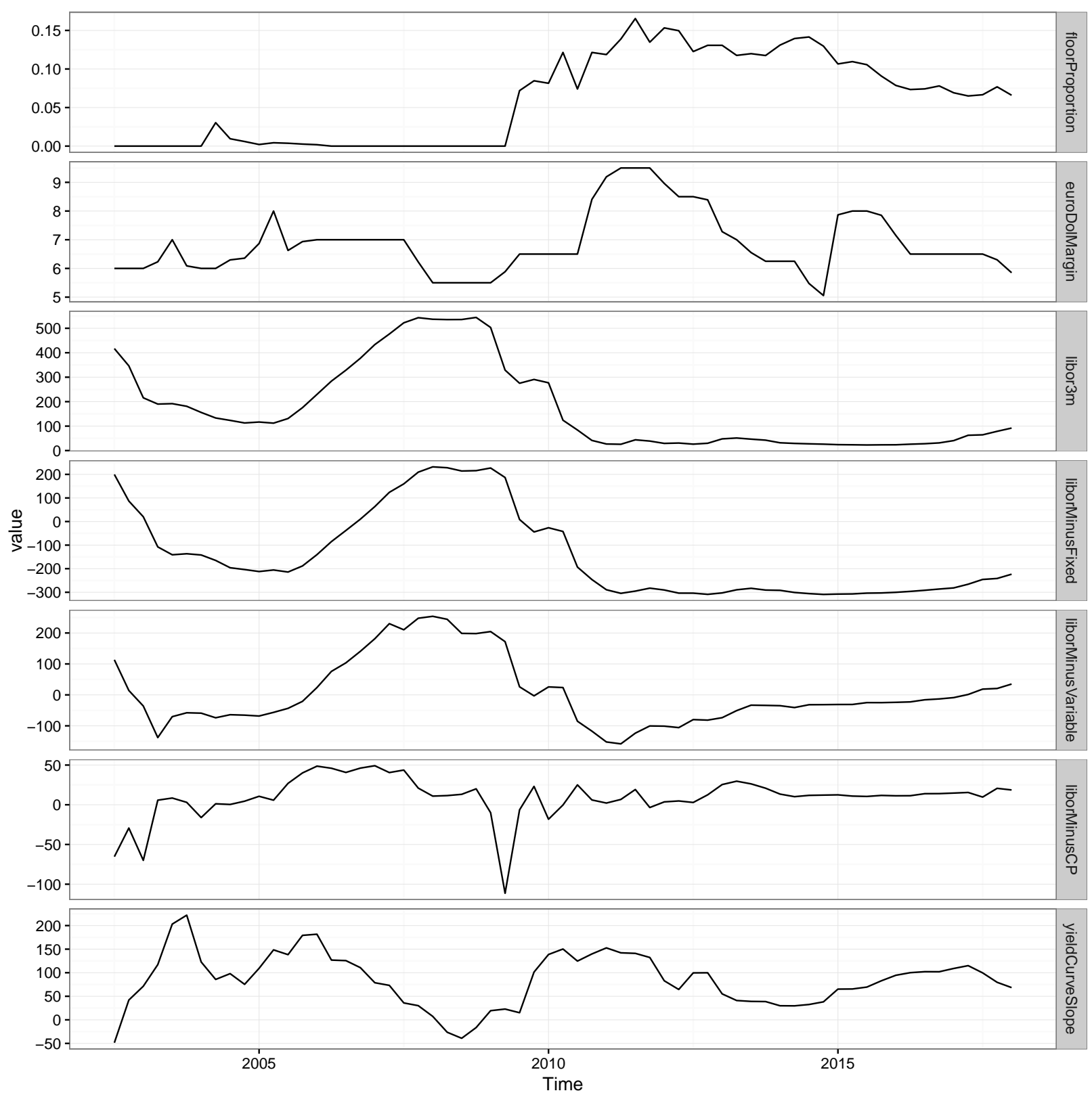


2012, during which floor use became commonplace. Similarly, although not as severely, loan participation funds shrank in total net assets during the onset of the crisis before experiencing growth in 2011 and beyond. Clearly, these mutual funds are a significant lender class in the loan market post-crisis. However, as seen in Table 5.2, there is no Granger causality between the net assets of loan participation funds and the significance of embedded floors. On the other hand, the volume of new CLOs G-causes floorProportion, but not vice versa. This relation suggests that the increase in floor usage relates to the rise of non-traditional lenders in the supply of capital to the loan market. This is at odds with the hypothesis that floor usage is driven by CLO arrangers' compensation incentives. Floors arose during a time in which CLOs were all but absent from the primary market.

The average expense ratio of loan participations funds is indicated in the third panel of Figure 5.3. There is a pronounced downward trend in this cost measure over time, likely due to scale economies in fund management. The trend runs counter to that in fund assets. In relation to floor significance, the fund expense ratio G-causes the average proportion of total spread arising from the floor (p-value .031) but not the other way around. This suggests that rather than floors resulting in the reduction in fund expenses (presumably through lower hedging costs), fund expense ratios lead floors.

Panel 4 in Figure 5.3 depicts the average bid-ask spread for large institutional flow loans tracked by S\&P in the secondary market. This is a proxy for liquidity in the leveraged loan market and therefore also a measure of the trading costs faced by lenders. Bid-ask spreads spiked during the crisis, increasing from 25-50 bps pre-crisis to as much as 125 bps in 2009 . These spreads appear to lead floors. As with fund expense ratios, the average bid-ask spread G-causes floors ( $p$ value .042) but not vice versa. Thus, measures of fund administrative and trading costs G-cause the proportion of interest arising from floors. Interpreting the bid-ask spread as a measure of liquidity, higher spreads coincide with periods in which there are fewer potential buyers in the market. Increases in spreads are consistent with the decline 
Table 5.2: Granger causality estimates of time series depicted in Figures 5.3 and 5.4. Two-way Granger causality estimates are of several time series with floorProportion, which measures the proportion of total spread arising from the embedded floor option (i.e. floorSpread / (floorSpread + oidSpread + allInDrawnSpread)). Tests are performed according to Yamamoto and Toda (1995). Directional Granger causality is assessed via Wald tests, with significant p values indicating the presence of G-causality. The number of lags refers to the number of lags in the VAR estimated in the process of assessing causality. The number of lags are determined by adding the maximum series order of integration to the optimal number of lags in the VAR evaluated using AIC. VARs are stable, with eigenvalues less than one. Residuals of each model are free of autocorrelation assessed using the Box-Ljung test. cloVol is the volume of new CLO issuance, measured in billions of USD. fundAssets is the total net asset value of mutual funds classified as 'Loan Participation Funds' in the CRSP database, measured in billions of USD. fundExpRatio is the average fund expense ratio of mutual funds classified as 'Loan Participation Funds' in the CRSP database. bidAskSpread is the average difference between bid and ask prices on large institutional flow facilities (S\&P LCD) in the secondary market. lifeInsDuration measures the empirical duration of a market-cap-weighted average portfolio of insurance companies (SICs 6310 and 6311) listed in the CRSP-Compustat database. Duration is measured as the coefficient on monthly changes in USD 3-month LIBOR in a regression of trailing 12 months of insurance company portfolio monthly returns on corresponding monthly changes in LIBOR. euroDolMargin is the average initial margin (bps) associated with eurodollar futures for members/hedge according to the CME Group. libor3m (bps) refers to the average USD 3-month LIBOR. liborMinusFixed (bps) and liborMinusVariable (bps) refer to average USD 3-month LIBOR minus median US bank holding company non-interest expense rate and USD 3-month LIBOR minus median US bank holding company interest expense rate, respectively. Bank costs (Chicago Fed Y9 report) are expressed as an annual interest rates, dividing each by total liabilities. liborMinusCP is average USD 3-month LIBOR minus the average rate on AA financial commercial paper reported by the NY Fed (H.15). yieldCurveSlope is the average difference (in bps) between the 5-year and 3 -month US Treasury rates within each quarter.

\begin{tabular}{|c|c|c|c|}
\hline Variable & Lags & $\begin{array}{r}\text { Variable Granger } \\
\text { causes floorProportion: } \\
\text { p value }\end{array}$ & $\begin{array}{r}\text { floorProportion Granger } \\
\text { causes Variable: } \\
\text { p value }\end{array}$ \\
\hline \multicolumn{2}{|c|}{ Institutional investor participation } & 0.039 & 0.153 \\
\hline fundAssets & 4 & 0.238 & 0.892 \\
\hline \multicolumn{4}{|c|}{ Trading and hedging costs } \\
\hline bidAskSpread & 3 & 0.042 & 0.686 \\
\hline orthogBidAskSpread & 2 & 0.002 & 0.700 \\
\hline euroDolMargin & 3 & 0.334 & 0.246 \\
\hline \multicolumn{4}{|c|}{ Interest rate hedging motives } \\
\hline lifeInsDuration & 5 & 0.970 & 0.435 \\
\hline EarningsCorrel & 4 & 0.760 & 0.871 \\
\hline \multicolumn{4}{|l|}{ Lender costs } \\
\hline fundExpRatio & 3 & 0.031 & 0.119 \\
\hline libor3m & 4 & 0.017 & 0.024 \\
\hline liborMinusFixed & 4 & 0.042 & 0.308 \\
\hline liborMinusInterest & 4 & 0.022 & 0.684 \\
\hline liborMinusCP & 2 & $<0.001$ & 0.421 \\
\hline yieldCurveSlope & 4 & 0.110 & 0.779 \\
\hline
\end{tabular}

in traditional lender participation (CLOs and mutual funds), which signal the likelihood that non-traditional lenders are somehow connected to the rise of LIBOR floors. In order 
to disentangle the liquidity effect from other factors, I estimate the following regression to orthogonalize the quarterly change in bid-ask spread from changes in CLO issuance and loan participation fund net assets.

$$
\Delta \text { BidAskSpread }_{t}=\alpha+\beta_{1} \Delta \text { FundAssets }_{t}+\beta_{2} \Delta \text { CloVol }_{t}+\text { orthogBidAskSpread }_{t}
$$

Estimates from this regression are listed in Table 5.3. Both measures of traditional lender participation bear significantly on changes in the bid-ask spread as expected. Positive changes in the participation of CLOs and loan funds lead to reductions in the bid-ask spread. Incorporating the series of residuals, orthogBidAskSpread, into my analysis of Granger causality, I find that orthogBidAskSpread G-causes floorProportion (p value 0.002). This relation runs only in this direction. Therefore, there is some factor(s) associated with the bid-ask spread, independent of traditional lender participation, that leads floors.

Table 5.3: OLS regression of first differences in the average quarterly bid-ask spread in the secondary market ( $\triangle$ BidAskSpread, (bps)) and those of loan participation funds' total net assets ( $\Delta$ FundAssets, (\$bil)) and CLO issuance ( $\Delta \mathrm{CloVol},(\$ b i l))$. Observations are quarterly between 1Q 2003 and 3Q 2016. Standard errors are listed in parenthesis below their respective coefficient estimates.

\begin{tabular}{lc}
\hline \hline & Dependent variable: \\
\cline { 2 - 2 }$\Delta$ FundAssets & $\Delta$ BidAskSpread \\
& $-1.917^{* * *}$ \\
$\Delta$ CloVol & $(0.468)$ \\
& $-0.745^{* *}$ \\
Constant & $(0.311)$ \\
& 0.152 \\
\hline Observations & $(2.691)$ \\
$\mathrm{R}^{2}$ & \\
Adjusted R ${ }^{2}$ & 55 \\
Residual Std. Error & 0.312 \\
F Statistic & 0.285 \\
\hline Note: & ${ }^{*} \mathrm{p}<0.1 ;{ }^{* *} \mathrm{p}<0.05 ;{ }^{* * *} \mathrm{p}<0.01$
\end{tabular}

Motives for interest rate hedging are varied and difficult to measure; however, I am able 
to measure the degree to which hedging motives vary in two specific cases: the degree to which US firms in aggregate possess natural interest rate hedges, and the sensitivity of life insurance companies to extremely low interest rates. The first of these relates to theories put forth by Agmon, Ofer, and Tamir (1981) and Santomaro (1983), which link the use of fixed rate debt to the degree to which a borrower's earnings form a natural interest rate hedge. In this case, floors should be preferred during times in which earnings are less positively correlated with LIBOR. Second, as Berends et al (2013) note, many life insurance companies issue annuities that guarantee minimum returns, which in turn lead these types of lenders to employ hedges against very low interest rates.

Due to the minimum returns in the products they offer, life insurance companies' equity values likely exhibit higher sensitivity to movements in interest rates during times when interest rates are extremely low. Panel 5 of Figure 5.3 shows this to be the case. This figure plots lifeInsDuration from the following regression:

$$
\text { lifeInsuranceReturn } n_{t}=\alpha+\text { lifeInsDuration } \Delta \text { libor } 3 M_{t}+\epsilon_{t},
$$

in which the previous 12 months of monthly life insurance company equity returns (on a value-weighted index consisting of all CRSP monthly observations with firm SICs 6310 and 6311) are regressed on the corresponding monthly changes in 3-month USD LIBOR. lifeInsDuration is therefore a measure of the sensitivity of aggregate life insurance company equity returns to changes in interest rates. This sensitivity was insignificantly different from zero between 2002 and 2009, but has since become more volatile. Interestingly, this sensitivity has not been exclusively positive post-2009, as one might expect given the these firms' inherent long positions in interest rates. This may reflect an increase in the size and/or number of hedging programs initiated by these firms in reaction to historically low interest rates. As life insurers are common participants in leveraged loans, embedded floors might 
well be an important part of those hedging programs. However, the data do not support this link. Table 5.2 shows no Granger causality between lifeInsDuration and floorProportion.

Panel 6 of Figure 5.3 depicts the correlation of 3-month USD LIBOR and aggregate US corporate profits over the previous 12 quarters. ${ }^{1}$ While theory suggests a link between this correlation measure and floor usage, given a floor's effect in fixing a loan's interest payments, there is no G-causality in either direction. The p values associated with the Wald tests listed in Table 5.2 for floorProportion and earnings correlation are both insignificant. Although future earnings correlation with LIBOR should matter in determining the choice of fixed (floor-adjusted) or floating rate debt, redefining lifeInsDuration using the next 12 quarters of earnings does not change the Granger-causality results.

Regardless of their motives in hedging against low interest rates, borrowers and lenders face costs in instituting those hedges. Among the options available, interest rate futures and swaps are obvious instruments through which hedges can be obtained. The costs incurred for taking these positions include fees charged by clearinghouses and commission merchants, bid-ask spreads, and initial margin/funding costs. Of these, initial margins are easiest to measure. Panel 2 of Figure 5.4 depicts the time series of the CME's initial margin requirement on Eurodollar futures for exchange members, euroDolMargin. These margins peaked during the crisis, reaching $\$ 950$ per $\$ 1$ million notional value in 2010 , but have otherwise averaged between $\$ 600$ to $\$ 700$. As these margins directly affect LIBOR hedging costs, higher margins may have spurred lenders to favor embedded floors over the alternative of securing swaps or futures from third parties. However, there is no Granger causality between Eurodollar margins and the proportion of interest arising from floors. Thus, higher hedging costs did not lead to an increase in embedded floors. In fact, from visual inspection of Figure 5.4, the increase in floor use appears to predate the increase in Eurodollar futures margins by about

\footnotetext{
${ }^{1}$ Corporate profits data are taken from the Bureau of Economic Analysis. The series omits inventory valuation and corporate consumption adjustments (FRED identifier: A053RC1Q027SBEA).
} 
a year.

Panel 3 in Figure 5.4 displays 3-month USD LIBOR. Clearly, the proportion of floor interest is inversely related to LIBOR. There is a common factor(s) linking LIBOR and floors, as evidence suggests libor3m G-causes floorProportion (p value 0.017) and vice versa ( $p$ value 0.024 ). Although, LIBOR alone offers little explanation for the emergence of floors; after all, lenders could alternatively negotiate larger all-in-drawn spreads to compensate for low base rates. This argument assumes that lenders were able to fund loans at LIBOR. It also ignores any fixed costs of lending that would lead lenders to prefer fixed interest payments when base rates are historically low. Testing whether violations of these assumptions provide explanations for the increase in embedded floors, I look at spreads between 3-month USD LIBOR and proxies of bank fixed costs, bank variable costs, and an alternative measure of short-term bank financing, rates on 90-day AA financial commercial paper.

The fourth panel of Figure 5.4 depicts the spread between 3-month USD LIBOR and median non-interest expense (liborMinusFixed), expressed as an equivalent annual interest rate, of US bank holding companies. Dreschsler, Savov, and Schnabl's (2017) theory that lenders with high fixed costs have incentive to convert some of their floating rate loans into fixed rate loans when interest rates drop, suggests that loans should incorporate embedded floors when the spread between LIBOR and fixed costs widens. Indeed, liborMinusFixed Gcauses floorProportion ( $\mathrm{p}$ value 0.042). This is consistent with lenders demanding embedded floors in response to lower interest rates relative to their fixed costs.

Similarly, the spread between 3-month USD LIBOR and the median interest expense of US bank holding companies, liborMinusInterest, Granger causes floorProportion (p value 0.022). Depicted in the fifth panel of Figure 5.4, liborMinusInterest shows the median bank's interest expense is somewhat slow to react to movements in LIBOR. This is likely due to long-maturity liabilities in the banks' sources of funding. Of note, the sudden drop in interest rates during the crisis left the median bank with an interest expense rate significantly higher 
than LIBOR. This gap gradually closed over time as banks rolled over existing liabilities, eventually closing by 2015. Forward looking banks may have viewed floors as a means of bridging that gap after a sudden, unexpected decline in interest rates.

There is some question as to the validity of LIBOR as an unbiased measure of funding costs, particularly during the crisis. With the benefit of hindsight, we know that some rate fixing banks mislead the British Bankers Association, in particular by reporting lower than actual borrowing rates. This particular downward bias in LIBOR reporting should be more likely during times of economic stress, as these are the times of greater liquidity concerns. If lenders believed LIBOR ceased to be a reliable benchmark of funding costs, floors may have been used as a means of removing fraudulent LIBOR from the interest calculation. One way to evaluate the validity of LIBOR is to compare it to an alternative funding source. Panel 6 of Figure 5.4 depicts the spread (liborMinusCP) between 3-month USD LIBOR and 90-day AA financial commercial paper rates. In many ways, this is an ideal comparison as both rates pertain to uncollateralized bank loans of roughly three months on a 360-day basis. Unsurprisingly given their similarity, the difference between these rates is typically close to zero. Noticeable deviations, however, occur during times of economic stress. During NBER recession quarters (2Q01:4Q01 and 1Q08:2Q09), liborMinusCP averaged -7 bps, versus and average of 12 bps in all other quarters. If the definition of recession is expanded to include the quarter immediately prior to the NBER indicator (1Q01 and 4Q07, in this case), liborMinus $C P$ averaged -22 bps during recessions and 16 bps otherwise. The slight positive spread outside of recessions likely reflects interbank credit risk and the slightly longer (0-2 days) tenor of LIBOR. The significant negative spread in the fourth quarter of 2007 is likely due to the sharp increase in asset-backed commercial paper rates bleeding into the broader financial sector [Kacperczyk and Schnabl (2010)]; however, this spread continued to be negative or near zero in several quarters thereafter, in addition to being negative during 2001 following the dot-com crash. As both time periods can be characterized as 
instances in which banks were more likely to under-report funding costs, it is conceivable that liborMinusCP, as a proxy for inaccurate LIBOR, should lead the use of embedded floors. Table 5.2 shows this to be the case, as liborMinusCP G-causes floorProportion (p value $<0.001)$

Lastly, there appears to be no Granger causality in either direction between the slope of the yield curve, approximated as the difference between 5-year and 3-month US Treasury rates, and the proportion of expected interest arising from embedded floors. This is somewhat surprising, as there is a mechanical relation between floor value and the slope of the yield curve (all else equal, steeper curves imply lower option values as rates are expected to rise above strike rates more quickly). There is weak evidence of this relation, as the p value associated with yieldCurveSlope G-causing floorProportion is nearly significant at the $10 \%$ level. The effect is muted because floorProportion measures the value of embedded floors relative to total interest in each quarter, not simply the option values themselves.

\subsection{On the probability of including a floor option in a leveraged loan}

I estimate the probability that loan $i$ incorporates a LIBOR floor via the following probit specification on the pooled LCD data:

$$
\begin{aligned}
\operatorname{Pr}\left(\text { hasFloor }_{i}=1\right)=\Phi( & \alpha \text { contract Attributes }_{i}+\beta \text { facilityType }_{i}+ \\
& \gamma \text { syndicate Attributes }_{i}+\delta \text { borrower Attributes }_{i}+ \\
& \left.\zeta \text { purposeIndustryEffect } s_{i}\right) .
\end{aligned}
$$

Table 5.4 lists the estimated coefficients of three specifications of Eq. (5.5). All control for 
fixed effects related to loan purpose. Industry effects are dropped in specifications (2) and (3) as they appear to offer little explanatory power. A critical omission from specifications (1) and (2) are temporal effects. This is to prevent quasi-complete separation arising from sharp and sustained increase in floor usage post-2008. To address this, I add year fixed effects to specification (3) and estimate the model using the penalized maximum likelihood estimator proposed by Heinze and Schemper (2002). Specifications (2) and (3) are more selective on borrower-specific attributes, as data on debt-EBITDA ratios, sales, returns on assets, and earnings correlation with interest rates reduce the sample size considerably.

The coefficient of primary interest is ebitdaCorrel, which measures the future correlation of the borrower's next 12 quarters of EBITDA with the three-month LIBOR. By design, I have endowed lenders and borrowers with perfect foresight regarding this correlation. Concerns arise because this measure uses future earnings; however, the presence of a floor is unlikely to significantly affect future EBITDA as the embedded floor does not qualify for hedge accounting and so does not enter EBITDA and interest expense is not included in this measure of earnings. Also, floors do not appear to affect firm investment that might otherwise alter future earnings. ${ }^{2}$ Use of past earnings to estimate this correlation is also problematic for two reasons: first, many leveraged loans are used to complete mergers and acquisitions, which significantly change the firm's make-up going forward; and second, theory implies future earnings are what matter. And, I argue managers and lenders possess some predictive ability regarding the covariance of interest rates and earnings.

The estimate for ebitdaCorrel is consistent with Agmon, Ofer, and Tamir (1981) and Santomaro (1983). Borrowers that possess higher earnings correlations (and therefore natural interest rate hedges) are more likely to contract on a purely floating rate loan. This result is robust to the inclusion of year fixed effects in specification (3), remaining significant at

\footnotetext{
${ }^{2}$ In unreported event studies (using loan issuance as the event date), firms that pay floor-adjusted interest on their loans show no significant difference from firms that pay purely floating rates in terms of asset growth or growth in net PPE.
} 
Table 5.4: Estimates of the probability that a floor is embedded in a leveraged loan. Specifications (1) and (2) are probit specifications with dependent variable hasFloor indicating whether a loan includes a floor option. Observations with missing OIDs are assumed to be issued at par. Omitted categories for facility type and S\&P rating are revolvers and unrated facilities, respectively. Data are LCD observations only. ebitdaCorrel captures the correlation between a borrower's 12 quarters of EBITDA following loan issuance and the corresponding quarterly series of three month USD LIBO rates. Other variable definitions are as indicated in Table A-1. Data are winsorized at $1 \%$ from each tail.

\begin{tabular}{|c|c|c|c|c|c|c|}
\hline & \multicolumn{6}{|c|}{ Dependent variable: hasFloor } \\
\hline & \multicolumn{4}{|c|}{ probit } & \multirow{2}{*}{\multicolumn{2}{|c|}{$\begin{array}{c}\text { probit } \\
\text { (bias reduction) } \\
\text { (3) }\end{array}$}} \\
\hline & \multicolumn{2}{|c|}{ (1) } & \multicolumn{2}{|c|}{$(2)$} & & \\
\hline & Estimate & Std. error & Estimate & Std. error & Estimate & Std. error \\
\hline constant & $-6.160 * * *$ & 0.247 & $7.767^{* * *}$ & 0.91 & $-5.521 * * *$ & 1.172 \\
\hline \multicolumn{7}{|l|}{ Contract characteristics } \\
\hline $\log$ (facilityAmount) (\$mil) & $0.145^{* * *}$ & 0.025 & 0.115 & 0.097 & $-0.242^{*}$ & 0.125 \\
\hline maturity (months) & -0.002 & 0.002 & 0.006 & 0.006 & $0.023^{* *}$ & 0.010 \\
\hline allInDrawn (bps) & $0.007 * * *$ & 0.0002 & $0.007 * * *$ & 0.001 & $0.003^{* * *}$ & 0.001 \\
\hline altOidSpread (bps) & $0.014^{* * *}$ & 0.002 & $0.027^{* * *}$ & 0.006 & $0.029^{* * *}$ & 0.009 \\
\hline slope (bps) & $0.002^{* * *}$ & 0.0003 & 0.0004 & 0.001 & 0.0001 & 0.002 \\
\hline covLite & $1.251^{* * *}$ & 0.067 & $1.228 * * *$ & 0.282 & 0.795 & 0.504 \\
\hline hasPpc & $-0.425^{* * *}$ & 0.063 & $-0.423^{* *}$ & 0.17 & -0.252 & 0.216 \\
\hline \multicolumn{7}{|l|}{ Facility type } \\
\hline term loan A & $-0.262 *$ & 0.137 & -0.492 & 0.485 & -0.362 & 0.406 \\
\hline term loans $\mathrm{B}, \mathrm{C}$, or $\mathrm{D}$ & $1.032^{* * *}$ & 0.061 & $1.042^{* * *}$ & 0.233 & $2.434^{* * *}$ & 0.307 \\
\hline secondLien & $-1.714^{* * *}$ & 0.252 & & & & \\
\hline \multicolumn{7}{|l|}{ Syndicate characteristics } \\
\hline hasBreakPrice & $0.703^{* * *}$ & 0.050 & $1.321^{* * *}$ & 0.205 & $0.509 * *$ & 0.243 \\
\hline leadReputation & $3.025^{* * *}$ & 0.200 & $5.260^{* * *}$ & 0.713 & 0.568 & 1.028 \\
\hline \multicolumn{7}{|l|}{ Borrower characteristics } \\
\hline spRatingBBB + to $\mathrm{BBB}-$ & 0.182 & 0.143 & $1.777^{* * *}$ & 0.512 & $0.972^{* *}$ & 0.455 \\
\hline spRatingBB + & $0.313^{* * *}$ & 0.107 & $1.758^{* * *}$ & 0.488 & 0.492 & 0.435 \\
\hline spRatingBB & $0.152^{*}$ & 0.091 & $1.618^{* * *}$ & 0.486 & $0.780^{*}$ & 0.420 \\
\hline spRatingBB- & $0.176^{* *}$ & 0.072 & $1.409 * * *$ & 0.457 & 0.462 & 0.375 \\
\hline spRatingB + & -0.022 & 0.065 & $1.145^{* *}$ & 0.461 & 0.584 & 0.399 \\
\hline spRatingB & 0.047 & 0.069 & $1.000^{*}$ & 0.513 & 0.052 & 0.580 \\
\hline spRatingB- & $-0.412^{* * *}$ & 0.131 & 0.539 & 0.652 & -0.487 & 0.884 \\
\hline spRatingCCC + and below & $-1.867 * * *$ & 0.294 & -0.328 & 0.880 & -0.963 & 1.155 \\
\hline sponsored & $0.272^{* * *}$ & 0.052 & 0.214 & 0.158 & -0.143 & 0.215 \\
\hline $\log ($ salesAtClose) (\$mil) & & & $-0.152^{* *}$ & 0.073 & -0.138 & 0.099 \\
\hline debtEbitda & & & $-0.043^{* *}$ & 0.018 & -0.008 & 0.021 \\
\hline & & & -1.299 & 0.799 & $-2.238^{* *}$ & 1.128 \\
\hline ebitdaCorrel & & & $-0.646^{* *}$ & 0.266 & $-0.883^{* *}$ & 0.368 \\
\hline Time effects & \multicolumn{2}{|c|}{ No } & \multicolumn{2}{|c|}{ No } & \multicolumn{2}{|c|}{ Yes } \\
\hline Industry effects & \multicolumn{2}{|c|}{ Yes } & \multicolumn{2}{|c|}{ No } & \multicolumn{2}{|c|}{ No } \\
\hline Loan purpose effects & \multicolumn{2}{|c|}{ Yes } & \multicolumn{2}{|c|}{ Yes } & \multicolumn{2}{|c|}{ Yes } \\
\hline Pseudo R2 & \multicolumn{2}{|c|}{0.623} & \multicolumn{2}{|c|}{0.639} & \multicolumn{2}{|c|}{0.857} \\
\hline Observations & \multicolumn{2}{|c|}{10,304} & \multicolumn{2}{|c|}{1,734} & \multicolumn{2}{|c|}{1,734} \\
\hline Akaike Inf. Crit. & \multicolumn{2}{|c|}{$4,819.537$} & & & & \\
\hline
\end{tabular}

Note:

${ }^{*} \mathrm{p}<0.1 ;{ }^{* *} \mathrm{p}<0.05 ;{ }^{* * *} \mathrm{p}<0.01$ 
the five percent level. Figure 5.5 plots the fitted probabilities of including a floor option as a function of the earnings correlation, holding other variables at their means. A rug plot is included to indicate the distribution of the data across ebitdaCorrel. The probability that loans included floors for borrowers at the $10^{\text {th }}$ percentile of earnings correlation $(-0.31)$ is estimated at $71 \%$ versus $64 \%$ for borrowers at the $90^{\text {th }}$ percentile $(0.42)$. The average partial effect of a unit change in ebitdaCorrel on the likelihood of embedding a floor is about 4.5\%, significant at the $5 \%$ level. However, this evidence must be considered in light of the range of correlations observed in the data. A unit change from -.5 to .5 spans the majority of observations. Therefore, while the point estimate is significant, the economic significance and marginal effect are less so.

Of the variables related to trading likelihood, most bear significantly on the inclusion of floor options as expected. Cov-lite loans and those that trade in the secondary market around the time of issuance are more likely to include floors. Although, significance varies depending on which specification is considered. And, while maturity and size are known to correlate with trading likelihood, these relations do not hold in relation to floors (signs reverse or are insignificant depending on specification). Institutional tranches are more likely to embed floors, evidenced by the coefficient estimate on term loans B through D relative to the omitted facility type, revolver. I rely on the dummy variable hasBreakPrice as a proxy for the ex ante belief that a loan will trade on the secondary market. Given the significantly positive coefficient estimateon hasBreakPrice in all three specifications, floors are more likely to be embedded in loans that are expected to trade. The probability that a loan is issued with an embedded floor option increases if the loan also includes bond-like covenants. This result is expected given cov-lite loans are preferred in cases for which coordination issues within the loan syndicate are high. Due to the positive relation between coordination issues and the change in syndicate participants introduced by frequent trading and its associated higher hedging costs, the positive coefficient on covLite further supports the hypothesis that 
Figure 5.5: Fitted values of the likelihood of embedding a floor in a leveraged loan according to the degree to which the borrower's EBITDA is correlated with LIBOR. Agmon, Ofer, and Tamir (1981) and Santomaro (1983) predict that higher correlations coincide with higher use of floating rate debt. Floor options change floating rate contracts to fixed rate while LIBOR remains below the strike rate; therefore, lower correlation should coincide with a higher probability that a loan is issued with a floor. Point estimates from model specification (2) along with the corresponding 95 percent confidence intervals are depicted, along with a rug plot indicating the range of the underlying data. Data are restricted to highly leveraged loans and so are taken solely from S\&P LCD.

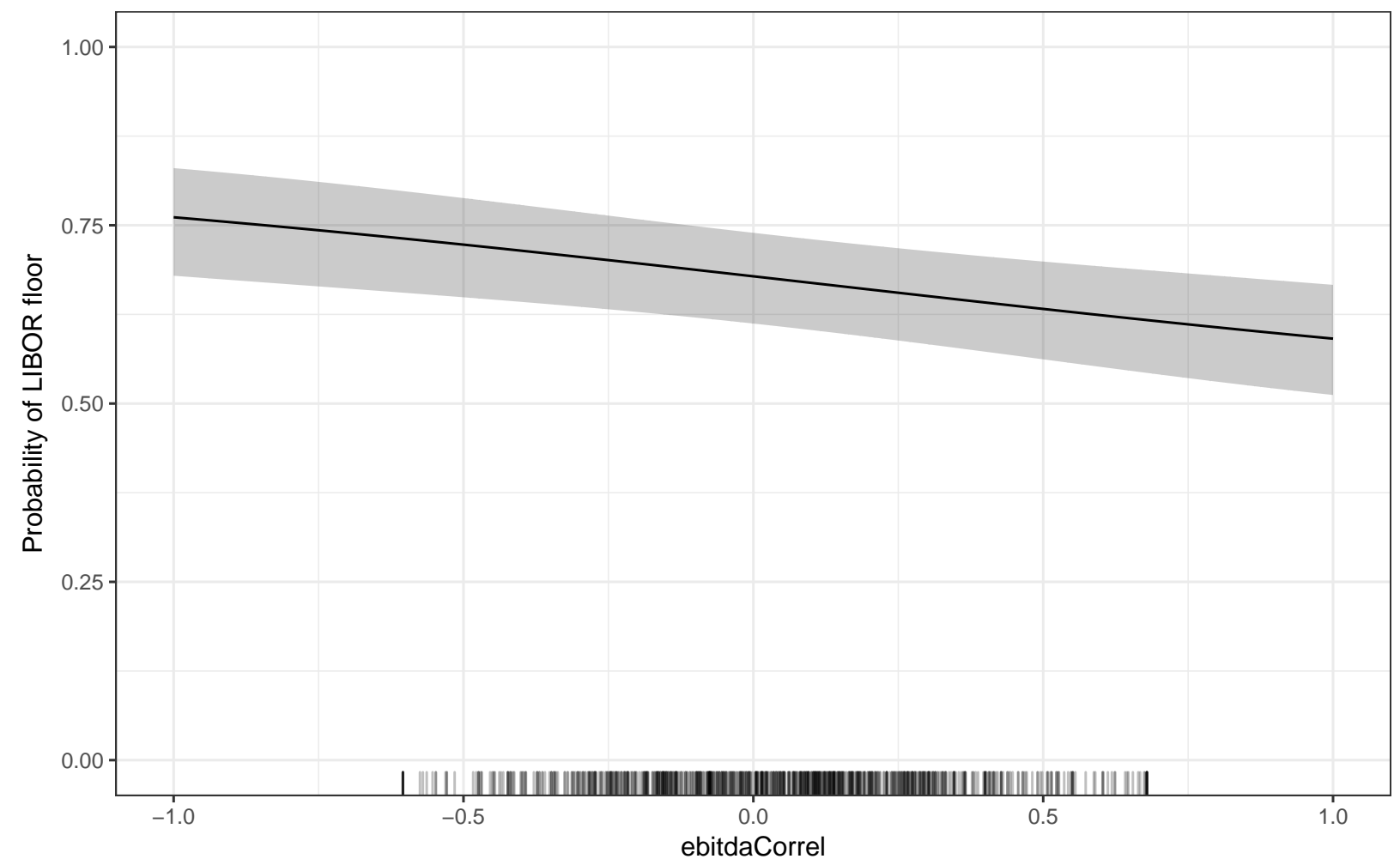

floors are embedded as a result of higher expected trading activity in the secondary market.

Higher credit ratings translate to higher floor usage. The omitted category pertains to loans that have no rating, so relative to those facilities, loans rated higher than $\mathrm{B}+$ tend to have significantly higher likelihood of embedding a floor. The coefficient estimates on second lien loans are also negative, suggesting credit risk plays an important role in the determination of which loans get LIBOR floors. Indeed, higher debt-EBITDA ratios are negatively correlated with embedded floors as well.

The reputation of the syndicate, as proxied by the largest number of deals over the pre- 
vious three years between the lead arranger and any participant, also bears positively on the probability of including a floor. This effect is independent of those of interest and oid spreads, which is interesting in light of Ivashina's (2009) evidence that syndicate reputation correlates with lower all-in drawn spreads. Higher reputation should alleviate adverse selection issues and result in lower overall loan pricing; however, here, higher reputation correlates with increased floor usage, raising the projected interest on the loan.

Concerning loan pricing variables, coefficient estimates on the OID spread and all-indrawn spread are both positive and significant, suggesting these two components are complimentary to LIBOR floors in determining market clearing yields. The positive correlation between OIDs and floors is expected given their opposing effects on sensitivity to interest rates and likelihood of loan cancellation; however, the link between all-in-drawn spreads and floors is less clear. The positive correlation between the two is independent of the borrower's creditworthiness, which is controlled for by credit ratings and, in the case of specifications (2) and (3), borrower profitability and leverage.

The slope of the yield curve appears to have little effect on the likelihood that a floor is embedded in a loan. The coefficient estimate associated with slope, defined as the difference between the US Treasury rate associated with the loan's maturity and with the 3-month rate as of the origination date, is significant in specification (1) but not in specifications (2) and (3). Further, the average partial effect of a $87 \mathrm{bps}$ increase in slope (coincides with a move from the first quartile to the fourth) corresponds to a 2.33 percentage point increase in the likelihood of including a floor according to specification (1). Thus, the slope of the yield curve has little, if any, economic effect on the likelihood of including a floor. This result is interesting in light of the choice lenders and borrowers face in determining loan pricing: namely, if yield curves are flat, a fixed rate loan and a variable rate loan, subject to an in-the-money floor option, are more or less indistinguishable save for a negligible option premium. Further, the slope of the yield curve directly affects the value of the embedded 
floor and alters the weightings necessary for calculating the floor- and oid-spreads, which conceivably alter the attractiveness of floors to certain lenders (asset managers, for example, may prefer the front-loaded cash flow schedule associated with floors in upward-sloping yield curve environments).

\subsection{On the effect of floors on loan extensions}

When borrowers return to the loan market to extend the maturity of their loans, lenders have the option of participating in the extension or walking away. This provides an interesting setting to assess the source of demand for floor options. A large number of the amendments in my sample occurred between 2009 and 2010, a time when borrowers were drawing down additional funds under credit facilities [Ivashina and Scharfstein (2010)]. It is unlikely that borrowers were simultaneously seeking loan extensions and principal reductions during this time. Therefore, if adding a LIBOR floor results in larger principal extensions, the demand for floors is likely to originate from the supply of credit. To test this, I regress the proportion of extended principal to preexisting principal, which I call extendedRatio, on whether the amendment also adds a LIBOR floor. To control for selection effects, I employ Heckman's two-step procedure as follows:

First stage:

$$
\begin{gathered}
\operatorname{Pr}\left(\text { hasExtension }_{i}=1\right)=\Phi\left(\delta_{0}+\delta_{1} \text { covenantRelie }_{i}+\delta_{2} \text { spreadChange }_{i}+\right. \\
\left.\delta_{3} \text { addFloor }_{i}+\gamma^{\prime} \text { year }_{\mathbf{i}}\right)
\end{gathered}
$$

Second stage:

$$
\begin{aligned}
\text { extendedRatio }_{i}= & \beta_{0}+\beta_{1} \text { covenantRelie }_{i}+\beta_{2} \text { spreadChange }_{i}+ \\
& \beta_{3} \text { addFloor }_{i}+\beta_{4} \text { imr }_{i}+\gamma^{\prime} \text { year }_{\mathbf{i}}+\epsilon_{i}
\end{aligned}
$$


I estimate Eqs. (5.6) and (5.7) for institutional and pro rata tranches separately and report results in Table 5.5. The coefficient estimate on addFloor in specification (2) indicates that institutional tranches were extended with significantly more principal when floors were included. To put this estimate in perspective, the unconditional average extendedRatio for these loans is $62 \%$. Where floors were included, the extension ratio increased by about 34 percentage points. As seen in specification (3), OLS estimates that ignore the selection effect suggest a lower - but still significant - effect from adding floors (an increase of 20 percentage points). The estimate on the inverse mills ratio $(i m r)$ coefficient suggests that there is a strong selection effect in the institutional sample. Interestingly, while the change in all-indrawn spread, spreadChange, does factor significantly in the likelihood that an amendment extends a loan, it has no effect whatsoever on the amount which is extended.

The same is not true of pro rata tranches, as seen in specifications (4), (5), and (6). While the OLS specification does attribute a significantly positive effect from floors, raising the extended ratio by close to eight percentage points, the effect from floors vanishes after controlling for selection. Although, in this case, the inverse mills ratio is only significant at the $10 \%$ level, so one could make the case that the OLS estimates are valid. Regardless, there is clearly a difference between the quantities of loans that were extended in institutional and pro rata tranches. Adding a floor to a loan allowed borrowers to entice significantly more principal for their loan extensions from institutional investors. This suggests that demand for floors was primarily driven by lenders, particularly those in institutional tranches.

The effect of floors on loan extensions appears concentrated in observations during the crisis. Tables A-8 and A-9 in the appendix display results from reestimating the analysis separately for loans issued between 2009 and 2010 and those issued thereafter. Of note, the positive coefficient on addFloor is only significant during the crisis. 
Table 5.5: Estimates of the percentage of loans extended when LIBOR floors are added to existing loan pricing. Models are estimated on the samples of loan amendments that result in extensions to pro rata facilities and institutional facilities separately. Columns 1, 2, 4, and 5 are stages one, two, one, and two from Heckman's selection procedure, with stage 1 probits estimating the likelihood that an amendment includes an extension. The dependent variable in the OLS specifications, extendedRatio equals the proportion of extended loans as a result of the amendment, i.e. $\$$ new loans / \$ preexisting loans. Explanatory variables are as follows: covenantRelief takes a value of one for amendments that alter the covenant structure or cure a covenant violation on the existing loan, and zero otherwise; addFloor takes a value of one in cases for which a LIBOR floor is added to the loan pricing terms as a result of the amendment, and zero otherwise; spreadChange denotes the change (in bps) to the loan's all-in-drawn spread as a result of the amendment; and, imr is the Inverse Mills Ratio from the first stage of Heckman's two-step procedure. Extensions data span the years 2009 through 2016. OLS standard errors (columns 3 and 6) are clustered by year of amendment. Standard errors associated with the second stage estimates (columns 2 and 5) are corrected for estimation error in the first stage.

\begin{tabular}{|c|c|c|c|c|c|c|}
\hline & \multicolumn{3}{|c|}{ Institutional extensions } & \multicolumn{3}{|c|}{ Pro rata extensions } \\
\hline & \multirow{2}{*}{$\begin{array}{c}\text { hasExtension } \\
\text { probit } \\
(1)\end{array}$} & \multicolumn{2}{|c|}{$\begin{array}{c}\text { extendedRatio } \\
O L S\end{array}$} & \multirow{2}{*}{$\begin{array}{c}\text { hasExtension } \\
\text { probit } \\
(4)\end{array}$} & \multicolumn{2}{|c|}{$\begin{array}{c}\text { extendedRatio } \\
O L S\end{array}$} \\
\hline & & $(2)$ & (3) & & $(5)$ & (6) \\
\hline constant & $\begin{array}{c}-0.636^{* *} \\
(0.196)\end{array}$ & $\begin{array}{l}-0.126 \\
(0.270)\end{array}$ & $\begin{array}{c}0.645^{* * *} \\
(0.062)\end{array}$ & $\begin{array}{c}-0.648^{* * *} \\
(0.193)\end{array}$ & $\begin{array}{l}-1.693 \\
(1.242)\end{array}$ & $\begin{array}{c}0.697^{* * *} \\
(0.030)\end{array}$ \\
\hline covenantRelief & $\begin{array}{c}-1.660^{* * *} \\
(0.141)\end{array}$ & $\begin{array}{c}-0.753^{* *} \\
(0.234)\end{array}$ & $\begin{array}{l}-0.057 \\
(0.056)\end{array}$ & $\begin{array}{c}-0.592^{* * *} \\
(0.137)\end{array}$ & $\begin{array}{l}-0.863 \\
(0.682)\end{array}$ & $\begin{array}{l}-0.003 \\
(0.038)\end{array}$ \\
\hline addFloor & $\begin{array}{c}0.330 \\
(0.205)\end{array}$ & $\begin{array}{l}0.337^{* *} \\
(0.107)\end{array}$ & $\begin{array}{c}0.200^{* * *} \\
(0.067)\end{array}$ & $\begin{array}{l}-0.271 \\
(0.232)\end{array}$ & $\begin{array}{l}-0.253 \\
(0.400)\end{array}$ & $\begin{array}{c}0.078^{* * *} \\
(0.029)\end{array}$ \\
\hline spreadChange & $\begin{array}{c}0.002^{* * *} \\
(0.001)\end{array}$ & $\begin{array}{c}0.001 \\
(0.0005)\end{array}$ & $\begin{array}{l}-0.001 \\
(0.001)\end{array}$ & $\begin{array}{l}-0.002 \\
(0.001)\end{array}$ & $\begin{array}{l}-0.002 \\
(0.002)\end{array}$ & $\begin{array}{l}-0.001 \\
(0.001)\end{array}$ \\
\hline $\mathrm{imr}$ & & $\begin{array}{c}0.629^{* * *} \\
(0.168)\end{array}$ & & & $\begin{array}{l}1.893^{*} \\
(1.031)\end{array}$ & \\
\hline Year effects & Yes & Yes & Yes & Yes & Yes & Yes \\
\hline Observations & 603 & 153 & 153 & 580 & 91 & 91 \\
\hline Adjusted $\mathrm{R}^{2}$ & & 0.164 & 0.149 & & 0.163 & 0.157 \\
\hline Log Likelihood & -235.378 & & & -304.583 & & \\
\hline Akaike Inf. Crit. & 500.756 & & & 639.165 & & \\
\hline Residual Std. Error & & 0.229 & 0.231 & & 0.174 & 0.175 \\
\hline F Statistic & & $3.675^{* * *}$ & $3.663^{* * *}$ & & $2.574^{* * *}$ & $2.672^{* * *}$ \\
\hline
\end{tabular}

\subsection{Analysis of syndicate composition in relation to floors}

I examine the composition of the lending syndicate between those facilities that have floors and those that do not. Given the evidence that floors appear to be concentrated in institutional facilities, an examination of those tranches would be ideal. However, due to the issues surrounding primary assignments, the lender shares data in Dealscan is an unreliable 
source. I therefore confine my study of lenders to revolving credit facilities issued on or after 2008. Lenders which are most likely to enter deals via assignment instead of signing a credit agreement are the least likely to participate in these facilities.

To construct a sample for comparison, I use propensity score matching to select nonfloor facilities to complement each floor-adjusted revolver in the LCD sample. Matches are determined by a nearest neighbor matching process in which the propensity score is calculated (using a logit) as the likelihood of including a floor given facility amount and allin-drawn spread. Comparisons of means of several syndicate-related variables across these two samples are listed in Table 5.6. Panel A lists these comparisons for all floors, regardless of value, while Panel B restricts the analysis to the subsample of revolvers that contain floor spreads of at least 50 bps.

Variables of interest are dummies indicating participation of a particular types of lenders and the proportion of the syndicate that submit rates for the calculation of LIBOR.

Conclusions drawn from both panels are similar. The proportion of LIBOR contributing banks is 5.8 percentage points higher in facilities that do not have floors. Viewed through the lens of a moral hazard framework, this is consistent with banks signaling a lower likelihood of future downward bias in LIBOR when they themselves would share in the costs associated with such manipulation. Although, this difference falls to about 3.6 percentage points if the definition of a floor-adjusted facility is one with a floorSpread of at least 50bps and fails to be significant at even the $10 \%$ level.

Table 5.6 reveals that asset managers are present in over twice as many floor-adjusted facilities than those with purely floating rates. Similarly, finance companies also exhibit an affinity for floors. They are present in almost half of floor facilities but only a third of non-floor facilities. This is consistent with earlier results that floors tend to be concentrated in institutional tranches. Asset managers conceivably prefer floor-adjusted interest income not only due to concerns regarding LIBOR manipulation but also because of compensation 
Table 5.6: Differences in means of lending syndicate variables among revolving credit facilities with and without embedded floors. Each observation (facility) that contains a floor is matched with a non-floor facility based on propensity scores. Scores are calculated by minimizing distances between observations along allInDrawn spread, and facilityAmount. The window of analysis was restricted to loans issued on or after 2008. A total of 338 observations are found to contain embedded floors, yielding a total sample of 676 facilities (Panel A). Panel B presents a similar analysis, restricting the hasFloor treatment to those loans with significant floor spreads, i.e. those greater than 50 bps. A total of 610 facilities (305 with significant floors, and 305 without) are used in Panel B. liborContributors denotes the percentage of syndicate lenders that are LIBOR submitting banks. nLenders is the number of lenders in the syndicate at issuance. Other variable definitions are listed in Tables A-1 and 4.2. Lender dummy variables for which participation amounted to less than $5 \%$ of the sample were dropped. $\mathrm{p}$ values pertain to two-sided, paired t tests for continuous variables and Pearson's Chi square proportion tests for dummy variables.

\begin{tabular}{lrrrr}
\hline \hline \multicolumn{1}{c}{ Panel A: all floors } & & & & \\
& & & & \\
& hasFloor $=1$ & hasFloor $=0$ & floor - no floor & p value \\
\hline facilityAmount (\$mil) & 58.920 & 62.993 & -4.073 & 0.681 \\
allInDrawn (bps) & 482.027 & 481.901 & 0.126 & 0.989 \\
maturity (months) & 58.454 & 56.836 & 1.618 & 0.024 \\
nLenders & 4.530 & 4.435 & 0.095 & 0.684 \\
liborContributors & 0.310 & 0.368 & -0.058 & 0.012 \\
cloManager & 0.118 & 0.065 & 0.053 & 0.016 \\
govtSupported & 0.018 & 0.041 & -0.024 & 0.069 \\
iBank & 0.805 & 0.814 & -0.009 & 0.769 \\
commercialBank & 0.822 & 0.828 & -0.006 & 0.839 \\
financeCompany & 0.476 & 0.334 & 0.142 & $<0.001$ \\
\hline
\end{tabular}

\begin{tabular}{lrrrr}
\hline \hline \multicolumn{1}{c}{ Panel B: significant floors (floorSpread $>\mathbf{5 0}$ bps) } & & & & \\
& hasFloor $=1$ & hasFloor $=0$ & floor - no floor & p value \\
\hline facilityAmount (\$mil) & 51.393 & 54.455 & -3.061 & 0.751 \\
allInDrawn (bps) & 487.705 & 489.262 & -1.557 & 0.863 \\
maturity (months) & 58.402 & 56.868 & 1.534 & 0.032 \\
nLenders & 4.387 & 4.082 & 0.305 & 0.124 \\
liborContributors & 0.315 & 0.352 & -0.036 & 0.141 \\
cloManager & 0.128 & 0.052 & 0.075 & 0.001 \\
govtSupported & 0.016 & 0.036 & -0.020 & 0.128 \\
iBank & 0.790 & 0.820 & -0.030 & 0.358 \\
commercialBank & 0.813 & 0.807 & 0.007 & 0.837 \\
financeCompany & 0.498 & 0.321 & 0.177 & $<0.001$ \\
\hline
\end{tabular}

issues surrounding target rates of return. Although finance companies almost certainly do not share that motive. Perhaps a better explanation for why these two investor types would prefer floors is due to their reliance on cash flow from assets to meet fixed costs and supply future investment. And unlike banks, institutional investors may themselves rely on funding through revolving credit facilities that contain floors. Additionally, finance companies face 
funding costs tied to commercial paper rates, which became expensive relative to LIBOR during the crisis [see Figure 5.4]. The rise of commercial paper rates relative to LIBOR during that time, whether due to LIBOR manipulation or otherwise, conceivably led finance companies to invest in floor-adjusted loans. The desire to convert floating rate assets into fixed rate assets during periods of low interest rates is likely just as high for institutional lenders as they are for banks. In particular asset managers must balance investment objectives against the need to satisfy redemptions. In this respect, floors may have allowed funds to satisfy investor withdrawals without resorting to asset sales, which can lead to fire sales in times of stress.

\subsection{Analysis of bank attributes in relation to floors}

To evaluate the hypothesis that lenders demand floors as a means of covering fixed costs when interest rates are low, I merge bank holding company data with lender share data from Dealscan and loan records from LCD. Focusing again on revolvers issued on or after 2008, I match each floor facility with a non-floor facility via propensity score matching. Matching criteria are again facility amount and the all-in-drawn spread.

I define the variable liborMinusFixed as the difference between three-month USD LIBOR, lagged three months prior to loan issuance, and a bank's noninterest expense expressed as an annual interest rate. As this is a bank-specific, it is a different definition than that used in the time series analysis, which relied on the median bank's non-interest expense.

The comparison of bank-specific variables among floor and non-floor facilities is displayed in Table 5.7. Panel A lists these comparisons for all floors, regardless of value, while Panel B restricts the analysis to the subsample of revolvers that contain floor spreads of at least 50 bps. I find evidence in support of Dreschsler, Savov, and Schnabl's (2017) theory that banks

prefer more fixed assets during times of low interest rates. Specifically, lenders in floor- 
adjusted revolvers not only have larger noninterest expenses (fixed costs) but also higher interest expenses as well. On average, banks in floor facilities have noninterest expenses that are $10 \mathrm{bps}$ higher than those of non-floor facilities. The difference is more pronounced in facilities with floor spreads of at lest 50 bps; in those cases, the average bank's interest and noninterest expenses are over 13 and 20 bps higher, respectively. Banks that participate in floor-adjusted facilities are also much smaller. The average bank in floor-adjusted loan syndicates has $\$ 100$ million fewer assets than those in non-floor facilities.

While the positive correlation between higher fixed costs and floor usage is consistent with Dreschsler, Savov, and Schnabl (2017), their model predicts that these banks should have greater pricing power over deposit rates. That they also have higher interest expenses is therefore surprising. Perhaps most significant, the spread between lagged LIBOR and noninterest expense is between 29 and 37 bps wider for banks in floor-adjusted facilities. This suggests that banks are more likely to lend at floor-adjusted rates when the floating rate on their assets is particularly low relative to their fixed costs. 
Table 5.7: Differences in means of bank holding company variables (BHC data supplied by the Chicago Federal Reserve's call reports archive) among revolving credit facilities with and without embedded floors. Each observation (facility) that contains a floor is matched with a non-floor facility based on propensity scores. Scores are calculated by minimizing distances between observations along allInDrawn spread and facilityAmount. The window of analysis was restricted to loans issued on or after 2008. For inclusion, a facility must have at least one lender that can be matched to the BHC data. A total of 290 observations are found to contain embedded floors, yielding a total sample of 580 facilities (Panel A). Panel B presents a similar analysis, restricting the hasFloor treatment to those loans with significant floor spreads, i.e. those greater than 50 bps. A total of 522 facilities (261 with significant floors, and 261 without) are used in Panel B. BHC data are are at quarterly frequency. interestExpense and noninterestExpense denote a bank's interest and noninterest expense annualized and scaled by total liabilities, respectively. deposits and cÉfiLoans are a bank's quarterly average deposits and commercial \& industrial loan balance scaled by assets. Other variable definitions are listed in Table A-1. p values pertain to two-sided, paired t tests.

\begin{tabular}{|c|c|c|c|c|}
\hline \multicolumn{5}{|l|}{ Panel A: all floors } \\
\hline & hasFloor $=1$ & hasFloor $=0$ & floor - no floor & $\mathrm{p}$ value \\
\hline facilityAmount (\$mil) & 65.285 & 68.866 & -3.582 & 0.753 \\
\hline allInDrawn (bps) & 473.448 & 474.052 & -0.603 & 0.947 \\
\hline maturity (months) & 58.181 & 56.641 & 1.541 & 0.054 \\
\hline interestExpense (bps) & 104.501 & 97.930 & 6.571 & 0.124 \\
\hline noninterestExpense (bps) & 373.675 & 363.594 & 10.080 & 0.058 \\
\hline bankAssets (\$mil) & 691.109 & 810.292 & -119.183 & 0.007 \\
\hline deposits (\% of assets) & 0.357 & 0.344 & 0.013 & 0.217 \\
\hline c\&iLoans ( $\%$ of assets) & 0.115 & 0.111 & 0.003 & 0.421 \\
\hline libor-noninterestSpread (bps) & -337.846 & -308.342 & -29.504 & $<0.001$ \\
\hline
\end{tabular}

\begin{tabular}{lrrrr}
\hline \hline \multicolumn{1}{c}{ Panel B: significant floors (floorSpread $>\mathbf{5 0}$ bps) } & & & & \\
& hasFloor $=1$ & hasFloor $=0$ & floor - no floor & p value \\
\hline facilityAmount (\$mil) & 56.197 & 58.723 & -2.526 & 0.815 \\
allinDrawn (bps) & 479.981 & 480.843 & -0.862 & 0.926 \\
maturity (months) & 58.205 & 57.144 & 1.061 & 0.132 \\
interestExpense (bps) & 108.511 & 95.426 & 13.085 & 0.005 \\
noninterestExpense (bps) & 377.297 & 356.744 & 20.553 & $<0.001$ \\
bankAssets (\$mil) & 691.659 & 803.353 & -111.694 & 0.019 \\
deposits (\% of assets) & 0.357 & 0.338 & 0.019 & 0.106 \\
c\&iLoans (\% of assets) & 0.114 & 0.11 & 0.004 & 0.339 \\
libor-noninterestSpread (bps) & -341.577 & -304.016 & -37.561 & $<0.001$ \\
\hline
\end{tabular}

\subsection{Estimating the probability of embedding floors ab- sent borrower-specific and temporal effects}

Offering further insight into the probability of embedding a floor given contract characteristics, Table 5.8 displays the results of a probit specification similar to Eq. (5.5). Unlike the estimates in Table 5.4, these are estimated on the sample of facilities for which a floor 
facility can be matched to a non-floor facility within the same loan package (same borrower at the same time). Column (1) presents the estimates from a regression on the full matched sample; while column (2) is estimated on the subset of matches that are exclusively term loans. The latter is far smaller than the full sample as the majority of non-floor facilities are revolvers. Borrower- and time-related controls are omitted from these specifications as they are perfectly balanced due to construction of the sample. This approach allows for a more focused analysis on the relation between floors and other contract terms.

Data on whether a loan breaks for trading are too limited to be included in the matched analysis. However, other factors known to correlate with ex ante secondary trading activity, such as maturity and facility amount, are consistent with the hypothesis that floors are concentrated in the facilities that are expected to trade post-issuance. Specifically, both facility amount and maturity are positively correlated with the presence of a LIBOR floor. Dummy variables indicate that floors are concentrated in institutional term loans, which is again consistent with the hypothesis that floors are included in facilities that exhibit a high likelihood of secondary trading. However, coefficients on performance pricing covenants and cov-lite features are now insignificant.

Second lien facilities are less likely to incorporate floors. Although the significance of this result falls short of the $5 \%$ level for both matched samples. Somewhat related, the all-indrawn spread is found to be positively correlated with floor inclusion in the larger sample, but not when examining term loans exclusively, which is arguably the better test as revolvers likely have a different pricing equation than term loans due to their partially funded nature. OIDs are again found to be significantly positively related to LIBOR floor usage, consistent with their expected complementarity with floors due to their opposing effects on duration and cancellation option value. 
Table 5.8: Probit estimates of the probability that a floor option is embedded in a loan facility. Observations are restricted to those facilities that are matched within the same loan package, but differ in floor usage. Facilities with floors are therefore matched one-for-one with those that do not have floors, balancing unobserved covariates associated with time and borrower. Column (1) includes all such facilities, while column (2) further restricts this sample by omitting all revolving credit facilities. Observations with missing OIDs are assumed to be issued at par. Variable definitions are listed in Table A-1. Data are winsorized at $1 \%$ from each tail. Standard errors are in parentheses below their respective coefficient estimates.

\begin{tabular}{|c|c|c|}
\hline & \multicolumn{2}{|c|}{ Dependent variable: hasFloor } \\
\hline & $(1)$ & $(2)$ \\
\hline constant & $\begin{array}{c}-2.596^{* * *} \\
(0.497)\end{array}$ & $\begin{array}{c}-3.523^{* * *} \\
(0.701)\end{array}$ \\
\hline $\log ($ facilityAmount) (\$mil) & $\begin{array}{c}0.202^{* * *} \\
(0.057)\end{array}$ & $\begin{array}{c}0.371^{* * *} \\
(0.088)\end{array}$ \\
\hline maturity (months) & $\begin{array}{c}0.021^{* * *} \\
(0.004)\end{array}$ & $\begin{array}{c}0.026^{* * *} \\
(0.005)\end{array}$ \\
\hline secondLien & $\begin{array}{c}-0.429^{*} \\
(0.245)\end{array}$ & $\begin{array}{l}-0.647 \\
(0.396)\end{array}$ \\
\hline covLite & $\begin{array}{l}-0.057 \\
(0.142)\end{array}$ & $\begin{array}{l}-0.067 \\
(0.192)\end{array}$ \\
\hline hasPpc & $\begin{array}{l}-0.025 \\
(0.159)\end{array}$ & $\begin{array}{c}0.067 \\
(0.223)\end{array}$ \\
\hline allInDrawn (bps) & $\begin{array}{c}0.001^{* * *} \\
(0.0004)\end{array}$ & $\begin{array}{l}0.0004 \\
(0.001)\end{array}$ \\
\hline oidSpread (bps) & $\begin{array}{c}0.011^{* * *} \\
(0.003)\end{array}$ & $\begin{array}{c}0.016^{* * *} \\
(0.006)\end{array}$ \\
\hline termLoan & $\begin{array}{c}1.005^{* * *} \\
(0.237)\end{array}$ & \\
\hline proRata & $\begin{array}{c}-2.401^{* * *} \\
(0.222)\end{array}$ & $\begin{array}{c}-2.482^{* * *} \\
(0.241)\end{array}$ \\
\hline Pseudo R2 & 0.824 & 0.536 \\
\hline Observations & 2,522 & 496 \\
\hline Log Likelihood & -308.281 & -159.566 \\
\hline Akaike Inf. Crit. & 636.562 & 337.131 \\
\hline
\end{tabular}

\subsection{On the impact of LIBOR floors on term loan prices in the secondary market}

To assess the effect floors have had on term loan prices in the secondary market, I estimate empirical durations on three equal-weighted loan indexes. Each index is formed of loans that 
have equal strike rates on their LIBOR floors. Ideally, examination of the price behavior of loans with and without LIBOR floors should be compared to determine the relative sensitivity to movements in interest rates. However, the data for which adequate price information exists is relegated to a subsample of loans nearly all of which have embedded floor options. I therefore construct indexes of loans that have strikes equal to 75,100 , and 125 bps, whose prices I call $P_{75}, P_{100}$, and $P_{125}$. A total of 85 loans are used in the 75 bps index, 360 loans in the 100 bps index, and 48 in the 125 bps index. Each index's price is normalized to 100 as of March 1, 2013. Indexes are updated as new loans are issued and old loans drop out of the sample.

If floor options have had a meaningful impact on the sensitivity of loans to changes in interest rates, loan prices should have adjusted inversely to movements in LIBOR and with magnitudes increasing with the strike rate. Quantifying this sensitivity, I estimate the following OLS regression for each of these indexes:

$$
\Delta \ln \left(P_{t}\right)=\alpha+\beta \Delta \text { libor } 3 M_{t}+\epsilon_{t}
$$

where $\Delta \ln \left(P_{t}\right)$ is the weekly change in the natural log of the price of the index and $\Delta l i b o r 3 M$ is the corresponding weekly change in USD three-month LIBOR. $\beta$ can be interpreted as the empirical duration of the index, i.e. the approximation of its modified duration. Results are listed in Table 5.9.

The 125 bps index is by far the most sensitive, followed by the 100 basis point index. The 75 basis point index is the least sensitive, with a coefficient on interest rate changes only marginally different from zero. An increase in the LIBOR rate of 1 percentage point would have resulted in a $2.9 \%$ decrease in $P_{75}, 11.3 \%$ decrease in $P_{100}$, and a $32.3 \%$ decrease in $P_{125}$. Floor options have had a significant effect on the interest rate sensitivity of these loans. 
Table 5.9: Empirical duration estimates for loan indexes formed on LIBOR floor strike value. Dependent variables $\Delta \ln \left(P_{75}\right), \Delta \ln \left(P_{100}\right)$, and $\Delta \ln \left(P_{125}\right)$ are weekly log differences (weekly returns) in the prices of equal-weighted indexes containing loans with floor option strike rates of 75, 100, and 125 basis points (bps), respectively. Midpoints between bid and ask prices are used in the calculation of index returns. Indexes are normalized to 100 percent of par value as of March 1, 2013. Loans are added to each index as they become effective, adding to the collective return of each index in subsequent periods until they are repaid. A total of 85 loans are used in the 75 bps index, 360 loans in the 100 bps index, and 48 in the 125 bps index. The explanatory variable, $\Delta$ libor $3 M$ is weekly change in USD three-month LIBOR. Standard errors are listed in parentheses below their respective coefficiant estimates.

\begin{tabular}{|c|c|c|c|}
\hline & \multicolumn{3}{|c|}{ Dependent variable: } \\
\hline & $\Delta \ln \left(P_{75}\right)$ & $\Delta \ln \left(P_{100}\right)$ & $\Delta \ln \left(P_{125}\right)$ \\
\hline & (1) & $(2)$ & (3) \\
\hline constant & $\begin{array}{l}-0.0003 \\
(0.0002)\end{array}$ & $\begin{array}{c}-0.001^{* * *} \\
(0.0002)\end{array}$ & $\begin{array}{c}-0.002^{* *} \\
(0.001)\end{array}$ \\
\hline$\Delta$ libor3M (bps) & $\begin{array}{c}-2.938^{*} \\
(1.686)\end{array}$ & $\begin{array}{c}-11.263^{* * *} \\
(2.101)\end{array}$ & $\begin{array}{c}-32.294^{* * *} \\
(5.881)\end{array}$ \\
\hline Observations & 135 & 135 & 135 \\
\hline Adjusted $R^{2}$ & 0.015 & 0.171 & 0.179 \\
\hline Residual Std. Error $(\mathrm{df}=133)$ & 0.002 & 0.002 & 0.007 \\
\hline F Statistic $(\mathrm{df}=1 ; 133)$ & $3.038^{*}$ & $28.733^{* * *}$ & $30.156^{* * *}$ \\
\hline
\end{tabular}

\subsection{On the effect of LIBOR floors on optional prepayment terms}

To test whether embedded floors coincide with call premiums, I estimate the following two OLS regressions:

$$
\text { distanceToCall }_{i}=\beta_{0}+\beta_{1} \text { floorSpread }_{i}+\beta_{2} \text { floorSpread }_{i}^{2}+\delta \text { controls }_{i}+\epsilon_{i},
$$

and

$$
\begin{aligned}
& \text { initialCall }_{i}=\beta_{0}+\beta_{1} \text { floor Spread }_{i}+\beta_{2} \text { floor Spread }_{i}^{2}+\beta_{3} \text { olsSpread }_{i}+ \\
& \beta_{3} \text { ols Spread }{ }_{i}^{2}+\delta \text { controls }{ }_{i}+\epsilon_{i} \text {. }
\end{aligned}
$$


To alleviate concerns regarding omitted variables bias, I estimate Eqs. (5.9) and (5.10) on a subset of term loans that are matched one-for-one according to the presence of call premiums. In these cases, term loans with call premiums are matched to facilities that are issued as part of the same loan package but do not contain call premiums. This condition proves to be more restrictive than the matching on floor use, as the sample is reduced to only 238 loans.

distance ToCall, defined as the sum of the OID and initial call premium, approximates how far out of the money the borrower's cancellation option is at the time of origination. Whereas initialCall measures only the call premium pertaining to the earliest possible prepayment.

Results are displayed in Table 5.10. Columns (1), (2), and (3) show a positive linear relation between the level of the floor spread and distance ToCall. Columns (4) (5), and (6) show a positive but concave relation between the floor spread and the initial call premium. Both results are consistent with the increased interest rate sensitivity induced by embedding LIBOR floors, which in turn motivate inclusion of call provisions.

Call premiums are more prevalent in institutional tranches than in pro rata facilities, which in this sample consist of bridge loans and amortizing term loans (TL As). These fees also do not scale with the size or maturity of the facility. This runs counter to the intuition that increasing the expiration date on the cancellation option increases the option's value. All else equal, more valuable cancellation options should coincide with stricter call protection if these provisions are the primary vehicle through which lenders extract compensation for prepayment risk. Facilities with a second lien claim on the borrower's assets have an additional 54 bps of call protection, on average. This effect is independent of the higher interest spread associated with these loans as the regression also controls for the all-in-drawn spread, which is found to have no relation to the level of call premiums.

Since performance pricing adjusts loan spreads to match the borrower's credit risk, I expect the inclusion of a PPC to have a negative effect on the level of call protection. However, the opposite is true in Table 5.10, which indicates the presence of a PPC coincides 
Table 5.10: OLS regressions of initial call premium and distance to call (the sum of initial call premium and OID) on floor and OID spreads. Observations are restricted to those term loan facilities that are matched within the same loan package, but differ in call usage. Facilities with call premiums are matched one-for-one with those that do not have call premiums, balancing unobserved covariates associated with time and borrower. Variable definitions are listed in Table A-1. Data are winsorized at 1\% from each tail. Robust standard errors clustered at the loan package level are in parentheses below their respective coefficient estimates.

\begin{tabular}{|c|c|c|c|c|c|c|}
\hline & \multicolumn{6}{|c|}{ Dependent variable: } \\
\hline & \multicolumn{3}{|c|}{ distanceToCall } & \multicolumn{3}{|c|}{ initialCall } \\
\hline & $(1)$ & $(2)$ & $(3)$ & $(4)$ & $(5)$ & $(6)$ \\
\hline constant & $\begin{array}{c}47.135^{* * *} \\
(12.867)\end{array}$ & $\begin{array}{c}-107.606 \\
(88.690)\end{array}$ & $\begin{array}{c}-107.840 \\
(89.814)\end{array}$ & $\begin{array}{c}12.423^{* * *} \\
(4.040)\end{array}$ & $\begin{array}{c}74.961^{* *} \\
(35.571)\end{array}$ & $\begin{array}{c}72.879^{* *} \\
(35.239)\end{array}$ \\
\hline floorSpread (bps) & $\begin{array}{c}3.637^{* * *} \\
(1.074)\end{array}$ & $\begin{array}{c}1.966 \\
(1.249)\end{array}$ & $\begin{array}{c}2.050^{* * *} \\
(0.425)\end{array}$ & $\begin{array}{c}2.914^{* * *} \\
(0.371)\end{array}$ & $\begin{array}{c}2.042^{* * *} \\
(0.548)\end{array}$ & $\begin{array}{c}1.959^{* * *} \\
(0.505)\end{array}$ \\
\hline floorSpread $^{2}$ (bps) & $\begin{array}{l}-0.011 \\
(0.012)\end{array}$ & $\begin{array}{c}0.001 \\
(0.014)\end{array}$ & & $\begin{array}{c}-0.022^{* * *} \\
(0.004)\end{array}$ & $\begin{array}{c}-0.016^{* * *} \\
(0.005)\end{array}$ & $\begin{array}{c}-0.015^{* * *} \\
(0.005)\end{array}$ \\
\hline proRata & & $\begin{array}{l}-18.489 \\
(23.846)\end{array}$ & $\begin{array}{l}-17.729 \\
(30.105)\end{array}$ & & $\begin{array}{c}-41.233^{* * *} \\
(10.329)\end{array}$ & $\begin{array}{c}-41.217^{* * *} \\
(10.251)\end{array}$ \\
\hline $\log ($ facilityAmount $)(\$$ mil $)$ & & $\begin{array}{c}6.538 \\
(7.596)\end{array}$ & $\begin{array}{c}6.501 \\
(7.440)\end{array}$ & & $\begin{array}{l}-3.308 \\
(3.540)\end{array}$ & $\begin{array}{l}-3.087 \\
(3.518)\end{array}$ \\
\hline maturity (months) & & $\begin{array}{l}1.302^{*} \\
(0.779)\end{array}$ & $\begin{array}{l}1.296^{*} \\
(0.705)\end{array}$ & & $\begin{array}{l}-0.145 \\
(0.245)\end{array}$ & $\begin{array}{l}-0.137 \\
(0.239)\end{array}$ \\
\hline secondLien & & $\begin{array}{l}-15.371 \\
(48.863)\end{array}$ & $\begin{array}{l}-15.352 \\
(48.626)\end{array}$ & & $\begin{array}{l}54.361^{*} \\
(32.057)\end{array}$ & $\begin{array}{c}54.440^{*} \\
(31.906)\end{array}$ \\
\hline covLite & & $\begin{array}{c}17.614 \\
(17.982)\end{array}$ & $\begin{array}{c}16.975 \\
(20.652)\end{array}$ & & $\begin{array}{c}8.581 \\
(8.031)\end{array}$ & $\begin{array}{c}8.572 \\
(7.957)\end{array}$ \\
\hline hasPpc & & $\begin{array}{c}3.972 \\
(19.613)\end{array}$ & $\begin{array}{c}3.979 \\
(19.579)\end{array}$ & & $\begin{array}{c}13.830^{* * *} \\
(4.646)\end{array}$ & $\begin{array}{c}14.061^{* * *} \\
(4.806)\end{array}$ \\
\hline allInDrawn (bps) & & $\begin{array}{l}0.136^{*} \\
(0.071)\end{array}$ & $\begin{array}{l}0.137^{*} \\
(0.070)\end{array}$ & & $\begin{array}{l}-0.039 \\
(0.029)\end{array}$ & $\begin{array}{l}-0.041 \\
(0.029)\end{array}$ \\
\hline oidSpread (bps) & & & & $\begin{array}{c}0.424 \\
(0.887)\end{array}$ & $\begin{array}{c}0.418 \\
(0.859)\end{array}$ & $\begin{array}{c}0.858^{* *} \\
(0.368)\end{array}$ \\
\hline oidSpread $^{2}$ (bps) & & & & $\begin{array}{c}0.005 \\
(0.011)\end{array}$ & $\begin{array}{c}0.006 \\
(0.010)\end{array}$ & \\
\hline Observations & 238 & 238 & 238 & 238 & 238 & 238 \\
\hline $\mathrm{R}^{2}$ & 0.291 & 0.323 & 0.323 & 0.373 & 0.440 & 0.439 \\
\hline Adjusted $\mathrm{R}^{2}$ & 0.285 & 0.296 & 0.299 & 0.362 & 0.413 & 0.414 \\
\hline Residual Std. Error & 145.354 & 144.215 & 143.902 & 58.346 & 55.952 & 55.897 \\
\hline F Statistic & $48.209^{* * *}$ & $12.075^{* * *}$ & $13.642^{* * *}$ & $34.596^{* * *}$ & $16.168^{* * *}$ & $17.764^{* * *}$ \\
\hline
\end{tabular}

with an additional 14 bps of call premium, on average. Interestingly, the level of call premiums appears positively correlated with the size of OIDs, indicating these two features are 
complementary despite their somewhat redundant effect on prepayment risk.

The all-in-drawn spread is positively related to the distance ToCall, a result that is likely driven by a positive relation between OIDs and interest spreads. Thus, the effect of high interest spreads on the likelihood of cancellation might be accounted for through higher issue discounts. This view is consistent with the OID serving as a signaling mechanism indicating a borrower's likelihood to exercise the cancellation option, similar to the role that points play in residential mortgages. Note, as well, that performance pricing is uncorrelated with distance ToCall, which is surprising given the theoretical relation between these covenants and prepayment risk.

According to specification (3), an additional basis point of floor spread corresponds with cancellation fees that are two bps further out of the money. Floors therefore bear significantly on the moneyness of cancellation options consistent with lenders adjusting for floor-related prepayment risk.

Further exploring the relation between call premiums, OIDs, and embedded LIBOR floors, I estimate the probability that any call premium, regardless of level, is included in a loan conditional on that loan's OID and floor spreads. I estimate the following probit specifications:

$$
\begin{aligned}
\operatorname{Pr}\left(\text { hasCall }_{i}=1\right)= & \left(\beta_{0}+\beta_{1} \text { hasFloor }_{i}+\beta_{2} \text { oidSpread }_{i}+\beta_{3} \text { oidSpread }_{i}^{2}+\right. \\
& \text { controls } \left._{i}\right)
\end{aligned}
$$




$$
\begin{gathered}
\operatorname{Pr}\left(\text { hasCall }_{i}=1\right)=\Phi\left(\beta_{0}+\beta_{1} \text { hasFloor }_{i}+\beta_{2} \text { floor Spread }_{i}+\beta_{3} \text { oidSpread }_{i}+\right. \\
\left.\beta_{4} \text { oidSpread }_{i}^{2}+\text { Scontrols }_{i}\right) .
\end{gathered}
$$

Estimates are listed in Table 5.11. Column (1) estimates the probability of incorporating a call premium conditional on the inclusion of a floor option, regardless of strike rate. The dummy variable hasFloor has a significantly positive coefficient estimate indicating the presence of a floor option is highly correlated with the use of call protection. The average partial effect of a floor in specification (1) on the probability that a loan facility includes a call premium is $52.7 \%$ (statistically significant at the $1 \%$ level). Column (2) exchanges the floor indicator for a quadratic specification in floor spread. Consistent with the results from OLS regressions on the level of call premiums, the probability of incorporating call protection is a positive concave function of the floor spread.

Interestingly, the effect of floors on call premiums appears concentrated along the extensive margin (whether a loan contains a floor of any value). Specification (3), for example, indicates a large jump in the use of call premiums given the presence of a floor, but a slight negative effect from the size of the floor spread conditional on a floor being present.

The coefficient estimates on the controls are mostly consistent with those in the OLS specifications of Table 5.10. Again, performance pricing is found to have little effect on the likelihood that call premiums are included in a loan contract, which is puzzling considering their obvious effect on the borrower's inclination to exercise her cancellation option. 
Table 5.11: Probit estimates of the probability of incorporating a call premium in a loan facility given LIBOR floor- and OID-related variables. Observations are restricted to those term loan facilities that are matched within the same loan package, but differ in call usage. Facilities with call premiums are matched one-for-one with those that do not have call premiums, balancing unobserved covariates associated with time and borrower. Variable definitions are listed in Table A-1. Data are winsorized at 1\% from each tail. Standard errors are listed in parentheses below their respective coefficient estimates.

\begin{tabular}{|c|c|c|c|}
\hline & \multicolumn{3}{|c|}{ Dependent variable: } \\
\hline & \multicolumn{3}{|c|}{ hasCall } \\
\hline & $(1)$ & $(2)$ & $(3)$ \\
\hline constant & $\begin{array}{l}-1.041 \\
(1.307)\end{array}$ & $\begin{array}{l}-1.227 \\
(1.257)\end{array}$ & $\begin{array}{l}-1.199 \\
(1.376)\end{array}$ \\
\hline hasFloor & $\begin{array}{c}2.046^{* * *} \\
(0.339)\end{array}$ & & $\begin{array}{c}2.948^{* * *} \\
(0.489)\end{array}$ \\
\hline floorSpread (bps) & & $\begin{array}{c}0.067^{* * *} \\
(0.012)\end{array}$ & $\begin{array}{c}-0.015^{* * *} \\
(0.006)\end{array}$ \\
\hline floorSpread $^{2}$ (bps) & & $\begin{array}{c}-0.001^{* * *} \\
(0.0001)\end{array}$ & \\
\hline oidSpread (bps) & $\begin{array}{c}0.016 \\
(0.020)\end{array}$ & $\begin{array}{c}0.025 \\
(0.020)\end{array}$ & $\begin{array}{c}0.023 \\
(0.021)\end{array}$ \\
\hline oidSpread $^{2}$ (bps) & $\begin{array}{l}-0.0001 \\
(0.0003)\end{array}$ & $\begin{array}{l}-0.0002 \\
(0.0002)\end{array}$ & $\begin{array}{l}-0.0002 \\
(0.0003)\end{array}$ \\
\hline proRata & $\begin{array}{c}-1.499^{* * *} \\
(0.447)\end{array}$ & $\begin{array}{c}-1.716^{* * *} \\
(0.428)\end{array}$ & $\begin{array}{c}-1.582^{* * *} \\
(0.460)\end{array}$ \\
\hline $\log ($ facilityAmount) (\$mil) & $\begin{array}{l}-0.022 \\
(0.134)\end{array}$ & $\begin{array}{c}0.038 \\
(0.129)\end{array}$ & $\begin{array}{c}0.008 \\
(0.142)\end{array}$ \\
\hline maturity (months) & $\begin{array}{c}0.011 \\
(0.010)\end{array}$ & $\begin{array}{c}0.015 \\
(0.009)\end{array}$ & $\begin{array}{c}0.010 \\
(0.010)\end{array}$ \\
\hline secondLien & $\begin{array}{l}-0.241 \\
(0.564)\end{array}$ & $\begin{array}{c}0.087 \\
(0.567)\end{array}$ & $\begin{array}{l}-0.193 \\
(0.574)\end{array}$ \\
\hline covLite & $\begin{array}{l}0.522^{*} \\
(0.296)\end{array}$ & $\begin{array}{c}0.390 \\
(0.302)\end{array}$ & $\begin{array}{c}0.222 \\
(0.335)\end{array}$ \\
\hline hasPpc & $\begin{array}{c}0.624 \\
(0.399)\end{array}$ & $\begin{array}{c}0.565 \\
(0.364)\end{array}$ & $\begin{array}{c}0.639 \\
(0.423)\end{array}$ \\
\hline allInDrawn (bps) & $\begin{array}{c}-0.002^{*} \\
(0.001)\end{array}$ & $\begin{array}{c}-0.003^{* *} \\
(0.001)\end{array}$ & $\begin{array}{l}-0.002 \\
(0.001)\end{array}$ \\
\hline Pseudo R2 & 0.594 & 0.579 & 0.617 \\
\hline Observations & 238 & 238 & 238 \\
\hline Log Likelihood & -66.998 & -69.501 & -63.235 \\
\hline Akaike Inf. Crit. & 155.995 & 163.002 & 150.470 \\
\hline
\end{tabular}




\section{Chapter 6}

\section{Conclusion}

Use of LIBOR floors in syndicated loans is examined. While typically omitted in loans prior to 2008, their use has become common in the years since, particularly in the leveraged market segment. These options, which effectively convert floating rate interest payments to fixed while rates are low, have become a significant component in leveraged loan pricing. Immediately after the financial crisis of the late 2000s, the median floor accounted for almost a fifth of total interest compensation above the base interest rate. This proportion has fallen in subsequent years but remains about three times the size of upfront fees (OIDs).

Several motives for including floor options are assessed. Of these, I find the most evidence in support of Dreschsler, Savov, and Schnabl's (2017) hypothesis that lenders prefer fixed rate assets in low interest rate environments as a means of covering their fixed costs. Banks in floor-adjusted credit lines are shown to have larger expenses in general and a wider disparity between their fixed costs and LIBOR. I also find weak support for Agmon, Ofer, and Tamir's (1981) and Santomero's (1983) theories regarding the preference for fixed versus floating rate debt. As predicted, loans that are issued with a floor (and therefore at a fixed rate) are disproportionately made to borrowers that lack the natural interest rate hedge provided by

high correlation between earnings and LIBOR; however, the marginal effect is insignificantly different from zero. Evidence also suggests that floors may have been used as a means of protecting lenders against fraudulently low LIBOR fixings. A larger proportion of LIBOR 
submitting banks in a loan's lending syndicate is found to coincide with less floor usage, suggestive of lower moral hazard concerns. Additionally, the proportion of expected interest arising from embedded floors is predicted in the time series by the spread between commercial paper rates and LIBOR, an indicator of LIBOR's validity.

Rationalizing the use of embedded floors over other methods of interest rate hedging, embedded floors offer transaction and administrative cost savings over interest rate hedges secured through third parties, particularly in traded facilities. Consistent with this view, I find that floor options are concentrated in the large, institutional term loans that are most likely to trade in the secondary market.

As a consequence of including interest rate minimums, prices of floor-adjusted loans are shown to exhibit higher sensitivity to movements in interest rates. This increased price volatility increases the value of the borrower's cancellation option. Evidence suggests that lenders account for the increased probability of early termination by negotiating stricter call provisions in the form of call premiums and upfront fees, both of which decrease the value of the cancellation option. Facilities that contain floor options are 52.7 percent more likely to incorporate a call premium. Floors may also have affected the transmission of monetary policy through the floating rate channel discussed in Ippolito, Ozdagli, and Perez (2015). The introduction of LIBOR floors can explain their finding that the behavior of floating rate paying firms ceased to be affected by changes in the Fed Funds rate after 2008.

Future study of this topic would benefit from data on the continued use of floors as interest rates rise above historically low levels. Similarly, data on the funding costs and balance sheets of the institutional investors that participate in the leveraged loan market would aid in further research. 


\section{References}

[1] Asquith, Paul, Beatty, A., Weber, J., 2005, Performance pricing in bank loan contracts, Journal of Accounting and Economics, 40, 101-128.

[2] Awad, Andrew, McPartland, Kevin, 2015, Total cost analysis of interest-rate swaps vs. futures, Greenwich Associates.

[3] Bachelier, Louis, 1900, Théorie de la spéculation, Annals Scientifique de l'É.N.S., 3, 7, $21-86$.

[4] Barnea, Amir, Haugen Robert A., and Senbet, Lemma W., 1980, A Rationale for Debt Maturity Structure and Call Provisions in the Agency Theoretic Framework, Journal of Finance, 35, 5, 1223 - 1234.

[5] Barucci, Emilio, 2003, Financial Markets Theory: Equilibrium, Efficiency and Information, Springer-Verlag London.

[6] Bauman, Jeff, Coleman, John, Powell, Rob, 2009, Creating inexpensive swaps, CME Group.

[7] Becker, Bo and Ivashina, Victoria, 2016, Covenant-Light Contracts and Creditor Coordination, Riksbank Research Paper Series No. 149; Swedish House of Finance Research Paper No. 17-1.

[8] Berends, K., R. McMenamin, T. Plestis, and R. Rosen 2013, The Sensitivity of Life Insurance Firms to Interest Rate Changes, Federal Reserve Bank of Chicago Economic 
Perspectives, 37, 2, $47-78$.

[9] Berg, Tobias, Saunders, A., Steffen, S., 2016, The Total Cost of Corporate Borrowing in the Loan Market: Don't Ignore the Fees, The Journal of Finance, 71, 1357 - 1392.

[10] Billett, Matthew T., Elkamhi, Redouane, Popov, Latchezar, Pungaliya, Raunaq S, 2016, Bank Skin in the Game and Loan Contract Design: Evidence from Covenant-Lite Loans, Journal of Financial \& Quantitative Analysis,51, 3, 839 - 873.

[11] Black, Fischer, 1976, The pricing of commodity contracts, Journal of Financial Economics, 3, 167 - 179 .

[12] Bodie, Z. and Taggart, R., 1978, Future Investment Opportunities and the Value of the Call Provision on a Bond, Journal of Finance, 33, 4, 1187 - 1200.

[13] Brennann, M. and Schwartz, E., 1977, Convertible bonds: valuation and optimal strategies for call and conversion, Journal of Finance, 32, 5, 1699 - 1715.

[14] Brophy, David J., Ouimet, P. P., Sialm, C., 2009, Hedge Funds as Investors of Last Resort?, Review of Financial Studies, 22, 541 - 574.

[15] Bruche, Max, Frederic Malherbe, and Ralf R. Meisenzahl (2017). Pipeline Risk in Leveraged Loan Syndication, Finance and Economics Discussion Series 2017-048. Washington: Board of Governors of the Federal Reserve System.

[16] Brueckner, Jan K., 1994, Borrower mobility, adverse selection, and mortgage points, Journal of Financial Intermediation, 3, 416 - 441.

[17] Chamblee, Gary D., Tenholder, J. A., 2005, Converging markets: leveraged syndicated loans and high-yield bonds, Commercial Lending Review, 7, 7-16.

[18] Campello, M., Giambona, E., Graham, J. R., Harvey, C. R., 2011, Liquidity Management and Corporate Investment During a Financial Crisis, Review of Financial Studies, 24, $1944-1979$. 
[19] Chava, Sudheer, Roberts, Michael R., 2008, How Does Financing Impact Investment? The Role of Debt Covenants, Journal of Finance, 63, 5, 2085 - 2121.

[20] Chava, Sudheer, Purnanandam, Amiyatosh, 2007, Determinants of the floating-to-fixed rate debt structure of firms, Journal of Financial Economics, 85-3, 755-786.

[21] Culp, Christopher L., 2013, Syndicated Leveraged Loans During and After the Crisis and the Role of the Shadow Banking System, Journal of Applied Corporate Finance, Vol. 25, No. 2.

[22] Dreschsler, Itamar, Savov, Alexi, Schnabl, Phillipp, 2017, Banking on Deposits: Maturity Transformation Without Interest Rate Risk, Working Paper.

[23] Drucker, Steven, Puri, Manju, 2009, On Loan Sales, Loan Contracting, and Lending Relationships, The Review of Financial Studies, 22, 7, 2835 - 2872.

[24] Dybvig, Philip H., 1995, Dusenberry's Ratcheting of Consumption: Optimal Dynamic Consumption and Investment Given Intolerance for any Decline in Standard of Living, Review of Economic Studies, 62(2), 287 - 313.

[25] Dym, S., 1998, A generalized approach to price and duration of non-par floating rate notes. The Journal of Portfolio Management, 24, 4, 102-109.

[26] Faulkender, Michael, 2005, Hedging or Market Timing? Selecting the Interest Rate Exposure of Corporate Debt, Journal of Finance 60, 931-962.

[27] Finnerty, John D., 1989, Measuring the duration of a floating rate bond, The Journal of Portfolio Management, 14, 4, 67-72.

[28] Ghandi, Chintan, Peng, S., Tyo, A., 2008, Special Topic: Is LIBOR Broken?, Citigroup US rate strategy focus, released April 10, 2008.

[29] Gatev, Evan, Strahan, Philip E., 2009, Liquidity risk and syndicate structure, Journal of Financial Economics, 93, 3, 490 - 504. 
[30] Gupta, Anurag, Singh, Ajai K., Zebedee, Allan A., 2008, Liquidity in the pricing of syndicated loans, Journal of Financial Markets, 11, 4, 339 - 376.

[31] Greene, William, 2004, The behavior of the maximum likelihood estimator of limited dependent variable models in the presence of fixed effects, Econometrics Journal, 7, 98-119.

[32] Gyntelberg, Jacob, Wooldridge, Philip, 2008, Interbank rate fixings during the recent turmoil, BIS Quarterly Report, March 2008. Bank of International Settlements.

[33] Heckman, James, 1976, The common structure of statistical models of truncation, sample selection and limited dependent variables and a simple estimator for such models, Annals of Economic and Social Measurement, 5 (4), 475 - 492.

[34] Heinze, G. and Schemper, M., 2002, A solution to the problem of separation in logistic regression. Statistics in Medicine 21, 2409-2419.

[35] Holmstrom, Bengt, 1979, Moral hazard and observability, Bell Journal of Economics 10, $74-91$.

[36] Holmstrom, Bengt, Tirole, Jean, 1997, Financial intermediation, loanable funds, and the real sector, Quarterly Journal of Economics 112, 663 - 691.

[37] Hull, John. Options, Futures, and Other Derivatives, 3rd edition. Upper Saddle River, N.J.: Pearson/Prentice Hall, 1997.

[38] Ivashina, Victoria, 2009, Asymmetric Information Effects on Loan Spreads, Journal of Financial Economics, 92, $300-319$.

[39] Ivashina, Victoria, Scharfstein, David, 2010, Bank lending during the financial crisis of 2008, Journal of Financial Economics, 97, 3, 319 - 338.

[40] Ivashina, Victoria, Sun, Zheng, 2009, Institutional demand pressure and the cost of corporate loans, Journal of Financial Economics, 99, 3, 500 - 522. 
[41] Kirti, Divya, 2015, Why do bank dependent firms bear interest rate risk?, working paper.

[42] Kish, Richard J., Livingston, Miles, 1992, Determinants of the call option on corporate bonds, Journal of Banking and Finance 16, 687 - 703.

[43] Krause, Allen, 1973, The Bond Refunding Decision in an Efficient Market, Journal of Financial and Quantitative Analysis, 793 - 806.

[44] Lim, Jongha, Minton, Bernadette A., Weisbach, Michael S., 2014, Syndicated loan spreads and the composition of the syndicate, Journal of Financial Economics, 111, 1, $45-69$.

[45] Miller, Steven, 2006, A Syndicated Loan Primer, Standard \& Poor's: A Guide to Loan Markets, September, 7-25.

[46] Monticinia, Andrea, Thornton, Daniel L., 2013, The effect of underreporting on LIBOR rates, Journal of Macroeconomics, 37, 345 - 348.

[47] Myers, Stewart C., 1977, Determinants of Corporate Borrowing, Journal of Financial Economics, 5, 2, $147-175$.

[48] Nandy, Debarshi K., Shao, Pei, 2010, Institutional Investment in Syndicated Loans, UBC Winter Finance Conference 2008 Paper; EFA 2009 Bergen Meetings Paper.

[49] Nawalkha, Sanjay K., Zhang, J., and Chambers, D. R., 1999, Pricing and duration of floaters and interest rate swaps with embedded options, The Journal of Alternative Investments, $1,4,58-70$.

[50] Perold, Andre, Black, Fisher, 1992, Theory of Constant Proportion Portfolio Insurance, Journal of Economic Dynamics \& Control 16, 403 - 426.

[51] Phalippou, Ludovic, 2009, Beware of venturing into private equity, The Journal of Economic Perspectives, 23, 1, 147-166. 
[52] Ramaswamy, K., Sundaresan, S. M., 1986. The valuation of floating-rate instruments. Journal of Financial Economics, 17, 251 - 272.

[53] Roberts, Michael, 2015, The role of dynamic renegotiation and asymmetric information in financial contracting, Journal of Financial Economics, 61 - 81.

[54] Thatcher, Janet S., 1985, The Choice of Call Provision Terms: Evidence of the Existence of Agency Costs of Debt, Journal of Finance, 40, 2, 549 - 561.

[55] Sarkar, Sudipto, 2001, Probability of call and the likelihood of the call feature in a corporate bond, Journal of Banking \& Finance, 25, 505 - 533.

[56] Smith, C. W. Jr., Smithson, C. W., and Wakeman, L. M., 1988, The Market for Interest Rate Swaps, Financial Management, 17(4), 34 - 44.

[57] Smith, Donald J., 2006, Negative duration: the odd case of GMAC's floating-rate note, Journal of Applied Finance, 16, 2, 37 - 44.

[58] Stein, Jeremy, 2012, Monetary policy as financial stability regulation, The Quarterly Journal of Economics, 127(1), 57 - 95.

[59] Sufi, Amir, 2007, Information Asymmetry and Financing Arrangements: Evidence from Syndicated Loans, Journal of Finance, 62, 2, 629 - 668.

[60] Toda, Hiro H., Yamamoto, Taku, 1995, Statistical inference in vector autoregressions with possibly integrated processes, Journal of Econometrics, 66, 225 - 250.

[61] Toomet, O. and Henningsen, A., 2008, Sample Selection Models in R: Package sampleSelection, Journal of Statistical Software 27 (7), http://www.jstatsoft.org/v27/i07/.

[62] Wittenberg-Moermann, Regina, 2008, The role of information asymmetry and financial reporting quality in debt trading: Evidence from the secondary loan market, Journal of Accounting and Economics, 46, 2, 240 - 260. 
[63] White, Halbert, 1980, A heteroskedasticity-consistent covariance matrix estimator and a direct test for heteroskedasticity, Econometrika, 48, 817-838.

[64] Yan, David, 2012, Who gets the incentives: a review of CLO incentive management fees, Credit Suisse Fixed Income Research, May, 2012.

[65] Yawitz, J. B., Kaufold, H., Macirowski, T., Smirlock, M., 1987, The Pricing and Duration of Floating Rate Bonds, The Journal of Portfolio Management, 13, 49 - 56.

[66] Youle, Thomas, 2015, How much did manipulation distort the libor?, Working paper. 
Appendices 


\section{A-1 Additional data description}

Table A-1: Variable definitions. Data are described in section 4.

\begin{tabular}{|c|c|c|c|}
\hline Variable & Type & Source & Definition \\
\hline hasFloor & Dummy & S\&P, LCD, Bloomberg & $\begin{array}{l}1 \text { if a facility contains an embedded floor } \\
\text { option with a non-zero strike rate, and } \\
\text { o otherwise }\end{array}$ \\
\hline floorStrike & Basis points & S\&P, LCD, Bloomberg & Strike rate on the floor option \\
\hline hasCall & Dummy & S\&P, LCD, Bloomberg & $\begin{array}{l}1 \text { if a facility includes a call premium, } \\
\text { and } 0 \text { otherwise }\end{array}$ \\
\hline initialCall & Basis points & S\&P, Dealscan, Bloomberg & The initial call premium on a loan. \\
\hline distanceToCall & Basis points & S\&P, Dealscan, Bloomberg & $\begin{array}{l}\text { The initial call premium on a loan plus } \\
\text { its OID. }\end{array}$ \\
\hline hasBreakPrice & Dummy & S\&P, LCD & $\begin{array}{l}1 \text { if } S \& P \text { records that the facility breaks } \\
\text { for trading in the secondary market } \\
\text { around the time of issuance }\end{array}$ \\
\hline termLoan & Dummy & S\&P LCD, Dealscan, Bloomberg & $\begin{array}{l}1 \text { if a tranche is a term loan and } 0 \text { oth- } \\
\text { erwise }\end{array}$ \\
\hline proRata & Dummy & S\&P LCD, Dealscan, Bloomberg & $\begin{array}{l}1 \text { if a tranche is a pro rata facility, i.e. } \\
\text { Term Loan A or Revolver, and o other- } \\
\text { wise }\end{array}$ \\
\hline hasPpc & Dummy & Dealscan & $\begin{array}{l}1 \text { if a facility contains performance pric- } \\
\text { ing, and } 0 \text { otherwise }\end{array}$ \\
\hline libor3M & Basis points & FRED & $\begin{array}{l}\text { Three month USD LIBOR on the day a } \\
\text { loan is issued }\end{array}$ \\
\hline slope & Basis points & FRED & $\begin{array}{l}\text { Difference between US Treasury rates } \\
\text { associated with tenors of } 3 \text { months and } \\
\text { the loan's maturity on the day a loan is } \\
\text { issued }\end{array}$ \\
\hline $\log$ (facility Amount) & $\ln ($ millions of USD) & Dealscan & $\begin{array}{l}\text { The natural log of a facility's principal } \\
\text { amount at issuance }\end{array}$ \\
\hline maturity & Months & Dealscan & $\begin{array}{l}\text { Number of months between facility is- } \\
\text { suance and expiration }\end{array}$ \\
\hline secondLien & Dummy & S\&P, Dealscan, Bloomberg & $\begin{array}{l}\text { o if a facility has a first lien claim on } \\
\text { the borrower's assets, and } 1 \text { for a second } \\
\text { lien claim }\end{array}$ \\
\hline sponsored & Dummy & Dealscan & $\begin{array}{l}1 \text { if a deal is sponsored by a private eq- } \\
\text { uity fund, and o otherwise }\end{array}$ \\
\hline covLite & Dummy & S\&P, Bloomberg & $\begin{array}{l}1 \text { if a facility has incurrence covenants, } \\
\text { and } 0 \text { if it has more creditor-protective } \\
\text { maintenance covenants }\end{array}$ \\
\hline leadReputation & Continuous & Dealscan & $\begin{array}{l}\text { Maximum number of links between the } \\
\text { lead arranger and a member of the syn- } \\
\text { dicate, scaled by the total number of } \\
\text { deals arranged by the lead arranger over } \\
\text { the three years prior to loan issuance } \\
\text { [see, Ivashina (2009)] }\end{array}$ \\
\hline $\log ($ sales AtClose) & $\ln ($ millions of USD) & Dealscan & $\begin{array}{l}\text { The natural log of a borrower's total } \\
\text { revenue around the time of loan is- } \\
\text { suance }\end{array}$ \\
\hline roa & Continuous & Compustat & $\begin{array}{l}\text { The borrower's return on assets around } \\
\text { the time of loan issuance }\end{array}$ \\
\hline debtEbitda & Continuous & Compustat & $\begin{array}{l}\text { The borrower's debt/EBITDA ratio } \\
\text { around the time of loan issuance }\end{array}$ \\
\hline allInDrawn & Basis points & Dealscan & $\begin{array}{l}\text { The facility's all-in drawn spread over } \\
\text { LIBOR as of loan issuance }\end{array}$ \\
\hline oid & Basis points & S\&P, Dealscan, Bloomberg & $\begin{array}{l}\text { The discount (or premium) to par with } \\
\text { which a loan is issued. Also referred to } \\
\text { as an upfront fee. }\end{array}$ \\
\hline oidSpread & Basis points & S\&P, Dealscan, Bloomberg & $\begin{array}{l}\text { Amortized value of the OID expressed } \\
\text { as an additional spread over LIBOR. } \\
\text { See Eq. (3.13) }\end{array}$ \\
\hline floorSpread & Basis points & S\&P, Dealscan, Bloomberg & $\begin{array}{l}\text { Amortized value of the LIBOR floor op- } \\
\text { tion expressed as an additional spread } \\
\text { over LIBOR. See Eq. ( } 3.11)\end{array}$ \\
\hline
\end{tabular}


Table A-2: Distributions across loan purpose, borrower industry and S $\$ \mathrm{P}$ issuer credit rating. Most of the data are concentrated within the single- and double-B ratings. The BBB category contains all loans issued by borrowers with ratings of either BBB-, BBB, or BBB + . Similarly, the CCC category pertains to loans issued by borrowers with ratings of $\mathrm{CCC}+$ and below. Data are from S\&P LCD and are exclusive to the leveraged loan market.

\begin{tabular}{|c|c|c|c|c|c|c|c|c|c|c|c|}
\hline & Unrated & A- & $\mathrm{BBB}$ & $\mathrm{BB}+$ & $\mathrm{BB}$ & BB- & $\mathrm{B}+$ & $\mathrm{B}$ & B- & $\mathrm{CCC}$ & Totals \\
\hline \multicolumn{12}{|l|}{ Loan purpose } \\
\hline Acquisition & 1725 & 2 & 88 & 163 & 260 & 506 & 849 & 742 & 152 & 244 & 4731 \\
\hline Corporate purposes & 1398 & 2 & 199 & 267 & 398 & 587 & 601 & 480 & 140 & 103 & 4175 \\
\hline Debt repayment & 314 & 0 & 30 & 59 & 93 & 182 & 155 & 78 & 46 & 19 & 976 \\
\hline Other & 280 & 0 & 34 & 34 & 40 & 69 & 63 & 33 & 13 & 3 & 569 \\
\hline Recap & 352 & 0 & 3 & 10 & 41 & 95 & 226 & 200 & 50 & 89 & 1066 \\
\hline \multicolumn{12}{|l|}{ Borrower industry } \\
\hline Aerospace \& defense & 74 & 0 & 13 & 12 & 8 & 46 & 28 & 12 & 3 & 4 & 200 \\
\hline Automotive & 128 & 0 & 9 & 23 & 24 & 42 & 71 & 39 & 9 & 10 & 355 \\
\hline Building materials & 175 & 0 & 9 & 8 & 25 & 49 & 70 & 57 & 12 & 17 & 422 \\
\hline Cable & 82 & 0 & 4 & 21 & 16 & 30 & 25 & 18 & 3 & 2 & 201 \\
\hline Chemicals & 202 & 0 & 27 & 31 & 52 & 60 & 122 & 90 & 23 & 33 & 640 \\
\hline Computers \& electronics & 292 & 0 & 47 & 53 & 60 & 131 & 253 & 190 & 40 & 89 & 1155 \\
\hline Consumer nondurables & 37 & 0 & 1 & 0 & 7 & 6 & 12 & 18 & 10 & 10 & 101 \\
\hline Entertainment \& leisure & 81 & 0 & 17 & 13 & 20 & 53 & 70 & 52 & 8 & 10 & 324 \\
\hline Environmental & 38 & 0 & 2 & 5 & 16 & 23 & 18 & 2 & 2 & 2 & 108 \\
\hline Food \& beverage & 194 & 0 & 13 & 25 & 41 & 61 & 70 & 42 & 12 & 11 & 469 \\
\hline Forest products & 97 & 0 & 10 & 7 & 17 & 23 & 26 & 18 & 1 & 6 & 205 \\
\hline Gaming \& hotel & 61 & 0 & 8 & 26 & 20 & 56 & 64 & 20 & 13 & 8 & 276 \\
\hline Healthcare & 272 & 0 & 59 & 27 & 92 & 152 & 189 & 197 & 26 & 46 & 1060 \\
\hline Home furnishings & 70 & 0 & 3 & 3 & 13 & 22 & 17 & 14 & 4 & 9 & 155 \\
\hline Insurance & 51 & 0 & 4 & 4 & 8 & 9 & 20 & 45 & 9 & 14 & 164 \\
\hline Manufacturing \& machinery & 217 & 0 & 10 & 26 & 22 & 55 & 67 & 65 & 11 & 16 & 489 \\
\hline Metals \& mining & 121 & 0 & 11 & 24 & 21 & 49 & 22 & 21 & 12 & 5 & 286 \\
\hline Oil \& gas & 182 & 0 & 13 & 18 & 32 & 44 & 34 & 39 & 16 & 8 & 386 \\
\hline Other & 33 & 2 & 2 & 0 & 0 & 5 & 4 & 10 & 0 & 1 & 57 \\
\hline Printing \& publishing & 164 & 0 & 15 & 21 & 12 & 28 & 50 & 50 & 13 & 8 & 361 \\
\hline Radio & 28 & 0 & 1 & 2 & 0 & 19 & 25 & 16 & 2 & 4 & 97 \\
\hline Real estate & 119 & 0 & 5 & 15 & 24 & 14 & 16 & 2 & 10 & 1 & 206 \\
\hline Restaurants & 104 & 0 & 5 & 5 & 14 & 37 & 64 & 42 & 17 & 6 & 294 \\
\hline Retail & 211 & 0 & 5 & 24 & 26 & 51 & 65 & 66 & 22 & 11 & 481 \\
\hline Retail food \& drug & 73 & 0 & 2 & 1 & 15 & 19 & 25 & 11 & 5 & 3 & 154 \\
\hline Services \& leasing & 467 & 0 & 33 & 72 & 121 & 161 & 236 & 232 & 46 & 69 & 1437 \\
\hline Telecom & 164 & 0 & 7 & 16 & 26 & 54 & 82 & 69 & 48 & 25 & 491 \\
\hline Telecom equipment & 51 & 0 & 0 & 0 & 5 & 11 & 14 & 13 & 4 & 6 & 104 \\
\hline Textile \& apparel & 78 & 0 & 7 & 5 & 20 & 19 & 22 & 16 & 4 & 3 & 174 \\
\hline Transportation & 82 & 0 & 8 & 14 & 15 & 39 & 42 & 21 & 10 & 9 & 240 \\
\hline TV \& film & 68 & 0 & 1 & 9 & 23 & 21 & 34 & 30 & 1 & 9 & 196 \\
\hline Utilities & 53 & 2 & 3 & 23 & 37 & 50 & 37 & 16 & 5 & 3 & 229 \\
\hline Totals & 4069 & 4 & 354 & 533 & 832 & 1439 & 1894 & 1533 & 401 & 458 & 11517 \\
\hline
\end{tabular}


Table A-3: Summary statistics for the data subsets matched on floor use. Data are compiled from Thompson Reuters Dealscan, S\&P LCD, and Bloomberg. To be included, each observation that contains a floor option must be paired with another facility within the same loan package that does not contain a floor. Missing values for OID and initialCall are coded as zero. Dummy variables Bloomberg, SESP LC, and Dealscan indicate data source.

\begin{tabular}{|c|c|c|c|c|c|c|}
\hline Statistic & $\mathrm{N}$ & Mean & St. Dev. & Min & Median & Max \\
\hline \multicolumn{7}{|l|}{ Full matched sample } \\
\hline facilityAmount (\$mil) & 2,522 & 384.083 & 603.214 & 3.960 & 200.000 & $9,750.000$ \\
\hline allInDrawn (bps) & 2,522 & 438.530 & 183.533 & 40.000 & 400.000 & $1,750.000$ \\
\hline oid (bps) & 2,522 & 84.734 & 120.351 & 0.000 & 50.000 & $1,300.000$ \\
\hline floorStrike (bps) & 1,257 & 126.862 & 61.867 & 0 & 100 & 1,200 \\
\hline maturity (months) & 2,522 & 66.555 & 15.515 & 2 & 60 & 180 \\
\hline initialCall (bps) & 2,522 & 71.640 & 87.303 & 0 & 100 & 1,300 \\
\hline distanceToCall (bps) & 2,522 & 156.374 & 173.408 & 0.000 & 125.000 & $1,900.000$ \\
\hline secondLien (bps) & 2,522 & 0.088 & 0.283 & 0 & 0 & 1 \\
\hline hasFloor & 2,522 & 0.500 & 0.500 & 0 & 0.5 & 1 \\
\hline hasCall & 2,522 & 0.536 & 0.499 & 0 & 1 & 1 \\
\hline hasPpc & 2,522 & 0.132 & 0.338 & 0 & 0 & 1 \\
\hline covLite & 2,522 & 0.204 & 0.403 & 0 & 0 & 1 \\
\hline proRta & 2,522 & 0.485 & 0.500 & 0 & 0 & 1 \\
\hline termLoan & 2,522 & 0.543 & 0.498 & 0 & 1 & 1 \\
\hline Bloomberg & 2,522 & 0.050 & 0.218 & 0 & 0 & 1 \\
\hline S\&P LCD & 2,522 & 0.644 & 0.479 & 0 & 1 & 1 \\
\hline Dealscan & 2,522 & 0.306 & 0.461 & 0 & 0 & 1 \\
\hline \multicolumn{7}{|c|}{ Term loan only sample } \\
\hline facilityAmount (\$mil) & 496 & 647.407 & 820.967 & 20.000 & 392.000 & $9,750.000$ \\
\hline allInDrawn (bps) & 496 & 370.388 & 186.171 & 125.000 & 325.000 & $1,750.000$ \\
\hline oid (bps) & 496 & 62.515 & 112.268 & 0.000 & 38.750 & $1,200.000$ \\
\hline floorStrike (bps) & 248 & 128.528 & 94.189 & 0 & 100 & 1,200 \\
\hline maturity (months) & 496 & 66.371 & 17.953 & 2 & 66.5 & 120 \\
\hline initialCall (bps) & 496 & 65.927 & 68.963 & 0 & 100 & 500 \\
\hline distanceToCall (bps) & 496 & 128.443 & 145.829 & 0.000 & 100.000 & $1,400.000$ \\
\hline secondLien & 496 & 0.044 & 0.206 & 0 & 0 & 1 \\
\hline hasFloor & 496 & 0.500 & 0.500 & 0 & 0.5 & 1 \\
\hline hasCall & 496 & 0.579 & 0.494 & 0 & 1 & 1 \\
\hline hasPpc & 496 & 0.228 & 0.420 & 0 & 0 & 1 \\
\hline covLite & 496 & 0.179 & 0.384 & 0 & 0 & 1 \\
\hline proRata & 496 & 0.357 & 0.480 & 0 & 0 & 1 \\
\hline termLoan & 496 & 1.000 & 0.000 & 1 & 1 & 1 \\
\hline Bloomberg & 496 & 0.016 & 0.126 & 0 & 0 & 1 \\
\hline S\&P LCD & 496 & 0.460 & 0.499 & 0 & 0 & 1 \\
\hline Dealscan & 496 & 0.524 & 0.500 & 0 & 1 & 1 \\
\hline
\end{tabular}


Table A-4: Summary statistics for data subsets matched on call premium use. Data are compiled from Thompson Reuters Dealscan, S\&P LCD, and Bloomberg. To be included, each observation that contains a call premium must be paired with another facility within the same loan package that does not contain a call premium. Missing values for OID and floorSpread are coded as zero. Dummy variables Bloomberg, S\&BP $L C$, and Dealscan indicate data source.

\begin{tabular}{|c|c|c|c|c|c|c|}
\hline Statistic & $\mathrm{N}$ & Mean & St. Dev. & Min & Median & Max \\
\hline facilityAmount (\$mil) & 238 & 759.969 & 845.651 & 31.48 & 445 & $4,298.250$ \\
\hline allInDrawn (bps) & 238 & 392.584 & 186.827 & 159.25 & 325 & 940.750 \\
\hline floorStrike (bps) & 134 & 121.828 & 58.202 & 75 & 100 & 325 \\
\hline maturity (months) & 238 & 68.905 & 17.078 & 12 & 72 & 93.780 \\
\hline initialCall (bps) & 238 & 61.34 & 73.038 & 0 & 49.5 & 300 \\
\hline distanceToCall (bps) & 238 & 135.857 & 171.887 & 0 & 100 & $1,015.000$ \\
\hline floorSpread $(\mathrm{bps})($ no floor $=0)$ & 238 & 30.717 & 34.76 & 0 & 22.204 & 118.020 \\
\hline oidSpread (bps) & 238 & 10.128 & 16.622 & 0 & 5.163 & 96.196 \\
\hline hasFloor & 238 & 0.563 & 0.497 & 0 & 1 & 1 \\
\hline secondLien & 238 & 0.084 & 0.278 & 0 & 0 & 1 \\
\hline hasCall & 238 & 0.5 & 0.501 & 0 & 0.5 & 1 \\
\hline hasPpc & 238 & 0.235 & 0.425 & 0 & 0 & 1 \\
\hline covLite & 238 & 0.252 & 0.435 & 0 & 0 & 1 \\
\hline proRata & 238 & 0.324 & 0.469 & 0 & 0 & 1 \\
\hline termLoan & 238 & 1 & 0 & 1 & 1 & 1 \\
\hline Bloomberg & 238 & 0.025 & 0.157 & 0 & 0 & 1 \\
\hline S\&P LCD & 238 & 0.345 & 0.476 & 0 & 0 & 1 \\
\hline Dealscan & 238 & 0.63 & 0.484 & 0 & 1 & 1 \\
\hline
\end{tabular}




\section{A-2 Lender classification}

CLOs are identified as those classified by Dealscan as "Inst. Inv - CDO". Added to these were lenders whose names included the terms "CDO", "CLO", "CBO", "Loan Funding", and "Funding LLC." These include asset-backed commercial paper conduits. Several lenders were identified as CLOs from cross referencing Moody's press releases that supplied the initial tranche ratings. Farm Credit institutions were identified as those containing terms "ACA", "FCS", "PCA", "FLCA", "Farm Credit", or "ag." Life insurance companies were identified as those classified as "Inst. Inv - Insurance" or those with SIC codes of 6321 - 6361 and 6411. Distressed funds were identified by manually verifying lenders that Dealscan classifies as "Disstressed (vulture funds)" or those lenders whose names contain "distressed", "opportunity", or "special situations." Loan mutual funds are categorized similarly by searching keywords "floating rate", "float", "senior", "funding", "loan fund", "prime" and "bank loan." Remaining lenders that Dealscan classifies as "Mutual Funds," or "Inst. Inv - prime" were reclassified as other.

Hedge funds/managers and private equity funds/managers were identified by inspecting the remaining "Distressed (vulture funds)" not otherwise categorized and searching for keywords "Partners" in lender names and sifting through Dealscan's more ambiguous categories like "other", "Specialty", "Corporation", etc.. Manual verification involved web searches of company websites, SEC records Form D filings, and cross-referencing Dealscan's record of financial sponsors. I refer to these hedge/PE funds as asset managers.

Commercial Banks were identified as those that Dealscan classified as "US Bank", "Western European Bank", "African Bank", etc. while Investment banks were drawn from the set Dealscan labels as "Investment Bank." I amend the Investment bank pool to include those banks that are obviously mislabeled by Dealscan. For example UBS AG, UBS AG Stamford Branch, and UBS Loan Finance LLC are classified by Dealscan as "Western European 
Bank", "US Bank", and "Finance Company", respectively. While these classifications might be technically correct, the capacity in which UBS participates in leveraged loans is as an investment bank, not a deposit-taking institution.

In the final aggregation, lenders are categorized into the following 12 groups: CLO Manager, consisting of asset, hedge fund, and private equity managers and business development companies that are known to have issued at least one CLO; non-CLO manager, consisting of the remaining asset, hedge fund, and private equity managers; CLO Insurance, consisting of insurance companies that have issued at least one CLO; non-CLO Insurance, containing insurance companies that have not issued CLOs; Gov Supported, consisting of Farm Credit and development banks; Commercial Banks; Investment Banks; Finance Companies; CLOs; Mutual Funds; Distressed Funds; and, Other Lenders.

\section{A-3 Investment grade loan observations}

Data from S\&P's LCD omits investment grade loans by design. To bring additional investment grade observations into the analysis, I have rely on additional data from Thompson Reuters. Embedded floors in syndicated loans are difficult to track in Thompson Reuters Dealscan because the service offers no specific fields for these options. Information regarding floors is relegated to a 'comment' field at the loan facility level. I employ a text-based search within this field to identify facilities that contain floors. As a result, I am able to identify 5,525 facilities with embedded floors, of which 5,294 are based on LIBOR. These facilities are contained within 3,975 loan packages.

Matching on borrower name, date of issue, loan size, and maturity, I am able to match 3,035 of these facilities to records in S\&P and Bloomberg, services that provide fields for LIBOR floors. Given these latter databases likely offer more accurate data on floors, I use them as a basis of comparison. In total, I match 12,488 S\&P facilities and 5,209 Bloomberg 
facilities to records in Dealscan. Reconciling the existence of floors between these data providers yields a test of the accuracy of floor data in Dealscan. Table A-5 provides cross tabulations of the indicator hasFloor between Dealscan and these other two databases. Approximately $92 \%$ of facilities matched to LCD and $89 \%$ of facilities matched to Bloomberg agree on whether a floor is present. Although, over $95 \%$ of the mismatches involve cases for which floors according to S\&P or Bloomberg are omitted in Dealscan. Dealscan correctly identifies about three quarters of the floors listed in LCD, but only one quarter of those in Bloomberg. The difference in error rates is likely related to differences in the types of facilities in the Bloomberg and LCD samples. Specifically, the 5,209 Bloomberg facilities used in the reconciliation are those that are not also found in LCD. Therefore, the Bloomberg sample contains disproportionately more observations that could be classified as investment grade. Given this sample selection, I conclude that Dealscan's data under-reports floors, particularly those in investment grade loans. Of the 5,525 facilities in Dealscan that have information on floors, only 26 are listed as investment grade loans in the market segment file. Further, $59 \%$ of these facilities carry all-in-drawn spreads that are in the upper quartile of their respective calendar quarter's distribution of all loans in the database, indicating that the majority of these observations may confidently be classified as highly leveraged.

Table A-5: Reconciliation of floors recorded in Bloomberg (BB), Thompson Reuters Dealscan (TRD), and S\&P Leveraged Commentary and Data (LCD). Cross tabulations of the number of facilities with embedded floors $\left(\right.$ hasFloor $\left._{i}=1\right)$ are listed for database $i$, where $i=\mathrm{BB}$, TRD, and LCD. The number of facilities for which the data agree are listed on the diagonal of each matrix, with disagreements listed on the off-diagonal elements. Floor data are likely more accurate in the BB and LCD datasets because of explicit fields for LIBOR floors. Most errors are therefore likely due to misreporting in TRD.

\begin{tabular}{|c|c|c|c|c|}
\hline & \multicolumn{2}{|c|}{ S\&P LCD Reconciliation } & \multicolumn{2}{|c|}{ Bloomberg Reconciliation } \\
\hline & hasFloor $_{L C D}=0$ & hasFloor $_{L C D}=1$ & hasFloor $_{B B}=0$ & hasFloor $_{B B}=1$ \\
\hline hasFloor $_{T R D}=0$ & 8,736 & 914 & 4,446 & 566 \\
\hline hasFloor $_{T R D}=1$ & 44 & 2,794 & 11 & 186 \\
\hline Percent matched & $99.5 \%$ & $75.4 \%$ & $99.8 \%$ & $24.7 \%$ \\
\hline
\end{tabular}


As a source of information on embedded floors, Bloomberg may be an attractive alternative to S\&P's LCD. In addition to including a field for floors, Bloomberg has data on investment grade facilities. However, there are several limitations that lessen the usefulness of Bloomberg's data. First, it contains very few observations prior to 2008. Second, several fields reflect values as of the date data is downloaded, which may have changed since loan issuance. For these reasons, I limit the number of Bloomberg observations in this study to those that can be matched to records in Dealscan. Further, many of those matched observations overlap records from LCD. Therefore, many of the Bloomberg observations are discarded as redundant in this study; for example, only $5 \%$ of observations in the matched analysis are from Bloomberg.

Despite the data quality issues with Bloomberg, these data provide perhaps the best lens through which to assess the use of floors in investment grade loans. Of the 4,757 US-syndicated, USD-denominated syndicated loan facilities classified as "not leveraged" in Bloomberg as of January, 2016, only 408 were listed as containing LIBOR floors (8.5\%). ${ }^{1}$ Of those, 365 (89\%) have strike rates of zero. Given their scarcity and the number of zero strike rates where they are included, floors appear to be an immaterial aspect of the investment grade segment of the syndicated loan market.

\section{A-4 Sensitivity analysis of option valuation}

In valuing floors, I make assumptions regarding discount rates, the expiration of the option, expectations of future interest rates, the volatility measure, and the notional value applicable to each floorlet. In this section, I evaluate the sensitivity of implied option value to these assumptions.

The base case used in calculating floor spreads used throughout this study assumes the

\footnotetext{
${ }^{1}$ Observations listed as "not leveraged" are those with Bloomberg field LN_LEVERAGED equal to "N".
} 
following: market implied volatility from the prices of caps and floors that most closely match the strike rates and expirations of the embedded floor as of the time of loan issuance; expiration equal to loan maturity; and, amortization of $1 \%$ per year. These assumptions are likely incorrect for some loans, as I am unable to perfectly match market prices of floors to the strike rates and expirations of every embedded floor. In cases for which perfect matches are unavailable, I use prices of options whose terms are nearest those of the loan's floor. The resulting measurement error of the volatility used in the calculation of embedded floor values is minor. Further, the degree to which these estimates are biased is unclear, as volatility smiles vary across time and errors may be positive or negative depending on which market price is used as a proxy for implied volatility. Table A-6 provides some detail regarding these errors. Strike rate errors average 13.4 bps and expiration errors average about two weeks. Many of the strike rate errors correspond to zero strike rate floors for which there are no close substitutes in the marketplace.

Table A-6: Differences between strike rates and option expiration of embedded floors and the options for which market prices are used to determine volatility. Errors, $\epsilon$, are defined as embedded floor variable (strike rate or expiration) minus market floor variable. In cases for which an exact match cannot be found, market contracts are chosen to minimize these errors.

\begin{tabular}{|c|c|c|c|}
\hline \multicolumn{2}{|c|}{ Strike rate } & \multicolumn{2}{|c|}{ Expiration } \\
\hline Error (bps) & $\mathrm{N}$ & Error (months) & $\mathrm{N}$ \\
\hline$\epsilon \leq-50$ & 3 & $\epsilon \leq-6$ & 5 \\
\hline $0 \overline{>} \epsilon>-50$ & 827 & $0 \overline{>} \epsilon>-6$ & 331 \\
\hline$\epsilon=0$ & 2141 & $\epsilon=0$ & 3288 \\
\hline $0<\epsilon<50$ & 438 & $0<\epsilon<6$ & 437 \\
\hline$\epsilon \geq 50$ & 946 & $\epsilon \geq 6$ & 294 \\
\hline
\end{tabular}

Another source of valuation error arises from the assumption of option expiration. While I assume loans, and therefore their embedded floors, are held to maturity, in reality these loans are often prepaid. Roberts (2015) estimates the unconditional life of a loan is only 4.5 years. The effective life of a loan also varies with the level of mandatory amortization payments. While many institutional term loans amortize at a rate of $1 \%$ per year, some 
may require larger (smaller) payments, which serve to shorten (lengthen) the loan's effective maturity. The effect of loan maturity on the calculation of floor spreads is twofold. First, the assumed maturity impacts the floor's value through the number of floorlets. Second, the loan's maturity determines the number of periods over which the option value is annuitized, with longer periods resulting in lower floor spreads, all else equal. Amortization has a similar effect, with higher repayment rates lowering the option's notional value in later periods, thus weighting earlier periods more heavily in the calculation of floor spreads. The effect of this principal-weighting and maturity can be positive or negative on the value of floor spreads depending on the shape of the forward curve. If interest rates are expected to increase then the majority of floor value is derived from periods nearest loan origination because the moneyness of these earlier floorlets is greater than in later periods. In these cases, shortening maturity will increase the floor spread as the least valuable floorlets will be removed from the calculation and the basket of remaining floorlets will be annuitized over a shorter period. On the other hand, the opposite is true if interest rates are expected to decline; the most valuable floorlets will be removed from the calculation, resulting in lower floor values and lower floor spreads, despite the shorter annuity.

Table A-7 reports the summary statistics of floor spreads calculated according to various assumptions of volatility, option expiration, and loan amortization. Two samples are listed, one with all floors and another that omits floors that carry zero strike rates. The reason for their omission is the lack of market data for these floor strikes and the necessity of Bachelier's (1900) model in lieu of Black's (1976). Further, given the belief in a zero lower bound, it's conceivable that loan participants believed the values of these floors were essentially nil. Of the 417 observations with zero strikes, 305 are classified as pro rata facilities (233 revolvers and 72 term loans A) and so these floors have little effect on the estimates of institutional term loan floor spreads. Regardless, many of these floors have near-zero value, lowering both the median and mean floor spread estimates under all assumptions. Figure A-1 depicts 
the empirical cumulative distribution function (ECDF) estimates for each sample under the base case assumptions. The differences between these ECDFs clearly show the group of zero strike rate floors yield floor spreads clustered near zero.

Figure A-1: Empirical density estimate on floor spreads with and without observations that have zero strike rates. Floors with zero strike rates are valued using Bachelier's (1900) pricing model; all non-zero strike rate floors are valued using Black's (1976) pricing model. In both cases, option pricing assumes expiration equal to loan maturity, amortization of $1 \%$ per year, and implied volatilities from the prices of caps and floors that most closely match the strike rate and expiration of the embedded option as of the loan's issuance date.

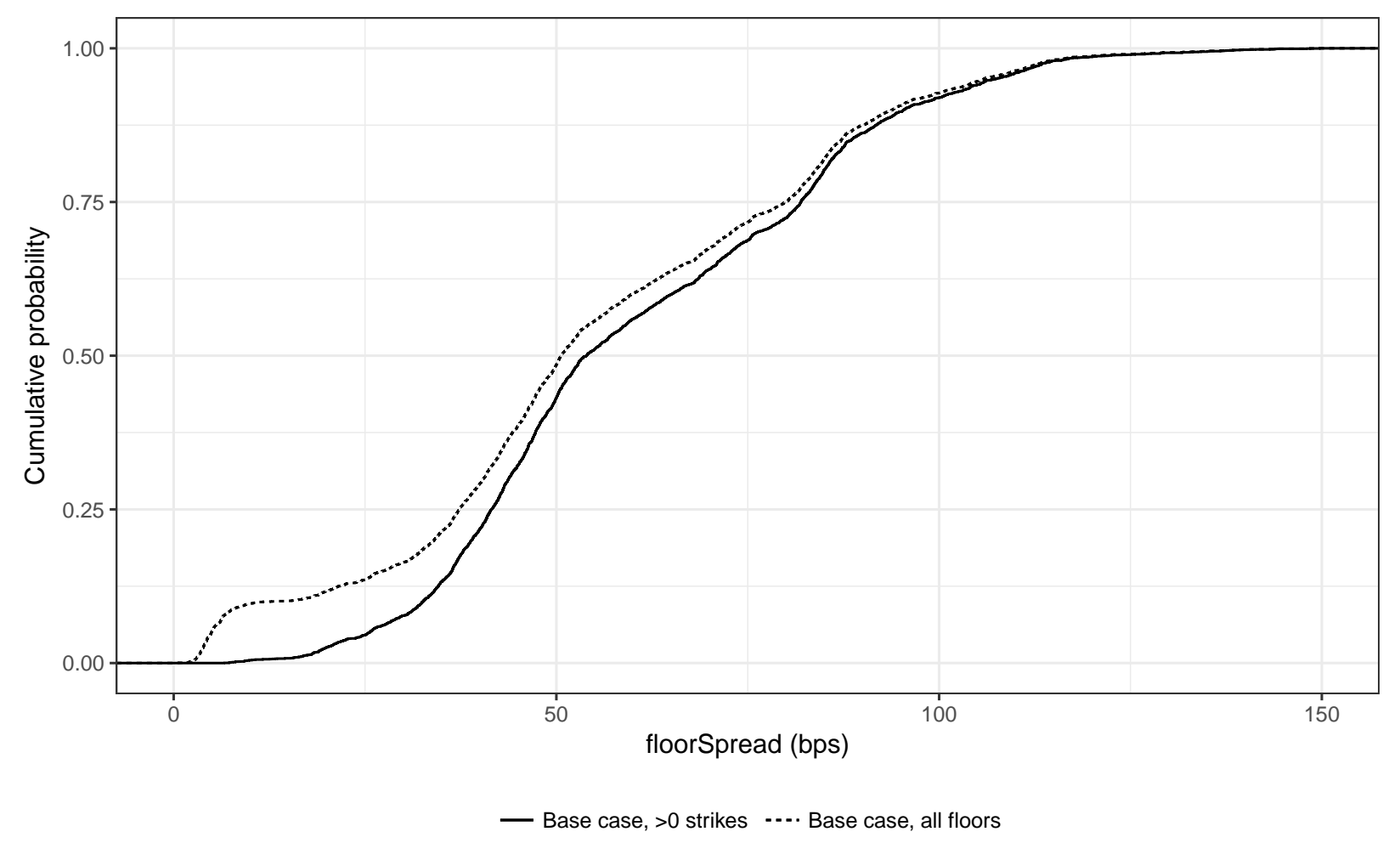

Changing the assumed expiration date on the option to the lesser of loan maturity and 4.5 years has the largest impact on the median floor spread (increasing to 54.9 bps from 50.9 bps for all floors, and 57.6 bps from 54.4 bps for those with non-zero strikes). The inverse relation between assumed expiration and the floor spread is due to positively sloped forward curves in nearly all observations. Almost as influential, perturbing the volatility estimate by $\pm 10 \%$, results in median spreads of 48.1 bps to 53.9 bps for all loans, and 51.8 bps and 57.0 bps for those with non-zero strikes. Lastly, changing the assumed amortization rate 
Table A-7: Floor spread sensitivity analysis. Summary statistics of floor spreads (bps) are listed alongside the assumptions made in option valuation. Volatility takes three values: 'market' volatility refers to the volatility measure implied from prices of caps and floors that most closely match the embedded floor's expiration and strike rate at the time of loan issuance; ' $1.1 \times$ market' assumes volatility is $10 \%$ higher than market; ' $0.9 \times$ market' assumes volatility is $10 \%$ lower than market. Option expiration either assumes the loan's maturity, or the lesser of loan maturity and 4.5 years. Amortization refers to the annual rate of scheduled principal reductions on the loan. Two samples are considered, one with all embedded floors and another that omits all floors with zero strike rates (417 observations). The latter sample omits floors values calculated using Bachelier's (1900) model.

\begin{tabular}{|c|c|c|c|c|c|c|c|}
\hline \multicolumn{3}{|c|}{ Assumptions } & \multicolumn{5}{|c|}{ floorSpread (bps) summary stats } \\
\hline Volatility & Expiration & Amortization & Mean & Std. Dev. & Q1 & Median & Q3 \\
\hline \multicolumn{8}{|l|}{ All floors } \\
\hline $\begin{array}{l}\text { market } \\
\text { market }\end{array}$ & $\begin{array}{l}\text { loan maturity } \\
4.5 \text { years max }\end{array}$ & $\begin{array}{l}1 \% \\
1 \%\end{array}$ & $\begin{array}{l}57.1 \\
58.9\end{array}$ & $\begin{array}{l}32.6 \\
33.3\end{array}$ & $\begin{array}{l}37.5 \\
39.0\end{array}$ & $\begin{array}{l}50.9 \\
54.9\end{array}$ & $\begin{array}{l}80.7 \\
83.3\end{array}$ \\
\hline $1.1 \times$ market & loan maturity & $1 \%$ & 59.9 & 32.9 & 40.4 & 53.9 & 83.3 \\
\hline $0.9 \times$ market & loan maturity & $1 \%$ & 54.3 & 32.3 & 34.5 & 48.1 & 77.6 \\
\hline market & loan maturity & $0 \%$ & 56.9 & 32.6 & 37.3 & 50.7 & 80.5 \\
\hline market & loan maturity & $2 \%$ & 57.2 & 32.7 & 37.7 & 51.1 & 80.8 \\
\hline $1.1 \times$ market & 4.5 years $\max$ & $2 \%$ & 61.2 & 33.5 & 41.3 & 57.0 & 85.4 \\
\hline $0.9 \times$ market & loan maturity & $0 \%$ & 54.1 & 32.3 & 34.4 & 47.8 & 77.4 \\
\hline \multicolumn{8}{|c|}{ Omitting zero strikes } \\
\hline market & loan maturity & $1 \%$ & 62.4 & 29.4 & 41.7 & 54.4 & 82.5 \\
\hline market & 4.5 years $\max$ & $1 \%$ & 64.5 & 29.8 & 43.3 & 57.6 & 85.5 \\
\hline $1.1 \times$ market & loan maturity & $1 \%$ & 65.3 & 29.6 & 44.5 & 57.0 & 85.1 \\
\hline $0.9 \times$ market & loan maturity & $1 \%$ & 59.5 & 29.3 & 38.8 & 51.8 & 79.8 \\
\hline market & loan maturity & $0 \%$ & 62.3 & 29.4 & 41.5 & 54.2 & 82.3 \\
\hline market & loan maturity & $2 \%$ & 62.6 & 29.5 & 41.9 & 54.7 & 82.6 \\
\hline $1.1 \times$ market & 4.5 years $\max$ & $2 \%$ & 66.9 & 30.0 & 45.9 & 59.9 & 87.1 \\
\hline $0.9 \times$ market & loan maturity & $0 \%$ & 59.3 & 29.3 & 38.6 & 51.6 & 79.7 \\
\hline
\end{tabular}

\pm one percentage point has little effect on floor spreads, moving the median by only about two tenths of a basis point in either direction. Due to its effect on weighted average life of the loan/option, the effects of amortization rates are opposite those of assumed expiration (higher amortization results in shorter effective loan maturity).

Changing multiple assumptions at a time, I calculate floor spreads under two extreme scenarios. For the highest estimates, I assume volatilities $10 \%$ higher than market, expiration of at most 4.5 years, and $2 \%$ amortization per year. For the lowest, I assume volatilities $10 \%$ lower than market, expiration equal to loan maturity, and no amortization. The resulting floor spread estimates have medians of $57.0 \mathrm{bps}$ and $47.8 \mathrm{bps}$ for all loans as well as $59.9 \mathrm{bps}$ and 51.6 bps for those with non-zero strike rates. Figure A-2 compares the ECDFs of these 
estimates with those of the base case for all floors.

Figure A-2: Empirical density estimates of floor spreads under three sets of assumptions. The base case assumes the loan amortizes at 1\% per year, that option expiration equals the maturity of the loan, and uses implied volatilities from the prices of caps and floors that most closely match the strike rate and expiration of the embedded option as of the loan's issuance date. This base case lies between two extreme cases. The case with the highest floor values assumes a maximum expiration of 4.5 years, $2 \%$ amortization per year, and volatilities that are 10\% larger than those in the base case. The case with the lowest values assumes expiration equal to loan maturity, no amortization, and volatilities that are $10 \%$ lower than the base case.

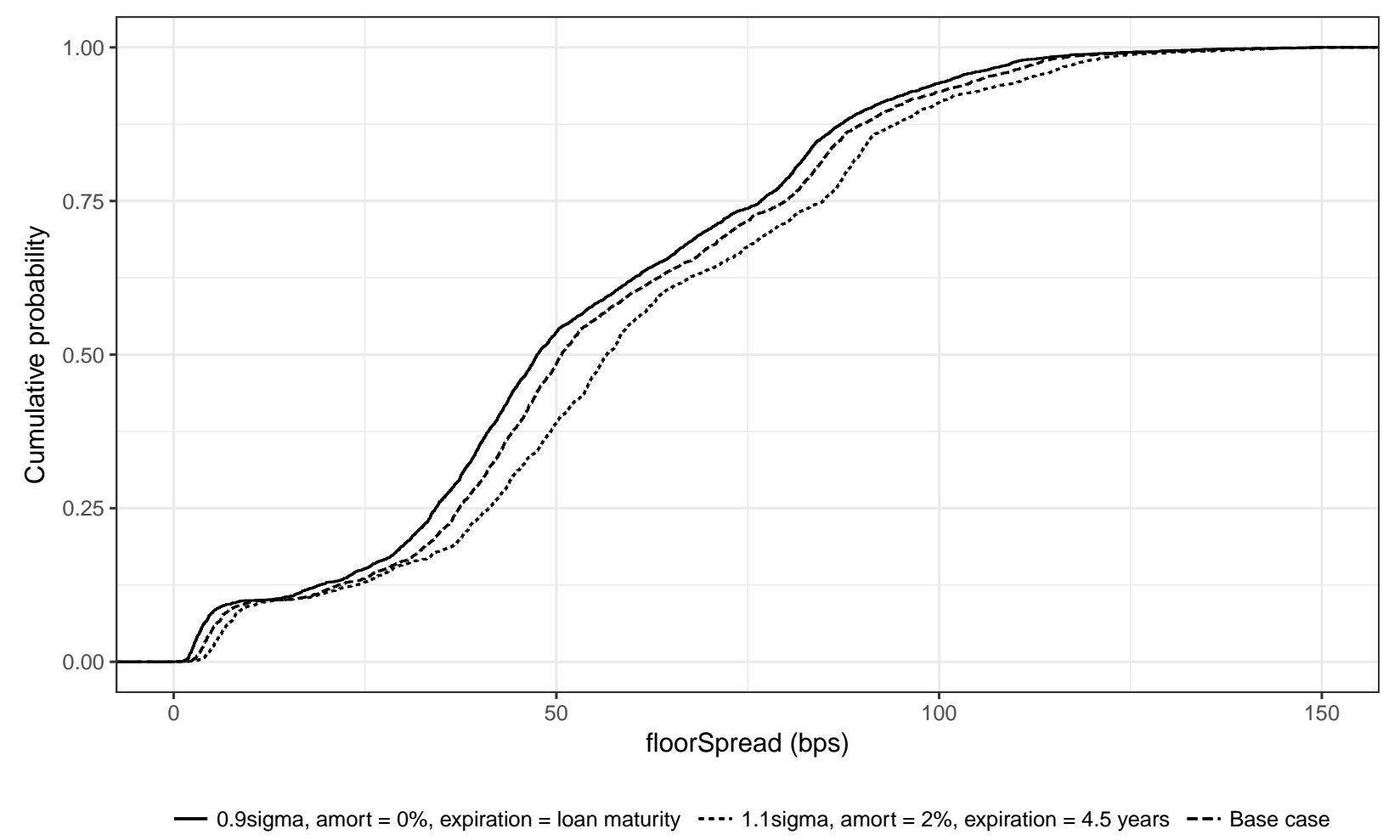

\section{A-5 Loan extension analysis segmented by crisis years}

The effect of added floors in institutional loan extensions is driven exclusively by observations during or shortly after the credit crisis. Reestimating the analysis on a subsample of loans extended during 2009 and 2010 reveals a larger effect of added floors on the amount of principal borrowers were able to extend. Table A-8 depicts the estimates of Eqs. (5.6) and (5.7) on this crisis sample. Referring to column (2) of Table A-8, the selection model 
estimates the effect of adding a floor to be a $39 \%$ increase in the extended principal amount. There is also a significant positive selection effect during this time period, as the inverse mills ratio $(\mathrm{imr})$ is significant at the $1 \%$ level. Given borrowers' liquidity concerns during this time [Campello et al (2011)], reductions in principal were likely the result of credit supply, not demand. Viewing the results in Table A-8 in this light, the coefficient on addFloor indicates that institutional lenders required embedded floors as a condition for extending credit during and immediately after the crisis.

Table A-8: Crisis period (2009 - 2010) estimates of the percentage of loans extended when LIBOR floors are added to existing loan pricing. Columns 1, 2, 4, and 5 are stages one, two, one, and two from Heckman's selection procedure, with stage 1 probits estimating the likelihood that an amendment includes an extension. The dependent variable in the OLS specifications, extendedRatio equals the proportion of extended loans as a result of the amendment, i.e. $\$$ new loans $/ \$$ preexisting loans. Explanatory variables are as follows: covenantRelief takes a value of one for amendments that alter the covenant structure or cure a covenant violation on the existing loan, and zero otherwise; addFloor takes a value of one in cases for which a LIBOR floor is added to the loan pricing terms as a result of the amendment, and zero otherwise; spreadChange denotes the change (in bps) to the loan's all-in-drawn spread as a result of the amendment; and, imr is the Inverse Mills Ratio from the first stage of Heckman's two-step procedure. Extensions data span the years 2009 through 2016. OLS standard errors (columns 3 and 6) are clustered by year of amendment.

\begin{tabular}{|c|c|c|c|c|c|c|}
\hline & \multicolumn{3}{|c|}{ Institutional extensions } & \multicolumn{3}{|c|}{ Pro rata extensions } \\
\hline & \multirow{2}{*}{$\begin{array}{c}\text { hasExtension } \\
\text { probit } \\
\text { (1) }\end{array}$} & \multicolumn{2}{|c|}{$\begin{array}{c}\text { extendedRatio } \\
O L S\end{array}$} & \multirow{2}{*}{$\begin{array}{c}\text { hasExtension } \\
\text { probit } \\
\text { (4) }\end{array}$} & \multicolumn{2}{|c|}{$\begin{array}{c}\text { extendedRatio } \\
O L S\end{array}$} \\
\hline & & $(2)$ & (3) & & $(5)$ & (6) \\
\hline constant & $\begin{array}{c}-0.605^{* * *} \\
(0.219)\end{array}$ & $\begin{array}{c}-0.794^{*} \\
(0.450)\end{array}$ & $\begin{array}{c}0.589^{* * *} \\
(0.088)\end{array}$ & $\begin{array}{c}-0.572^{* *} \\
(0.231)\end{array}$ & $\begin{array}{c}0.453 \\
(3.116)\end{array}$ & $\begin{array}{c}0.645^{* * *} \\
(0.026)\end{array}$ \\
\hline covenantRelief & $\begin{array}{l}-1.518^{* * *} \\
\quad(0.201)\end{array}$ & $\begin{array}{l}-1.115^{* * *} \\
(0.367)\end{array}$ & $\begin{array}{c}0.012 \\
(0.104)\end{array}$ & $\begin{array}{c}-0.854^{* * *} \\
(0.214)\end{array}$ & $\begin{array}{l}-0.065 \\
(1.716)\end{array}$ & $\begin{array}{c}0.041 \\
(0.048)\end{array}$ \\
\hline addFloor & $\begin{array}{c}0.274 \\
(0.234)\end{array}$ & $\begin{array}{c}0.390^{* * *} \\
(0.089)\end{array}$ & $\begin{array}{c}0.188^{* * *} \\
(0.066)\end{array}$ & $\begin{array}{l}-0.004 \\
(0.271)\end{array}$ & $\begin{array}{c}0.050 \\
(0.093)\end{array}$ & $\begin{array}{c}0.050 \\
(0.040)\end{array}$ \\
\hline spreadChange & $\begin{array}{c}0.002^{* *} \\
(0.001)\end{array}$ & $\begin{array}{c}0.001^{* *} \\
(0.001)\end{array}$ & $\begin{array}{c}-0.00002 \\
(0.001)\end{array}$ & $\begin{array}{l}-0.001 \\
(0.001)\end{array}$ & $\begin{array}{l}0.0001 \\
(0.002)\end{array}$ & $\begin{array}{c}0.0002 \\
(0.0003)\end{array}$ \\
\hline $\operatorname{imr}$ & & $\begin{array}{c}1.127^{* * *} \\
(0.363)\end{array}$ & & & $\begin{array}{c}0.159 \\
(2.577)\end{array}$ & \\
\hline Year effects & Yes & Yes & Yes & Yes & Yes & Yes \\
\hline Observations & 293 & 70 & 70 & 267 & 38 & 38 \\
\hline Adjusted $\mathrm{R}^{2}$ & & 0.194 & 0.087 & & -0.057 & -0.025 \\
\hline Log Likelihood & -106.739 & & & -94.381 & & \\
\hline Akaike Inf. Crit. & 223.478 & & & 198.762 & & \\
\hline Residual Std. Error & & 0.190 & 0.202 & & 0.197 & 0.194 \\
\hline F Statistic & & $4.319^{* * *}$ & $2.636^{* *}$ & & 0.600 & 0.772 \\
\hline
\end{tabular}


The same is not true of the sample of loan extensions between 2011 and 2016. Table A9 in the appendix displays estimates of Eqs. (5.6) and (5.7) on this post-crisis sample. There appears to be no effect of added floors on the amount of principal extended. This is unsurprising given most leveraged loans issued after 2009 contained floors at origination.

Table A-9: Post-crisis period (2011 - 2016) estimates of the percentage of extended loans when LIBOR floors are added to existing loan pricing. Columns 1, 2, 4, and 5 are stages one, two, one, and two from Heckman's selection procedure, with stage 1 probits estimating the likelihood that an amendment includes an extension. The dependent variable in the OLS specifications, extendedRatio equals the proportion of extended loans as a result of the amendment, i.e. $\$$ new loans $/ \$$ preexisting loans. Explanatory variables are as follows: covenantRelief takes a value of one for amendments that alter the covenant structure or cure a covenant violation on the existing loan, and zero otherwise; addFloor takes a value of one in cases for which a LIBOR floor is added to the loan pricing terms as a result of the amendment, and zero otherwise; spreadChange denotes the change (in bps) to the loan's all-in-drawn spread as a result of the amendment; and, imr is the Inverse Mills Ratio from the first stage of Heckman's two-step procedure. Extensions data span the years 2009 through 2016. OLS standard errors (columns 3 and 6) are clustered by year of amendment.

\begin{tabular}{|c|c|c|c|c|c|c|}
\hline & \multicolumn{3}{|c|}{ Institutional extensions } & \multicolumn{3}{|c|}{ Pro rata extensions } \\
\hline & \multirow{3}{*}{$\begin{array}{c}\text { hasExtension } \\
\text { probit } \\
(1)\end{array}$} & \multirow{2}{*}{\multicolumn{2}{|c|}{$\begin{array}{c}\text { extendedRatio } \\
O L S\end{array}$}} & \multirow{3}{*}{$\begin{array}{c}\text { hasExtension } \\
\text { probit } \\
(4)\end{array}$} & \multirow{2}{*}{\multicolumn{2}{|c|}{$\begin{array}{c}\text { extendedRatio } \\
O L S\end{array}$}} \\
\hline & & & & & & \\
\hline & & $(2)$ & $(3)$ & & $(5)$ & $(6)$ \\
\hline constant & $\begin{array}{c}0.111 \\
(0.267)\end{array}$ & $\begin{array}{l}1.147^{* *} \\
(0.525)\end{array}$ & $\begin{array}{c}0.880^{* * *} \\
(0.068)\end{array}$ & $\begin{array}{l}-0.001 \\
(0.264)\end{array}$ & $\begin{array}{l}-1.903 \\
(1.629)\end{array}$ & $\begin{array}{c}0.909^{* * *} \\
(0.045)\end{array}$ \\
\hline covenantRelief & $\begin{array}{c}-1.786^{* * *} \\
(0.203)\end{array}$ & $\begin{array}{c}0.288 \\
(0.842)\end{array}$ & $\begin{array}{c}-0.144^{* * *} \\
(0.044)\end{array}$ & $\begin{array}{c}-0.429^{* *} \\
(0.183)\end{array}$ & $\begin{array}{c}-1.235^{*} \\
(0.699)\end{array}$ & $\begin{array}{l}-0.032 \\
(0.047)\end{array}$ \\
\hline addFloor & $\begin{array}{c}0.505 \\
(0.426)\end{array}$ & $\begin{array}{c}0.073 \\
(0.240)\end{array}$ & $\begin{array}{c}0.183 \\
(0.150)\end{array}$ & $\begin{array}{l}-0.805 \\
(0.553)\end{array}$ & $\begin{array}{l}-2.093 \\
(1.328)\end{array}$ & $\begin{array}{c}0.183^{* * *} \\
(0.042)\end{array}$ \\
\hline spreadChange & $\begin{array}{c}0.003^{* * *} \\
(0.001)\end{array}$ & $\begin{array}{l}-0.001 \\
(0.001)\end{array}$ & $\begin{array}{l}-0.0004 \\
(0.0004)\end{array}$ & $\begin{array}{l}-0.002 \\
(0.001)\end{array}$ & $\begin{array}{c}-0.006^{*} \\
(0.003)\end{array}$ & $\begin{array}{l}-0.0005 \\
(0.0003)\end{array}$ \\
\hline $\mathrm{imr}$ & & $\begin{array}{l}-0.358 \\
(0.693)\end{array}$ & & & $\begin{array}{l}3.686^{*} \\
(2.134)\end{array}$ & \\
\hline Year effects & Yes & Yes & Yes & Yes & Yes & Yes \\
\hline Observations & 310 & 83 & 83 & 313 & 53 & 53 \\
\hline Adjusted $\mathrm{R}^{2}$ & & 0.157 & 0.166 & & 0.035 & -0.009 \\
\hline Log Likelihood & -113.573 & & & -128.089 & & \\
\hline Akaike Inf. Crit. & 245.146 & & & 274.179 & & \\
\hline Residual Std. Error & & 0.254 & 0.252 & & 0.156 & 0.160 \\
\hline F Statistic & & $2.702^{* * *}$ & $3.036^{* * *}$ & & 1.207 & 0.943 \\
\hline
\end{tabular}

